\title{
New Zealand Public Television, Public Service and Everything in Between: \\ The Success and Struggles of New Zealand on Air and Public Television
}

By

Jonathan McLeod

\author{
A thesis: \\ Submitted in fulfilment \\ of the requirements for the degree \\ of Master of Arts in Media Studies. \\ Victoria University of Wellington
}

2014. 


\section{Abstract}

This thesis explores the contemporary situation of 'public television' in New Zealand. As this country's longest-standing, most significant facilitator of the diverse range of locally-produced programmes that pursue the 'cultural identity' objectives that are regarded as centrally important to 'public television', the focus of this thesis will be on the role and contributions of public broadcast funding agency, New Zealand on Air. This focus has three main functions in this thesis, allowing it to: first, investigate the necessity of facilitating and producing 'public television'; second, to explore the successful ways in which this element of television has been delivered to viewers; and third, to examine the limitations posed by a highly commercial broadcast television environment on the pursuit of 'public television' objectives.

This undertaking is important because 'public television' faces a number of significant challenges in New Zealand, the most significant of which is inadequate public investment. Other challenges can be sourced to the intense competition and inadequate regulation of New Zealand television, which is a consequence of the deregulation and restructuring that it was subjected to in 1988-89. In the decades since, the broader environmental conditions encouraged by these changes have never been redressed. Presently, despite 'public television' fulfilling vital cultural functions, its situation has reached a crisis point, emphatically in regard to provisions for 'mainstream' broadcast audiences. For this reason, there needs to be an in-depth exploration of the issues and potentials in 'public television', to which this thesis aims to contribute.

The exploration that this thesis offers is structured in three chapters. The first examines the establishment and role of New Zealand on Air. The second addresses the ways in which 'public television' programmes are successfully facilitated through the considerations and funding allocations of NZoA. The third considers the limitations of New Zealand's television environment on the pursuit of 'public television' and argues the necessity for enhanced resources to be provided in order to improve the current situation. 


\section{Acknowledgements}

While writing a Master's Thesis can be an insular, lonely process, where one must battle themselves for months and months on end to create something that is worthwhile and that they can be proud of, it is true that nobody can complete it alone.

I would like to thank my supervisor, Associate Professor Trisha Dunleavy, without whose help and work in the subject, this project would have never been possible.

To everybody else who helped or read any part of this thesis, you know who you are, and your selfless deeds will never go forgotten.

And finally, to anyone that ever listened to me whine about how hard it is to do a thesis, you kept me sane for the past 18 months.

Cheers R\&R. M., T.T., S.R., K.M., K.T., B.L. 


\section{Table of Contents}

$\begin{array}{ll}\text { Abstract } & 2\end{array}$

$\begin{array}{ll}\text { Acknowledgements } & 3\end{array}$

Introduction $\quad 5$

Chapter One: The Importance of Public Television and

$\begin{array}{ll}\text { New Zealand on Air } & 20\end{array}$

Chapter Two: The Effectiveness and Strengths of New Zealand on Air and Public Television

50

Chapter Three: New Zealand Public Television - Limitations,

Missed Opportunities, and Potentials

83

Conclusion

115

Reference List 


\section{Introduction}

Public broadcasting is the jilted suitor at the marriage between politicians and privatisers. It stands out in the cold and rain, peering through the window at the merriment and toasting inside, a forlorn figure, dishevelled and increasingly disoriented, the institutions are still there, if they have not been sold off, but their purpose is continually questioned. Talk of public service or the public good is increasingly suspect. Audiences are now thought of as consumers rather than citizens, members of markets rather than of social and moral communities. Programmes have become product and viewers targets.

Graham Murdock, 1997: 9

British media scholar, Graham Murdock, paints a sorry picture for public broadcasting in a contemporary New Zealand broadcasting environment which is characterised by aggressive competition and continuing deregulation. 'Public television', specifically, finds itself in an increasingly difficult position in the small television market of New Zealand, as it struggles within a context that is unusually dominated by commercial providers, a situation that successive governments have made no adequate provision to change. If 'public television' in New Zealand keeps moving along the trajectory that was, and remains, sufficiently concerning to have elicited the above summation, then it risks becoming an 'endangered species' in New Zealand television overall. Unfortunately, it is now possible to imagine 'public television' becoming a set of memories and past achievements, as opposed to a tangible and secure presence that is available for the benefit of current and future generations.

Informed by Murdock's "Ghost at the Feast" imagery above (ibid.), this thesis will examine the precarious current position of 'public television' in New Zealand. This investigation will involve three specific 
avenues of inquiry. First, this thesis will consider why 'public television' is important to New Zealand audiences, and should therefore be facilitated by public funding and intervention. Second it will ask, what are the positive contributions of particular public institutions that are already being made in the area of 'public television'? Third, this thesis will investigate the fact that, in spite of the current contributions that are being made in this area, there are particular conditions and challenges which stand to undermine or limit the achievements of public institutions in respect of 'public television' objectives. Principally in regard to this third inquiry, it will be important to assess what additional support mechanisms and/or resources would (if provided) work to improve and maximise the ability of existing institutions to deliver a full range of 'public television' outcomes.

\section{What is Public Television?}

While 'public service' is important to this thesis and certainly informs the objectives and roles of 'public television', the central focus for this thesis will be around the wider definition of 'public television' which itself can be produced in order to achieve, but is not strictly limited to, traditional 'public service' ideals. Speaking at a symposium in 2011, Trisha Dunleavy suggested that, in the New Zealand context, 'public television' invokes a particular set of meanings and aspirations. 'Public television', as Dunleavy explained, refers to:

[D]elivery platforms and TV channels which operate free-to-air and to local programming that is facilitated by public investment and, as such, can deliver public service outcomes. Together, these platforms, channels and programmes determine what 'public television' means to New Zealanders. Importantly, public television exists to satisfy cultural and democratic needs which cannot be met without public investment on the one hand, and appropriate broadcasting policy and regulation on the other (Opening Address, Forum on the Future of Public Television in New Zealand, 22 June, 2011). 
It is the above definition of 'public television' that will delineate and underpin the use of this term throughout this thesis.

This thesis contends that the above concept of 'public television' (in the period since its 1988-89 restructuring) more accurately represents New Zealand's local television experience than the related concept of 'public service' is able to. This is because New Zealand broadcast television has traditionally lacked, as it does now, "a mainstream audience channel that is either dedicated to the pursuit of [public service broadcasting] PSB objectives and/or in receipt of direct public funding to support these" (Dunleavy 2012b: 1). However, New Zealand's public broadcasting institutions have, to varying degrees, sought to achieve 'public service' outcomes. In the context of these efforts, New Zealand's understanding of public television can be said to be derived from the wide-reaching, guiding principles of traditional 'public service broadcasting'. Accordingly, the development and evolution of 'public service', and its relevant objectives, are highly pertinent to a thesis whose central focus will be to examine New Zealand's public television in today's environment.

\section{The Evolution of Public Television and Public Service Ideals}

Television broadcasting is a "central institution within the public sphere, making essential information, knowledge, and cultural experiences available at the same time to all members of a particular society" (Gripsrud, 2004: 212). Therefore it is a "powerful medium" (Barnett cited in Dunleavy, 2005: 1) with a significant capacity to deliver the cultural objectives of public television to a range of different audiences. Around the world, television broadcasting has been characterised by two main funding paradigms, each with their own objectives. These paradigms are 'commercial broadcasting' and 'public service broadcasting'. The first is funded through advertising, while the second is funded from the public purse; a distinction that underpins the 
significant differences between these paradigms in terms of their objectives, priorities and outcomes. New Zealand "opted from the start for a 'mixed model' of television" (Dunleavy, 2005: 15), which meant that state-owned television received both commercial and public revenues, the objectives of both of these approaches existing in a perpetual state of tension as New Zealand broadcast television developed (ibid.: 15-16). While both of these paradigms are relevant here, the focus on New Zealand's public television sector and provisions brings to the fore notions of what 'public service' is understood to mean in television.

'Public service' is a term that is not only difficult to define but is also subject to a changing interpretation and role. This is due to its varied experiences in different countries around the world. As Dunleavy explains, "public service broadcasting ideals became influential during television's first decades" (2008: 795), a phase which John Ellis termed the "era of scarcity" (2000: 2). This era was characterised by "a few channels broadcasting for part of the day only" (ibid.: 39) in which there were "early concerns about the potentially negative 'effects' of a new mass medium" (Dunleavy, 2008: 796). A public broadcasting model, originally conceived for radio but then customised for television, was initially established in Britain by Lord John Reith, the first Director General of the British Broadcasting Corporation (BBC), and was copied or adapted by a range of countries thereafter. Reith was "convinced that governments rather than businesses should control broadcasting" in order to "foster greater equality between citizens through shared experiences" and, as such, should attempt to "inform, educate, and entertain" (ibid.). Within an environment that was characterised by a "dearth of TV channels" (ibid.) and accordingly by an unusual potential for members of a given country to have common experiences of television, 'public service' objectives were able to thrive and shared national television cultures were able to be established (Ellis, 2000: 46). 
However, with increasing private and commercial networks entering broadcasting systems throughout the 1980s and 1990s and new challenges and pressures in delivering public broadcasting, 'public service ideals' had to adapt and diversify in order to "remain relevant" and productive (Dunleavy, 2008: 796). The "continued dominance of public networks" that had marked the 'era of scarcity', was not able to be maintained and a reworking of priorities for contemporary public service broadcasting became necessary. Graham Murdock (1997: 17-18) outlined a more contemporary set of PSB objectives, all of which remain relevant in New Zealand in terms of both 'public service' and public television. As summarised by Dunleavy (2008: 797) these were:

1) Autonomy - specifically broadcasting's maintenance of an appropriate distance from both the state and commercial sector as 'major centres of institutionalised power';

2) Universal availability - to preserve broadcasting against 'physical or material barriers to inclusion' and maximise its ability to engage and involve the full range of citizens;

3) Programme diversity - which, in addition to broadening the generic, aesthetic and cultural range of programming that is offered, ensures the representation of a 'diversity of interests, voices and perspectives';

4) Innovation - to be facilitated by the active encouragement of formal, representational and other creative experimentation in programming;

5) Mainstreaming - the pursuit of 'recognition and respect for difference', to be achieved centrally through the incorporation of "minority" experiences and views' in 'the full range of primetime programming'; and

6) Access - the delivery of a 'genuine diversity of representation' through the inclusion of 'viewers as active participants rather than as simply spectators'.

Interestingly, 'autonomy' describes “broadcasting's maintenance of an appropriate distance from both the state and commercial sector" (Dunleavy, 2008: 797). This means that to constitute public service in its most complete form, there must be both public funding as well as some sort of non-commercial platform within a broadcasting system in order to 
fully deliver public service objectives. The lack of a non-commercial channel has often been the undermining factor for public service in New Zealand (ibid.). Having "demonstrated their continuing relevance", the most significant outcome of the above objectives has been an increase in "the formal and cultural diversity of programming beyond what the commercial sector alone can offer and in ways that allow for specified minority interests to be served" (ibid.).

With the full realisation of many of the changes that occurred in the 1980s and 1990s such as: a further proliferation of TV channels and services (precipitated by technological advances); the full effects of these things coming to fruition through "fragmentation of audiences" (which reduces the potential profitability of networks); and a "greater uniformity" between public and commercial schedules, further tensions and limitations have developed for public television (Dunleavy, 2008: 798). Although the continued importance of public broadcasting has been questioned as a result of the above developments, it remains valuable on the basis of its counteracting of 'market failure' (Collins, 2007: 171). In terms of television broadcasting, 'market failure' can be considered as referring to particular programming forms that a "contestable market will either not supply or, at best, will undersupply" (ibid.).

In New Zealand this 'undersupply' of public television programmes is magnified by "the limited size and English-speaking nature" of its market which has imposed "undesirable constraints on the diversity of domestic TV production" (Dunleavy, 2008: 799). New Zealand has been "comparatively disadvantaged in local content terms" and has therefore been subject to a "long-standing dependence on imported programming" (ibid.). Publicly funded efforts to counteract market failure in television have occurred in recognition of an inherent cultural, social, and/or civic value in providing such programmes. In New Zealand specifically, "public service objectives have been unusually synonymous" with maintaining the delivery of local programmes that include drama, documentary and a 
range of minority programmes which, if left to commercial providers alone, would not be available (ibid.: 799).

Dunleavy explains that "the contemporary context in which public television operates internationally is one of pluralist (multi-channel and multi-platform) provision and consequent intense competition" (2012b: 2). Therefore, "the BBC adopted and elaborated a notion of 'public value' both to legitimise its own institutional status and as a guide to its future conduct and practise" (Collins, 2007: 165). This is a framework through which public television systems around the world can be understood and relates particularly closely to New Zealand's current experience of public television.

'Public value' is characterised by four main 'drivers': "reach, impact, quality and value for money" which "testify to the BBC's commitment increasingly to reference its activities against user oriented needs and interests" (Collins, 2007: 167). This is an effective framework through which to perceive New Zealand public television considering the small size of the market (Dunleavy, 2008: 795). This is because as a result, audience reception of programming produced with public finance is an integral factor in the delivery of public service and of public television in New Zealand. As Collins suggests, public value could be considered a "partnership between users and providers", extending accountability to users, "but to users as citizens rather than as subjects or consumers" (2007b: 7). These four 'drivers' are a way through which public television and its objectives can be understood as well as measured. Relating to Murdock's earlier definition of public television objectives, the 'drivers' are also consistent with the purposes of New Zealand's public television programming and the public agencies which fund it.

Though public service and public television ideals were able to flourish in the initial era of television 'scarcity' (Ellis, 2000: 2), they have come under increasing pressures in the decades since then. This is strongly evident in New Zealand, a country which has always struggled to resource and pursue a full range of public television objectives (Dunleavy, 
2008: 795). As a result of a proliferation of commercial channels and television providers, public television broadcasters and agencies no longer "write the rules of the game", as Murdock describes it, as they once did, notably in the decades of TV 'scarcity' (1997: 9). Rather, it is neoliberal competition and commercial providers who write the rules, usually to the detriment of public television objectives. Consequently, public television "stands out in the cold and rain" waiting for someone to let it in (ibid.).

\section{New Zealand Television Reform and the Establishment of New Zealand on Air}

The situation for public television, as described above, is heightened in New Zealand because of the extreme restructuring and deregulation of the country's broadcasting environment that occurred between 1988 and 1991. New Zealand was left, as a result, with a broadcasting environment that "Minister of Broadcasting at the time, Richard Prebble, boasted [was] 'the most open [...] in the world"' (Kelsey, 1998: 112). As Dunleavy suggests, television was not exempt from the neoliberal agendas of the Fourth Labour Government, and in 1987, having "ripped through finance, forestry, transport, energy and other sectors, its radical 'reforms' were due for extension to social and cultural areas" (2005: 212). The central belief driving these changes, as Dunleavy observes, was that "the competition of the marketplace served the needs of the public better than the social organisation known as the public sector" (ibid.). New Zealand has had its own unique experience of neoliberal politics which was defined by this period in the 1980s with New Zealand travelling "more rapidly down the road to privatisation than almost anywhere else" (Murdock, 1997: 9). Spicer et al. assert that "New Zealand went the furthest in restructuring the entire broadcasting system" (1996: 81) and, as such, neoliberalism has had distinctive outcomes in this country.

To achieve the 'free market' ideals that have remained central to a neoliberal political philosophy, there were three "prerequisites" for 
restructuring the marketplace in which New Zealand businesses operated. As outlined by Dunleavy and Joyce (2011: 106) these were "the eradication of monopolies, the deregulation of formerly controlled markets to open them fully to competition, and the restructuring of public companies as profit-centred businesses". To achieve these things, public companies became State-Owned Enterprises (SOEs) so as to "achieve an initial separation between the commercial and non-commercial activities of state organisations" (ibid.). One intention of this was to allow these organisations to function in a situation of "'competitive neutrality' with equivalent private operators" (ibid.). In turn, public agencies were created to take on the non-commercial obligations that had been separated from the SOEs. Underlying the creation of these agencies was the government's "determination to reduce public investment to a minimum, with public funding being allocated to these only as far as 'market failure' could be demonstrated" (Dunleavy and Joyce, 2011: 106).

As a result of this restructuring, TVNZ was re-established as an SOE and, as such, its earlier public service objectives and direct public funding were both removed (Dunleavy and Joyce, 2011: 112-13; Murdock, 1997: 9). Instead, TVNZ would be expected to function as a competitive business (ibid.). However, the 'social objectives' of television, informed by the 1988 Stevenson Report (Dunleavy, 2005: 216), would be established so as to support those public outcomes that continued to be regarded as important for television. These included traditional aims to 'inform, educate and entertain', to provide programming for a range of audiences, and most importantly the idea of using public funding as a way to develop New Zealand culture and identity (Cabinet Minutes 1988 cited in Norris and Pauling, 2012: 11). These objectives would then be formalised in the 1989 Broadcasting Act. It was this Act which outlined the functions of the new independent funding agency (this called the Broadcasting Commission) that would be responsible for delivering television's 'social objectives' and would receive the public funding previously distributed to TVNZ. This organisation would be re-named New Zealand on Air (NZoA). Operating 
since 1989, NZoA has pursued a wide public television remit, a particularly important element of which has been to facilitate the production of programmes which contribute to 'cultural identity'. Although articulated in relation to drama, the key criteria for what would constitute 'cultural identity' that were outlined by Jo Tyndall when interviewed by Dunleavy in 2003, can speak for a wider range of programme forms. These included: "strong expressions of New Zealand culture"; "stories that say something about us as a nation"; and "an accurate reflection of the changing society" (Tyndall cited in Dunleavy, 2005: 284).

The deregulation and restructuring of New Zealand's television environment has remained important to this day. This is because the key changes it brought have never been significantly altered or even revisited. In view of this largely unchanged environment and situation, this restructuring and deregulation can be considered to have provided the structural foundations for the difficult and tenuous position in which public television now finds itself. The New Zealand television broadcasting environment is characterised by aggressive, largely unregulated competition and this environment has undermined the profitability of this country's free-to-air commercial broadcasters (Dunleavy and Joyce, 2011: 184-89). This is significant because, although these broadcasters provide the central outlets through which public television programmes are aired, their capacity to invest in local content has been much reduced by the struggles of their operating environment (ibid.: 188). Furthermore, successive governments have remained unwilling either to reregulate the television environment in ways that might help the broadcasters (ibid.: 204), or to ensure that there is adequate public funding through which to maintain a mainstream audience non-commercial TV channel (ibid.: 185). These concerns have become even more prominent since the current National government came into power in 2008 (ibid.: 253). This government's decisions about public television eliminated New Zealand's first non-commercial mainstream TV channels (TVNZ6 and TVNZ7) and 
have deprived local audiences of the wider range of public television programmes that these two channels were able to provide.

It is a situation of bad circumstances getting worse for New Zealand public television, as the intrusive effects of deregulation combine with the additional struggles caused by inadequate provisions for public television. However, in spite of this, and rather than public television being an idea "whose time has passed" (Murdock, 1997: 9) as some commentators may contend, Murdock's argument that "it is an idea whose time has finally come and that far from being redundant is indispensable" (ibid.), is as true today as it was in 1997. New Zealand's public television is in a tenuous position, which is why it is such an important topic for this thesis to examine.

\section{Importance of Public Television and New Zealand on Air}

Public television is important for a range of reasons that are outlined by Murdock (1997). However it is important to remember that in New Zealand, television's public funding and institutions exist in order to deliver local programmes that "satisfy cultural and democratic needs" (Dunleavy, 2011) which will not otherwise be supplied or will be undersupplied by the marketplace, due to their significant cost in comparison to cheaper imported programmes.

The commercial system delivers many hours of local programming to which public funding makes no necessary contribution, most significantly in the form of news and current affairs which maintain an integral commercial role in schedules. It could be argued that this is adequate in local programming terms. However, Murdock vehemently discredits this notion as he states that "information, by itself, is not enough" because it "dismembers the world, chopping it into discrete factual chunks" (1997: 12). He goes onto argue that: 
Knowledge ... offers frameworks of analysis and interpretation that allow people to see patterns ... to see where they have come from and where they might be moving. Within broadcasting, these explorations are as much part of contemporary drama and documentary programming as they are of current affairs. Different programme forms allow connections to be made and developed in different ways, which is why maintaining a diversity of programming is essential to the provision of adequate cultural resources for citizenship (ibid.).

What Murdock is referring to here is the necessity and importance of a range and diversity of local programmes. He sees public television and the responsibility of this in creating TV programming as extending beyond simply news and current affairs to programme categories such as drama and documentary. This is because people need "opportunities to encounter the widest possible range of social life and opinion, so that they can clarify and explore their own experience and aspirations" (ibid.: 10) in a way that they can understand not only themselves, but also the world around them. It is this necessity for local programme examples that can fulfil the complete range of public broadcasting objectives that legitimises political intervention and public funding within television. This is because, as has been established, the full range of programme forms will not be provided for by commercial broadcasters alone due to their lack of economic viability.

While the focus of this thesis is the contemporary situation of public television in New Zealand, an examination of public funding agency NZoA will take precedence above other organisations and institutions. The reason for this is that it is the organisation that receives the largest amount of direct public funding for television (NZoA Annual Report, 2012: 29; TMP Television Funding Decisions 2012-13; Māori Television Annual Report, 2012: 20) in order to enact its remit of reflecting and developing "New Zealand identity and culture" (Broadcasting Act, 1989: 17). Furthermore, it is the single agency that has existed for the entirety of the period since deregulation and restructuring occurred in New Zealand television and was created as a direct and immediate result of the new 
television environment that was established. Accordingly, NZoA reflects very closely New Zealand's public television experience of the past twentyfour years.

\section{Thesis Contents}

This thesis has a three part structure which relates directly to the central focus and questions of this examination. While the situation of public television in New Zealand has been introduced, the next three chapters will investigate why public television is important, how and to what effect it is currently delivered, and finally what redress is necessary to rectify the current situation. This is because an examination of the situation of public television in New Zealand, as the central focus of this thesis, will demonstrate why and how this needs to be protected now and into the future.

Chapter One, entitled 'The Importance of Public Television and New Zealand on Air', will examine and explain the conditions under which NZoA was established in 1989. It will then move to consider the responsibilities and aims of this organisation in terms of its integral role in facilitating public television programmes and objectives. NZoA's distinctive funding model will be described and approached from the perspective of the neoliberal agendas that facilitated and necessitated its creation, and how this might have been a contributing factor to the organisation being able to achieve its wide-ranging objectives. The investigation will then move to consider the specific functions of NZoA as a public agency, suggesting that through its facilitation of public television programmes, it can provide particular cultural and economic benefits that are important to New Zealand society. This first chapter will also examine NZoA's facilitation of programming as not merely being in the realm of 'local content' as is often suggested, but as programming with potentials to fulfil public service objectives. Finally it will consider the importance of free-to-air broadcasters to the achievement of NZoA's programme 
objectives. While the main focus will be on NZoA, the chapter will also introduce both Māori programme funder Te Māngai Pāho (TMP) and noncommercial public service channel Māori Television as two further institutions that are important to public television in New Zealand.

Chapter Two, "The Effectiveness and Strengths of New Zealand on Air and Public Television', will then develop from the first chapter by considering more closely the particular ways in which NZoA has been successful over its twenty-four year existence. First, it will examine how the contestable funding model has been effectively enacted by NZoA in order to make meaningful contributions to the public television environment. The chapter will then investigate a number of successful examples across NZoA's range of programme categories including drama, documentary, special interest, Māori, and children's programming. This will be to judge how NZoA has successfully achieved its public television goals and formal remit. By addressing Māori programming, this chapter will also look into the further possibilities that Māori Television as a noncommercial channel, and TMP as a broadcasting funding agency in this area, have brought to New Zealand's television environment. This will be in conjunction with exploring the contributions of NZoA to Māori programming, but also to evaluate the significance of collaboration between public agencies to a full achievement of public objectives in New Zealand television.

Chapter Three, 'New Zealand Public Television - Limitations, Missed Opportunities, and Potentials', will begin by discussing the constraints that exist for NZoA and public television. The constraints will be explained as deriving from NZoA's limited funding allocation and the unregulated commercial environment in which it must operate, which is most strongly exemplified in the category of documentary. This category will be explored in order to demonstrate the detrimental effects of the above limitations on NZoA's achievement of its formal remit. In response to these issues, the chapter will argue the necessity for further provision and address recent missed opportunities to remedy this situation, before exploring closely the 
example of Māori Television as a potential model for the successful functioning of a non-commercial public service channel. Through this examination, it will be argued that to achieve a full range of social objectives in public television, two main things must occur. The first is an increased funding provision. The second is major adjustment to the television broadcasting environment. This seems essential in order to create a context within which public agencies can function more effectively and without the stifling limitations of unregulated competition and commercialism. 


\section{Chapter One: The Importance of Public Television and New Zealand on Air}

\section{Introduction}

New Zealand on Air (NZoA) is arguably the most influential organisation in terms of public television in this country. This is because it is the organisation that receives the largest amount of public money and facilitates the delivery of programming that has the widest national impact (Dunleavy, 2012b: 1). This chapter has two main functions, first to examine how and why this agency was established and second, to explain its importance within New Zealand's public television sphere in terms of local programme facilitation. The chapter will also consider the formation and some of the roles of two other public television organisations: Te Māngai Pāho (TMP), a funding agency for Māori programming; and Māori Television, the main channel of the Māori Television Service that is run non-commercially. This is because, although NZoA might have the largest impact on public television, there are other important contributors to local programme funding which complement and operate outside the remit of NZoA.

This chapter will approach NZoA and public television in four main ways. First, it will provide a brief outline as to the establishment of NZoA as a result of the restructuring of New Zealand broadcasting in 1989. Second, it will consider the responsibilities of the organisation as outlined in the Broadcasting Act (1989). Third, it will explain the aims of NZoA, as this agency's own way of ensuring that it effectively achieves its formal responsibilities. Finally, it will examine the funding structure that characterises the organisation and is considered important to its success. The chapter will then investigate two specific questions about NZoA's operation and influence. One is that of how NZoA is able to counter 'market failure' in local programming to provide public goods with 
cultural and economic public value, and the other, that of how NZoAsupported TV programmes contribute to the representation and fostering of New Zealand 'cultural identity'.

\section{The Establishment of New Zealand on Air}

It is important, first of all, to address the conditions and environment in which NZoA was established, in order to understand the rationale underpinning its unique model and position as a public funder of TV production. From 1984 until the end of the decade, New Zealand was subject to wide-ranging deregulation and restructuring of state assets by the Labour government of the day, led by Prime Minister David Lange. This meant following a strong neoliberal (laissez faire) approach towards the market in terms of political policy and decision making. Television broadcasting was not exempt from the deregulation and restructuring that, by 1987, had already "ripped through finance, forestry, transport, energy and other sectors" (Dunleavy, 2005: 212). As Dunleavy argues, "[ $\mathrm{t}]$ he restructuring and deregulation of television proceeded on the key assumption that state-owned enterprises (SOEs) should operate on a 'strictly commercial' basis in a position of 'competitive neutrality' with rival companies" (ibid.). Key to this was the view that market 'competition' in these industries could better serve the public (ibid.), a view that went on to shape the future direction that New Zealand's television environment would take.

Fundamental to the deregulation of New Zealand broadcasting and pertinent to this thesis are two main pieces of legislation. The first was the BCNZ Restructuring Act (1988) that "dissolved" the Broadcasting Corporation of New Zealand (BCNZ), and precipitated the transformations that saw Television New Zealand (TVNZ) become a State-Owned Enterprise (SOE) (Dunleavy, 2005: 216). The second was the Broadcasting Act (1989), which included provision for the creation of a funding body for 
local programming that would come to be known as New Zealand on Air (NZoA) by July 1989 (ibid.).

Prior to this process of deregulation, television broadcasting in New Zealand consisted of two channels operated by Television New Zealand (TVNZ), which, along with Radio New Zealand (RNZ), were overseen by the Broadcasting Corporation of New Zealand (BCNZ). The BCNZ was owned and governed by the state and funded partly through the proceeds of a public broadcasting fee (Norris and Pauling, 2012: 10), the payment of which was obligatory for citizens with a television set. The BCNZ had responsibilities to public service under the Broadcasting Act (1976) but also received commercial revenue from advertising sales. In fact, since its creation, the BCNZ had become increasingly reliant on advertising revenue, and by 1985, 77.8 per cent of its total revenue came from this source (Smith, 1996: 17). Accordingly, the BCNZ embodied a specific tension between public outcomes and commercialism, or "the pursuit of mixed objectives" (Dunleavy, 2005: 215). Characteristic of the larger process of restructuring and deregulation across New Zealand's stateowned industries (Dunleavy, 2005: 214-15), the BCNZ's restructuring aimed to ease the conflicts caused as a result of these mixed objectives, by moving the responsibility and control of public money and public objectives away from commercial providers (Norris and Pauling, 2012: 11).

TVNZ becoming an SOE, as a consequence of the BCNZ Restructuring Act (1988), meant that it would now be run as a fully commercial enterprise with the objective of maximising profits (Dunleavy, 2005: 213). TVNZ no longer had any formal obligations in programming and its main objective would be to maximise and return dividends to Treasury (ibid; Norris and Pauling, 2012: 11). As a result of the two pieces of legislation mentioned above, the responsibility for the facilitation of New Zealand's public television, which had previously belonged to TVNZ, was effectively transferred to the new public funding agency NZoA (Dunleavy and Joyce, 2011: 112-13). 
This restructuring of the BCNZ exerted a powerful influence as to the future path for two of the most important institutions in New Zealand public television: TVNZ and the newly created NZoA. Bearing in mind that the changes of 1988-89 effectively separated the commercial and public roles formerly fulfilled by TVNZ, the foundations were laid for ongoing tensions between public television's commercial and public objectives, which now entailed collaboration between two institutions. Central to these tensions, which will be explored further in this thesis, was the interdependence and reliance of NZoA on commercial broadcasting outlets (which included TV3 as well as TVNZ) to deliver the programmes that public objectives and public funding would facilitate.

After removing from TVNZ any specific 'public service' programming responsibilities, along with any direct funding for non-commercial productions (Dunleavy and Joyce, 2011: 112-13), what were termed the 'social objectives' of broadcast programming were assessed in order to establish a new set of minimum obligations and outcomes for which the new public-funding agency, NZoA (initially called the Broadcasting Commission) would be responsible. They were broadly set out and agreed upon by the Labour Cabinet in 1988, and were:

To reflect and develop the New Zealand identity and culture by obtaining, commissioning and broadcasting a range of programmes to inform, educate and entertain; To ensure that the people of New Zealand have access to television and radio broadcasting services offering a range of programmes which will cater in a balanced way for varied interests of different sections of the community (Cabinet Minutes 1988 cited in Norris and Pauling, 2012: 11).

It is evident that these social objectives were seen to broadly embody some of the main imperatives of 'public service television', which is interesting as the term 'public service' is not included in the Broadcasting Act (1989) which formalised these social objectives in more detail (Norris and Pauling, 2012: 14). These social objectives would inform and limit 
what public television was about to become and, in a number of respects, has influenced how New Zealanders understand it to this day.

The specific objectives that were outlined in the Broadcasting Act (1989), closely informed by the August 1988 Stevenson Report (Dunleavy, 2005: 216), formed the remit for the new Broadcasting Commission. This would soon after be renamed New Zealand on Air in order to better reflect its commitments to both its specific audience and cultural objectives in programming (NZoA Annual Report, 1990; Norris and Pauling, 2012: 18). It was this commission that was established to maintain and provide public programming in the deregulated market which had been created. From 1989 onward, it was NZoA that would receive the public's license fee, which was abolished in 1999 and replaced by direct government funding (Dunleavy and Joyce, 2011: 113), and would represent public or social objectives within this new environment.

Resulting from the legislative changes above, two other public television organisations that remain today were precipitated, though not established until 1993 and 2004 respectively. These were: Te Māngai Pāho (TMP), a funding agency for Māori programming; and Māori Television, a non-commercial public service Māori TV channel which is part of the Māori Television Service.

Until 1993, when Te Māngai Pāho (TMP) was created, NZoA was solely responsible for the facilitation of Māori programming in New Zealand broadcasting (Dunleavy, 2005: 220). Established under the Broadcasting Amendment Act (1993), initially it was a sub-section of NZoA that focused on Māori language, culture and programming (tmp.govt.nz/television). However, it was reformulated in 1995 as a Māori broadcasting agency independent of NZoA (Dunleavy, 2005: 220) as a step toward greater institutional independence for Māori broadcasting (Dunleavy and Joyce, 2011: 177). Finally, in the year 2000, “TMP's policymaking and funding were shifted from the Ministry of Commerce to Te Puni Kokiri, the Ministry for Māori Development, facilitating appropriate indigenous control of Māori broadcasting" (Dunleavy, 2005: 280). The 
separation from NZoA and independent control of Māori programme funding was important in order to achieve an authentic Māori voice in New Zealand broadcasting. The creation of an institution to fund Māori programming also became far more important in the context of the "transformation of TVNZ from the public broadcaster it had previously been, into an advertiser-funded, profit-oriented business" (Dunleavy and Joyce, 2011: 176).

The 1988 restructuring of TVNZ also made it more necessary to establish “an independent, non-commercial Māori TV channel” (ibid.) because this change failed to make any appropriate provision in television for Māori language and culture (Easton, 2002: 227-228; Dunleavy and Joyce, 2011: 177). The obligation to Māori programming under the Treaty of Waitangi, which was eventually affirmed by the London Privy Council, recognised what Māori broadcasters and commentators had themselves been arguing since the late 1970s, that "the public broadcasting system is a vital present-day resource, and as such Māori are entitled to an equal share of it" (Fox, 2001: 260). As a result of the Privy Council hearing, the New Zealand Crown was instructed to fund Māori television, a decision that preceded the passing of the Māori Television Service Act (2003) and the inception of the Māori Television Service (MTS) as a new public TV network (Dunleavy, 2005: 281; Dunleavy and Joyce, 2011: 176; Smith, 2006: 27). MTS however, came about after the first attempt to start such a Māori TV project in 1996-97, named the Aotearoa Television Network, failed due to inadequate funding and provision (Dunleavy, 2005: 281). Māori Television was launched as MTS's 'flagship' channel in 2004 and its 'public service' remit and non-commercial funding would ensure the necessary provision for Māori language and culture, two things that had been lost once TVNZ was restructured (Easton, 2002: 227-228; Dunleavy and Joyce, 2011: 177). 


\section{Responsibilities of New Zealand on Air}

The objectives that were laid out in the Broadcasting Act (1989) are what form the foundation of, and inform, NZoA's funding policies. Most importantly, NZoA must "reflect and develop New Zealand identity and culture" as stated in the Act. It should do this by "promoting programmes about New Zealand and New Zealand interests" (Broadcasting Act, 1989: 17). As well as this, NZoA was asked to promote "Māori language and Māori culture" and also a range of broadcasts for the interests of: women, youth and children, along with persons with disabilities, and ethnic and religious minorities (ibid.). This was because all of these areas were where significant "'market failure' could be demonstrated", with the government determined to "reduce public investment in non-profitable activities to a minimum" (Dunleavy and Joyce, 2011: 106).

For commercially operating TV channels in a country like New Zealand, 'market failure' (a term that refers to the inability of commercial interests alone to provide certain goods and services) affects a range of locally-produced genres and programmes, because of the relatively high cost of production in relation to the potential advertising revenue that can be generated through their airing (Barnett, 2011: Forum on the Future of Public Television in New Zealand). However, it is only locally-produced programming that has the capacity to deliver the 'cultural identity' obligations that are set out in the Broadcasting Act (1989). It is for this reason that there needs to be a mechanism by which the production of such programming can be supported via public subsidy. NZoA is this mechanism, and so we can consider its main responsibility as funding and facilitating television programming in areas of market failure which can foster New Zealand identity and culture. This is because there is an essential 'public value' when it comes to such programming, which would otherwise not be provided.

NZoA are self-proclaimed "champion[s] of New Zealand content" (NZoA Annual Report, 2011: 3) and their most recognisable aphorism is "supporting local content" (nzonair.govt.nz). However, this is to sell the 
organisation short. It does not merely support local content because it is not in the business of assisting all locally-produced programmes, for example news, sports and current affairs, which are paid for by TVNZ, Mediaworks, and Prime as part of their commercial operation (Dunleavy and Joyce, 2011: 113). Instead, NZoA supports TV production in commercially at-risk areas, notably those which can progress the specific social objectives outlined above (ibid.). This is evident in the fact that, since its inception, NZoA has been required to ensure that "reasonable provision [be] made for the funding of television drama and documentaries" (Broadcasting Act, 1989: 17). These are both particularly challenging production forms to maintain because of their high cost and commercial risk. What can also be observed in respect of these forms is that they have been historically vulnerable within New Zealand's particular market, despite having the capacity for a significant impact in the area of 'cultural identity' for a wide range of viewers (Dunleavy, 2012a: 43; Norris and Pauling, 2012: 59, 61).

Serving mainstream viewers is important to NZoA because of its requirement to consider "the potential size of the audience likely to benefit" (Broadcasting Act, 1989: 19). This requirement has meant that NZoA has needed "to reconcile the level of funding invested in a given TV project with the size of the audience anticipated for it as a completed programme" (Dunleavy, 2010a: 303). This is one of the main strategies that has "distinguished NZoA's efforts to make a limited funding supply go as far as possible" to maximise its public television outcomes (ibid.: 309). This mainstream orientation has always been a guiding principle of the organisation and has also made NZoA's pursuit and accomplishment of public objectives in television quite distinctive.

However, provision is still made for NZoA's facilitation of Māori and 'special interest' programming. 'Special interest' programming can be defined as programming serving "audiences of different ethnic backgrounds, religions and physical abilities" (nzonair.govt.nz/TV/TVstrategy), and like Māori programming, is 
"essentially non-commercial, in that the broadcaster can expect little or no advertising revenue" from it due to the very small audiences such programmes usually attract (Norris and Pauling, 2012: 91). Māori and special interests are catered for and address issues of diversity, making available "a balanced range of programmes and content" (Broadcasting Act, 1989: 19).

In regard to Māori programming - which since 2003-04 has been provided for through Te Māngai Pāho and Māori Television, as two dedicated systems of funding outside of NZoA - public funding support is regarded as essential because te reo and tikanga Māori (language, culture and custom) are unique aspects of New Zealand society. Consequently, for broadcasting to be truly representative there must be a space for these in the environment. As NZoA puts it: "Māori broadcasting provides perspectives and stories that help define us as a nation" (NZoA Annual Report, 2010: 16). Furthermore, Smith and Abel address this point by claiming that Māori broadcasting, and more specifically Māori TV, "asks us to reconsider the meanings surrounding Aotearoa and New Zealand and to privilege the many different ways there are of understanding cultural and national belonging" (2008: 10).

Provision for a range of special interest programmes will always be necessary because they have very little commercial value through the mostly small, niche audiences they attract. This is reflected by their placement predominantly in time-slots with little commercial consequence, such as Sunday mornings, during which time commercials are not permitted to air (Stephens, 2004: 110). Although NZoA must consider the potential audience size to benefit from its programming (particularly when that involves a high production cost), its large remit and diverse range of responsibilities do involve a 'public service' ethos, even if this term was excluded from its founding legislation, the Broadcasting Act (1989). There are four main characteristics of NZoA that demonstrate this public service feature. First are the cultural responsibilities that inform and shape NZoA's investments in TV 
production. Second are NZoA's ongoing efforts to counteract market failure in those areas of local TV programming that are subject to it. Third is the range of programmes being funded by NZoA, this combining 'mainstream' with 'minority audience' forms and examples. Fourth is NZoA's ongoing commitment to funding Māori TV programmes, which it now pursues in collaboration with TMP and Māori Television as public providers that are both dedicated to Māori broadcasting. These core functions of NZoA, which have remained a constant influence on New Zealand's broadcast television since 1989, despite the country's television environment changing considerably, are important to remember in any exploration of this agency's facilitation of, and contributions to, public television.

\section{Aims of New Zealand on Air}

It may be difficult to separate the 'responsibilities' and 'aims' of NZoA, however, the 'responsibilities' can be considered as the particular objectives of the organisation, whereas the 'aims' are the way in which NZoA ensures that it can deliver these objectives in the most effective manner. NZoA's "values have been constant over time" (NZoA Statement of Intent 2011-14: 4) and, albeit not always articulated in this exact manner, are: 'innovation'; 'diversity'; and 'value for money'; these being the values which inform the programme funding decisions NZoA makes (ibid.).

As stipulated by NZoA, these three values are defined as follows:

Innovation - encouraging new ideas, creativity, and quality production standards; Diversity - (in projects, people and platforms) - promoting difference and competition to support the best ideas for the widest range of New Zealanders; Value for Money - making sure cost effective projects are enjoyed by significant numbers of relevant people (NZoA Statement of Intent 2012-15: 4).

These values are important in their capacity to ensure that NZoA's objectives are met. Through the framework they help provide, NZoA can 
more readily identify those projects which would not be made within the commercial context (as a result of market failure), as well as those that best represent and fulfil the ideals and outcomes to which NZoA is committed. Furthermore, they are important in view of NZoA's limited funding for TV production. Due to the wide range of TV categories NZoA must attend to, as well as the commercial necessity and public expectation for 'quality' outcomes in locally-produced programming, limits are inevitably placed on the annual volume of productions that can be funded by NZoA. Therefore these values help to ensure that NZoA's funding is deployed as effectively and efficiently as possible.

'Innovation' helps to ensure that funded projects provide a certain counterpoint and originality as compared with all other TV programming. If this programming does not offer something different from the established 'status quo' of commercially-funded local examples and of imported programmes (in conceptual, generic, and/or cultural respects), then there is little 'public value' in it, and it is unlikely that it will accomplish the desired public outcomes. The important consideration here is that programmes which rely on NZoA funding support are also justified by their cultural role. 'Diversity' attempts to make sure that there is a wide range of programming for a wide range of viewers, again informed by the idea that something new should be facilitated by public funding, rather than that which is already being provided by commercial funding alone. 'Value for money' guarantees that limited funding can still have far-reaching benefits. When applied to NZoA's 'mainstream' programming this means that it hopes to reach as large or broad an audience as possible. This is an aim that, aside from the exception of special interest programming, invariably means that NZoA-supported programmes are created for a 'primetime' position in the schedule (Dunleavy, 2012b: 4).

Together, these imperatives aim to maximise the public value of NZoA-funded programmes which is important in justifying public investment. This notion is made clear by the first Executive Director of 
NZoA, Ruth Harley, who wanted to not only "make programmes about New Zealanders and for New Zealanders, but to make programmes that they want to listen to or watch" and for this content to be "part of everybody's opportunity and ... consumption" (cited in Norris and Pauling, 2012: 17). It is again clear that, in spite of NZoA's remit and aims, it is not simply engaged in the funding of 'local content' for New Zealand television, but is responsible and committed to fulfilling elements of 'public service' through its decisions and facilitation of this programming.

In order to guarantee that these aims are met, NZoA is pro-active in obtaining (through the research it commissions) the forms of information that will maximise the effectiveness not only of its systems, methods and approaches to funding, but also of its funding decisions. Every year, for example, NZoA conducts a number of "value for money reviews" with the objective of "ongoing performance improvement" (NZoA Statement of Intent 2011-14: 5). This objective underlines a longstanding aim of NZoA to minimise administration costs so as to maximise its capacity to invest in television programming (ibid.). Two further examples are NZoA's regular commissioning of 'Public Perceptions Research' (PPR) and its own conducting of 'gap analysis' research (Dunleavy, 2012a: 56).

The PPR aims at understanding the "public's perception of local content and the role NZ On Air plays in delivering local content", in particular the importance, and delivery of relevant and necessary programmes (Public Perceptions Research, 2008/2009: 1). As Dunleavy (2012a: 56) explains, NZoA also conducts 'gap analysis' research in local drama and comedy, "aiming to identify what might be missing from the existing local supply" within these genres. This occurred with Shortland Street, a soap opera created as a result of research undertaken from 199091. This showed that with an "absence of any local soap example" and a large volume of foreign examples, teenagers were prone "to cringe at the sound of New Zealand accents, preferring to hear American or Australian ones instead" (ibid.). The importance of such reports and approaches is that NZoA has a responsibility to its audiences as well as to its remit. By 
carrying out and acting upon such research, NZoA can find out how it can better deliver its objectives to the audience, these being important in justifying the public investment involved (Dunleavy, 2012a: 56-7).

\section{The Funding Model of New Zealand on Air}

NZoA has a funding structure and institutional position which is unique for public television broadcasting around the world. Its structure is defined by how best to distribute limited funds in order to achieve as significant of an impact on public television as possible, or as Dunleavy succinctly put it, "making a little go a long way" (2010a: 302).

NZoA's structure is informed by the imperatives of "competitive neutrality, competitive tendering, and transparency" that informed the restructuring of public companies in New Zealand from 1984 (Dunleavy and Joyce, 2011: 115). The Broadcasting Act (1989) stated that NZoA should "invite competitive proposals" (20) which influenced the most distinctive feature of NZoA, which is the 'contestable fund'. The competitive process involves projects applying and competing for a slice of the funding pie with those projects that are seen to best fit the aims and responsibilities of NZoA, as discussed above, most likely to receive funding.

This 'contestable' fund allocated \$86.6 million for television in 2011 (NZoA Annual Report, 2012: 37) of which drama and comedy, at $\$ 27.7$ million, took up the largest proportion of funding, indicating its high cost (ibid.: 49). This pool of TV production money is split into two individual parts. One is the 'general' fund for all programming that meets NZoA's requirements, which itself is split into programming categories. The other is the 'Platinum Fund', which was created in 2008 and funds special projects that require an even higher level of subsidy than usual. An influential example has been costly one-off tele-features and documentary programmes (Quirk, 2012: 3-4). 
With its total annual funding both determined and allocated by the government (NZoA Annual Report, 2011: 3), NZoA's contestable funding model is a mechanism through which individual television programmes are allocated a portion of their total production cost so that they can be produced. As Dunleavy and Joyce have explained, this funding is allocated "directly to production companies or producers rather than to the network broadcaster" (2011: 116). Dunleavy has also observed that one aim of this contestable system of public funding for TV production was to achieve competitive neutrality between different broadcast TV networks, specifically between TVNZ and TV3, as the only examples in existence when NZoA was created (2010a: 305).

The reason that NZoA must strive to make a "little go a long way" (Dunleavy, 2010a: 302) is because of its limited funding which has been one of "the most important arbiters of its effectiveness" (ibid.), bearing in mind the long list of TV production forms, categories, and audiences that NZoA is responsible to. As Dunleavy has argued, NZoA was intended to be a part funder of programmes, and this assumption informed decisions about how much total funding for TV production it would need (2005: 216). In the context of such limited funding, however, an early decision for NZoA in regard to the projects it chose to fund, was that each of these would need to already have a broadcaster's commitment, the intention of this being that public funding would only be consumed by TV productions that would definitely be aired (Dunleavy, 2008: 804).

The Stevenson Report (1988), the findings of which informed the creation of NZoA, "had envisaged that NZoA would provide 'establishing grants' for TV production" (Dunleavy, 2010a: 306-7) with commercial funding being derived from the broadcasters and/or private investors. The Stevenson Committee's expectation was that local programmes would prove their commercial worth and that NZoA could therefore withdraw its funding following the successful establishment of programmes which had originally required NZoA funding (ibid.). This process was best exemplified by Shortland Street, a soap opera that was established with 
one-third of its production funding from NZoA, and whose public funding was withdrawn from 1995, after three years of production (Dunleavy, 2005: 244). It is important to underline that due to the high costs and challenges of a small national audience, commercial investment has not been sufficient to realise such a vision for other drama programmes (Dunleavy, 2010a: 306; Dunleavy and Joyce, 2011: 129). Hence, "a more flexible 'subsidy' model was adopted" with NZoA's contribution to individual productions averaging "64 per cent of the total cost" by 2009 , and as high as "92 per cent" for special interest programming (Dunleavy, 2010a: 307; NZoA Annual Report 2008: 45-7).

Chris Prowse, NZoA's second Chief Executive, reinforces this idea by describing what NZoA provides as not a grant or investment but rather a subsidy which ideally is the "minimum [that is] needed to get the programme made" (cited in Norris and Pauling, 2012: 38). Broadcasters are still expected to pay a license fee for NZoA-funded local programmes, however, just as they would for an imported programme. These license fees range from $\$ 4,000$ minimum per hour for non-commercial 'special interest' programming up to $\$ 60,000$ minimum per hour for primetime drama (Norris and Pauling, 2012: 39). In this way, the level of contribution from the broadcaster reflects the potential value that a programme will hold within its schedule. To the extent that the license fee that broadcasters will pay for a local programme is usually higher than the cost of acquiring an equivalent imported one, this fee is also reflective of the considered "value of New Zealand programming to their schedules" (Prowse cited in ibid.).

The notion of a broadcaster commitment was born out of the fact that programmes should be prioritised on the basis that "if produced [they] would be broadcast" (Broadcasting Act, 1989: 19). Because of its limited means, NZoA adopted this in its most extreme form, only allocating funding to programmes with a broadcaster commitment, ensuring that everything it chose to fund would air (Dunleavy, 2010a: 304). However, this means that broadcasters ultimately act as the 'gatekeepers' in terms of 
what content will be produced, with this foregrounding tensions between the commercial objectives of broadcasters and the public objectives of NZoA. As Smith explains, "[t]he commercial imperative of the networks forces ideas to be skewed towards the bland and inoffensive" which is "driven by the need for high-rating, mass-appeal programming" (1996: 118). Although mass audiences are important to NZoA it has other responsibilities as well, which are not the same as those of commercial TV networks. The consequence for NZoA and for viewers is that this rule has the "capacity to reduce risk-taking and innovation by NZoA-supported programmes" (Dunleavy and Joyce, 2011: 115). The dominant position of broadcasters in NZoA's funding model has a number of implications that will be explored further in the third chapter.

With the re-appropriation of public funding from the BCNZ to the newly formed NZoA in 1989, the government hoped to realise a greater efficiency and effectiveness in regard to the public money that was allocated for television broadcasting. Until 1999 (when it was abolished) this funding was provided by the public broadcasting fee, after which point it was provided directly from the government and general taxation (Dunleavy, 2005: 219; Dunleavy and Joyce, 2011: 113). This intention to realise greater funding efficiency for public television by being able to "justify every dollar of public funding" that it received is important to the understanding of NZoA (Dunleavy and Joyce, 2011: 114). As such, it has been an organisation that has been informed by and expected to deliver its funding based on the neoliberal notions and interconnected frameworks of 'contestability', 'transparency' and 'accountability'.

In simple terms, the principle of 'contestability' is based on the expectation that TV production proposals compete against each other in order to qualify for NZoA funding, and that funding can be awarded to programmes destined for both public and private networks (Dunleavy, 2005: 222-23; Dunleavy and Joyce, 2011: 115-16). As a result of this contestable process, which also facilitated a funder/producer/provider split, in theory at least (Dunleavy and Joyce, 2011: 115), funding 
'transparency' could be enhanced in respect of to whom, and how much, funding has been allocated being clear to all of the participants and groups involved (Norris and Pauling, 2012: 12). An important consequence of the contestability and transparency of NZoA's funding model is that the system is highly 'accountable', in terms of NZoA's funding decisions, to both the government and the public which are its social and financial stakeholders.

The imperative for contestability, transparency and accountability within NZoA's funding process, according to Harris (cited in Norris and Pauling, 2012: 55), is in stark contrast to those of broadcast networks. This can be perceived as the reason why public funding was removed from what was a mostly commercially driven and funded network in TVNZ, because broadcast networks "are subject to changes in fashion, ratings wars, commercial pressures, and changes in government policy", which undermines the fulfilment of the public objectives discussed (ibid.). Although broadcast networks still inform and shape NZoA's objectives as the deliverers of its content, the system described above provides a better balance and more transparency when it comes to public spending and the pursuit of public television objectives.

Operating with the same model as NZoA, not only because of its conception as part of the agency in 1993 but also because the necessity for it was born from the same neoliberal policy changes, is the Māori programme funder Te Māngai Pāho (TMP). TMP also functions by allocating funds to programme proposals on a competitive basis. However, its obligations and funding decisions are limited to promoting Māori language and Māori culture (tmp.govt.nz/about) through a focus on programmes to be produced in te reo Māori. In this way, TMP is slightly different from NZoA in terms of the scope of its responsibilities as well as its approaches to Māori broadcasting and programming. Because of this, TMP facilitates something distinctive within New Zealand public television. 
It is at this point that it is clear that NZoA and its model for allocating public funding to television was deeply influenced by the neoliberal ideals under which it was created. Although publicly-funded television does not strictly fit in with a neoliberal ideology, and in some instances is arguably antagonistic to it, neoliberalism has informed the manner in which public TV programming has been funded in New Zealand since 1989. This is in the way that its principles were applied to the funding mechanisms that were created to replace the earlier model which public broadcasting corporations (notably TVNZ) had monopolised until 1989. Accordingly, the 1989 creation of NZoA marked a significant change of direction for public television and one that continues to characterise New Zealand's television system to this day.

\section{Importance of NZoA and Public Television}

NZoA is a vital contributor to public television in New Zealand and is important in a range of ways. As suggested earlier in this chapter, countering the negative cultural effects of market failure in broadcasting is one of the most important responsibilities of NZoA. This is because there would be no need for such an organisation if it were not for the fact that, on its own, the New Zealand market will not supply all the desired programmes and outcomes which public broadcasting ideals aim to provide.

This situation is very strongly evident in the category of television drama and can be contextualised by comparing potential primetime advertising revenues for the three broadcast channels with the largest audience share, against the cost for hour-long locally-produced drama. According to John Barnett, the actual advertising revenue per hour for TV One is c. $\$ 90,000$, TV2 c. $\$ 130,000$ and TV3 c. $\$ 50,000$ (2011: Forum on the Future of Public Television in New Zealand), with these channels operating as the logical hosts for NZoA-funded examples of drama because of their audience reach. The actual production costs for local drama episodes 
provide a distinct disparity with the above advertising revenue figures. A local hour-long drama series, such as Go Girls Season 4, requires $\$ 525,000$ of funding per episode from NZoA (NZoA Annual Report, 2011: 49), with the minimum broadcaster license fee for such a programme being $\$ 60,000$, and as high as \$80,000 (Barnett, ibid.; Norris and Pauling, 2012: 39). There is an obvious financial shortfall between the advertising revenue that can be earned in a primetime schedule slot, and the much greater cost of producing local drama programmes as indicated by the necessary levels of investment from NZoA and broadcasters alike to produce each episode (see Dunleavy, 2012a: 53-54).

As a result, it is simply not feasible to produce original local drama in New Zealand without a significant contribution in terms of public funding. Consequently, New Zealand continues to be dependent on imported drama programming, mostly from much larger markets such as the United Kingdom and United States, which are significantly cheaper to purchase. As Horrocks explained, "a one-hour episode of a popular American or British drama series that would have cost, say, $\$ 3,000,000$ to make will be available for $\$ 25,000^{\prime 1}$ (cited in Dunleavy, 2012a: 53). This is much less than the at least $\$ 585,000$ per hour (this representing a drama episode's NZoA funding plus the broadcaster license fee) described for a local example above. As a result, New Zealand television screens are, and always have been, dominated by imported programming from the United Kingdom and United States (Dunleavy, 2005: 2; Dunleavy, 2012a: 43).

Barnett sums up the problem facing New Zealand television quite clearly by using the example of drama. He says that local drama "is only going to generate, in net advertising, about $10-15 \%$ of its production cost" (2010: onfilm.co.nz). This, as Barnett explains, is considerably less than the figures for imported dramas such as “Grey's Anatomy, which return three-to-four times their cost in ad revenue" (ibid). Bearing in mind these economic differences, Barnett goes on to assert that it is "unrealistic to

\footnotetext{
${ }^{1}$ This figure of $\$ 25,000$ is only approximate and represents an average, meaning a number of premium examples would cost much more than this.
} 
expect a [free-to-air] broadcaster to fund a lot of New Zealand primetime one-hour drama. Hence, the need for NZ On Air. The alternative [is] no New Zealand drama on our screens" (ibid.).

For these reasons, it is quite clear that it is really only economically viable for New Zealand TV broadcasters to purchase and screen foreign imported programming and not to commission and pay for original examples themselves. Without intervention in this market, certain types of local programming "would likely cease to exist" (Dunleavy, 2012a: 58) because the broadcasters simply could not supply the large amount of necessary funding for them to get made. This is most true of drama, comedy and documentary because these are such costly forms (Dunleavy, 2012a: 43; Norris and Pauling, 2012: 60).

Other unprofitable TV programme categories which are in turn underserved by commercial broadcasters, not necessarily due to their high production costs but because of their smaller audience levels, are children's and special interest programmes. The 'opportunity cost'2 for broadcasters in commissioning and scheduling these programmes is the expectation of higher "revenue from more commercial programmes" (Zanker, 2012a: 71). On this point, broadcasters "can expect little or no advertising revenue from [programmes with such small audiences]" (Norris and Pauling, 2012: 91).

Therefore, New Zealand broadcasting relies upon NZoA in order to facilitate such programming, through the strategic funding model described earlier, that is not likely to be provided if left to the market alone. NZoA's ability to counter market failure in these areas is strongly linked with its formal obligations to 'cultural identity', as explained earlier in this chapter (Broadcasting Act, 1989: 17-18). All of these programme forms and categories are capable of representing elements of local culture and identity which makes them important in fulfilling NZoA's obligations under the Broadcasting Act. NZoA counters the effects of market failure

\footnotetext{
${ }^{2}$ The opportunities forgone in making one choice over another; in this case choosing to air a new locally-produced TV programme rather than an imported one.
} 
because particular local programmes are considered a 'public good' and have a number of benefits that will be discussed shortly. Without NZoA's intervention and public funding, the range and diversity of local programming would be radically reduced. Local content on television would be limited to news, sports and current affairs programmes, as categories that do have a place in New Zealand's commercial broadcast schedules. Underpinning the considered schedule strength of these programmes is their ability not only to cultivate the country's largest TV audiences and advertising revenues, but also to be produced (bearing in mind the revenue they earn) at an affordable cost.

\section{Functions and Value of NZoA}

By now it is understood how NZoA intervenes in the television broadcasting environment. However, this intervention is rather arbitrary if there is no benefit to be derived from it. It is not justifiable to invest public money into such an area if the outputs are not then of demonstrable value to the New Zealand public. This section will identify and discuss the important functions that these outputs perform, along with the subsequent value of the programming that NZoA facilitates. This discussion can be divided into two separate and distinctive areas, the first of which is cultural, and the second of which is economic. These are the two ways that local programming that is facilitated by NZoA can be considered as a 'public good', both beneficial holistically, and also more specifically, to the New Zealand public.

The most important function, and the crucial benefit of NZoA-funded programming, is that it "reflect[s] and develop[s] New Zealand identity and culture" (Broadcasting Act, 1989: 17). This is the central remit for the organisation and consequently forms the framework for all of its decisions as well as the value and benefit it provides. The reason this notion is so important is the problem of market failure that has been discussed. If it were not for NZoA, there would be a significantly reduced range of 
programming available on New Zealand's main free-to-air TV channels that reflected New Zealand's culture and identity. In almost every case, NZoA-funded content has the sort of cultural value that is desired from and expected of publicly-funded TV programming. By reflecting New Zealand culture and identity it reinforces these things, providing national points of reference which are separate from foreign, imported representations. In the case of New Zealand which is a small, Englishspeaking market, these representations have been predominantly British and American (Dunleavy, 2005: 6).

One way that this has been manifested in New Zealand television has been by addressing 'cultural cringe', a term which "has come to describe the negative, rejecting reaction of some New Zealanders to domestic TV programmes" and to the local representations depicted in them (Dunleavy, 2005: 5). NZoA has helped to facilitate a vast array of quality programmes which have been important to presenting New Zealand culture and expertise to audiences. One of the initial and precipitating objectives of local soap opera Shortland Street - a programme whose creation was facilitated by NZoA - was to help address and reduce cultural cringe (Dunleavy, 2003: 19). Because of its "schedule regularity and characteristic longevity" as a daily serial whose episodes have been 'stripped' in a mid-primetime time-slot, it had a significant capacity to reduce cultural cringe by ensuring a "necessary immersion in identifiably New Zealand images and accents" (Dunleavy and Joyce, 2011: 129). Accepting that Shortland Street's longevity and profile make it an unusual example, this "immersion" is something to which a wide range of NZoAsupported TV programming has since contributed.

Because of NZoA's reach and level of funding within public television, it is quite rightly the most significant organisation that delivers programming with cultural value, which is vital when justifying public spending and ensuring there is a social benefit. Dunleavy and Joyce state that NZoA has a "unique influence in providing a necessary cultural counterweight to the commercial priorities of networks" (2011: 194), 
meaning that it is through NZoA that New Zealand can counter the cultural effects of a predominance of relatively cheaper, imported programming. This will be discussed in more detail in the second chapter of this thesis.

The content that NZoA supports not only has a distinctive cultural value, but there are also significant economic repercussions that are derived from these investments. Economic goals and imperatives are not entrenched in legislation per se, but there are specific economic benefits which are a positive by-product of the NZoA model and must be considered in relation to the importance and efficacy of the organisation.

With the restructuring that created NZoA and made TVNZ an SOE, direct funding to the in-house production unit of TVNZ ceased, "which saw it disestablish the majority of in-house production departments, a process that was largely completed by 1990" (Dunleavy and Joyce, 2011: 123). Instead production funds were bid for through the contestable process described. What ensued was "equal access to public funding support" for producers who could now pitch ideas to the networks and receive funding from NZoA (ibid.). This allowed and resulted in the constant strengthening and burgeoning of an independent production sector throughout the 1990s which is still sustained through the funding that NZoA provides (ibid.). The maintenance of this production sector has a number of repercussions which are intrinsically linked within a fragile framework. NZoA's distribution of funding is an integral catalyst for production in the television sector (ibid.) and the reason for this is that its level of funding is mostly constant, allowing stability within the industry and a platform on which it can grow. NZoA's television spending was merely $\$ 86.0$ million in 2010 (NZoA Annual Report, 2011: 23) in comparison to the $\$ 600$ million total (NZoA Statement of Intent 2011-14: 8) generated within the industry, which would not be possible without NZoA's constant and consistent presence.

Furthermore, without the range and volume of local content that NZoA facilitates, the opportunities for creative and technical personnel in television would be greatly reduced. If this was the case, then it is likely 
that New Zealand would fail to hold on to skilled people in this area against the lure of opportunities abroad (Dunleavy, 2005: 263). In this way, NZoA programming plays a significant part in the New Zealand screen industry as a whole.

These are direct benefits to the economy, however, NZoA's model also assisted in reducing the costs of television production and helped facilitate the creation of a highly efficient industry. The Chapman Report (1986) initially outlined the capacity for independent producers to "make programmes more cheaply" (186) and South Pacific Pictures (SPP) demonstrated this with its "considerably lower overheads per production hour" as it was staffed on a short-term contract system, which is in sharp contrast to an in-house production model which has "very high fixed costs to maintain" (Dunleavy and Joyce, 2011: 123-4). The contestable nature of NZoA's model also motivates competitive proposals which are judged partly in relation to their considered 'value for money', with this encouraging proposals to be as cost effective as possible, again helping to minimise production costs and maximise efficiency. NZoA claims that "New Zealand programme makers create some of the most cost-effective programming in the world" (Statement of Intent 2011-14: 9). All of these things considered, it is clear that NZoA's funding model is predicated upon expectations for economic efficiency, and it also delivers this, making it a public institution and funding allocation mechanism that would be extremely difficult to replace.

A final consequence of the move from purely in-house production to a model that was instead reliant on independent production, is that a greater range of production companies and personnel have been able to contribute to TV production, a change which "brought a wealth of new ideas, perspectives and approaches" to television production (Dunleavy and Joyce, 2011: 123). With a diversity of voices participating in New Zealand's screen production industry, the potentials for innovation and creativity in respect of the production outcomes is able to be encouraged. Although an 'in-house' system of production works well in some 
categories (such as news), it is less effective in many other areas (such as drama and documentary).

\section{NZoA and Public Service}

Public service objectives "have played an important role in New Zealand television since the medium's inception in 1960" (Dunleavy, 2008: 795). However, New Zealand has often been devoid of an explicit, formalised public service ethos and public service channels or mechanisms. This is due to three factors: New Zealand has a small market size and therefore struggles to fund such initiatives (ibid.); successive governments' "ambivalence" to its importance and therefore inconsistency of provision for it (ibid.); and the high level of commercial funding and therefore commercial influence within our television broadcasting environment (Smith, 1996: 17).

NZoA, however, has been one of the most consistent ways by which the New Zealand public has received particular local programmes, the presence of which, on broadcast television, helps television to meet desired public outcomes or social objectives as have been outlined earlier. Although NZoA defines the nature of the financial support it provides as simply 'supporting local content', it is important to realise that, in fact, the range of programming which it does fund has particular public service outcomes and it often fulfils a number of imperatives which characterise public service, particularly in relation to cultural identity.

In New Zealand, "public service objectives have been unusually synonymous" with notions of local content as provided by NZoA which supplies “local TV drama, documentary, children’s, Māori language, arts, music and comedy programming" (Dunleavy, 2008: 799). All of these are at risk commercially and are part of a range of programme forms and examples that can represent New Zealand's culture in diverse ways. Murdock emphasises this point when he says that "[if] New Zealanders ask 'what is public service, and who is it for?' the answer must be that it is 
about local content, which is tailored into a range of packages to a whole range of tastes'” (1997: 24).

Furthermore, NZoA funds a number of programmes that have an overt public service focus, a strong example being those programmes that are destined for broadcast on Māori Television, a non-commercial channel with a public service remit. In regard to Māori Television, NZoA mostly funds in the categories of 'high-end' factual programming or documentary (Parr, 2013), as well as Māori programmes for a mainstream audience. Because of Māori Television's non-commercial schedule, NZoA has the freedom to facilitate programmes that would not be accepted by a commercial broadcaster and can overtly fulfil public service objectives. If a mainstream non-commercial channel existed in addition to Māori Television, it would allow NZoA to facilitate a supply of mainstream noncommercial TV programmes. From the social functions and value that NZoA-supported TV programming provides, it is evident that it goes further than simply funding local content and that, in fact, it does accomplish many of the goals that are tantamount to public service.

\section{Free-to-Air Television: NZoA's Broadcast Platform}

That all of the programmes supported by NZoA are destined for free-to-air networks, the majority of which are produced for one of the three most established broadcast channels - TV One, TV2 (TVNZ) and TV3 (Mediaworks) - is significant in terms of the 'public value' of this programming. Free-to-air television is an integral and effective way to address and present New Zealand culture and identity for two main reasons. First is the continuing popularity and 'universal accessibility' of broadcast television as a platform (Murdock, 1997: 17). Second is that, as one of the predominant outlets for imported television programmes, which in great quantity have the capacity to undermine local culture and identity, it is vital that there is a counterforce in this area (Dunleavy, 2005: 5-7). 
It is often speculated that television is losing appeal as a medium as audiences move towards other modes of consumption through newer platforms, such as the internet and smart-phones, which can provide a more individualised content experience. However, the counterview that the television medium is not losing influence in today's media environment is gaining sway among influential commentators, in the light of new evidence about the kinds of viewing choices that viewers are understood to be making. A 2011 report from Deloitte argues that TV globally will "solidify its status as the current super media" as viewers will continue to watch more TV hours, total TV revenues will rise, the world's TV market will increase and that it will continue to command the world's attention, despite "some commentators' prophecies of imminent obsolescence" (2011: 20). NZoA has reinforced some of these international assertions by deploying new evidence of viewing behaviour in New Zealand. Informed by the findings of recent ratings survey data, NZoA affirms that "more people than ever are watching television", that "people are watching for longer" (NZoA Statement of Intent 2011-14: 7), and that 89 per cent of people still watch TV live (Public Perceptions Research, 2011: 30).

Although viewing behaviour is undeniably changing in the presence of additional platforms and services (these also providing additional ways to consume TV programmes), the evidence above appeases notions of the extent to which traditional broadcast television is being affected by this. Deloitte's observations stand to refute earlier claims that new media services and technologies have rendered television a less significant and central medium. Moreover, the continuing dominance of television as a multi-platform, yet still central medium, in New Zealand, continues to provide an important justification for the public investment that it receives.

This is important because NZoA's first obligation is to the mainstream majority audience. NZoA's remit necessitates that due consideration be given to the "potential size of the audience likely to 
benefit" (Broadcasting Act, 1989: 19) from the programmes that are funded, in order to maximise the 'public value' measures of 'reach', 'impact', and 'value for money' (Dunleavy, 2012b: 2). For this reason, it is noteworthy not only that most NZoA-support programmes are produced for either TVNZ or Mediaworks, but also that a majority of these programmes are produced for 'primetime' (that is 6-10.30 pm) timeslots. Together these two tendencies are geared to maximise the reach of the resulting programmes, along with their possible impact for viewers.

The majority of NZoA-supported programming is found on TV One, TV2 and TV3, because as a group of channels they together hold a "continuing concentration of audience eyeballs" on most weeknights (Dunleavy, 2012a: 46). ${ }^{3}$ Ruth Harley (NZoA's first CEO), explains one of the reasons for this, as she believed that to most effectively promote NZoA's objectives it had to intervene "in favour of mass interest [New Zealand] cultural product" (cited in Norris and Pauling, 2012: 17). She "wanted [New Zealand] content to be part of everybody's opportunity and part of everybody's basic consumption" (ibid.). This does not mean that special interest audiences and programming do not exist as another responsibility (Broadcasting Act, 1989: 17), however, the focus is on servicing the largest possible audiences. One of the main reasons for this is that NZoA funding is extremely limited and it therefore wants to get the most 'bang for its buck'. This means targeting a mainstream audience, especially in the most costly production categories. Dunleavy suggested that "with a market size of just 4.2 million, it has been difficult to fund the full range of PSB objectives" (2008: 795) and therefore NZoA funds with the intention of making New Zealand culture and identity - which is tied in with public service - as widely available as possible because this is perceived to maximise 'public value'.

\footnotetext{
${ }^{3}$ In line with this, these channels are the recipients of the majority of programming funded by NZoA which coincides with NZoA policy which tiers the free-to-air broadcasters in a hierarchy that is based on audience size (or 'reach'), as a way to maximise the potential viewership and audience impact for NZoA-supported TV programmes (Dunleavy, 2012b: 2).
} 


\section{Conclusion}

New Zealand on Air was established as part of a neoliberal shift in politics and the subsequent restructuring of New Zealand's broadcasting environment in 1988-89. The environment that was created assumed that market forces and competition would best serve the needs of New Zealanders in the area of television. However, NZoA was created in order to focus in areas subject to market failure and, within those areas, to deliver the 'social objectives' of public broadcasting. In New Zealand, this would mean a particular focus on representations of local culture and identity, for a range of audiences. These approaches would come to form New Zealand's own brand of public television and would have a long lasting effect on this country's public television.

The creation of NZoA, and its contestable funding model which followed the principles of contestability, transparency and accountability, testified to the influence of the neoliberal policies that produced it. These same principles have contributed to NZoA's effective functioning, success and integrity throughout its history by helping facilitate NZoA's continuing efforts to make a limited funding pool make as much impact on public television as possible.

In spite of the considerable environmental and technological changes occurring since 1989, NZoA continues to make a significant and highly valued contribution to New Zealand's public television, as there is an intrinsic importance (economically as well as culturally), to the programmes that NZoA facilitates. The most significant economic benefit is that of a healthy and flourishing screen production industry, which has been precipitated by the consistent funding stream that NZoA provides for television production. This achievement is significant, given that without NZoA, New Zealand television production would have continued to be characterised by fluctuations and inconsistent funding, due to the array of other priorities for TV networks. 
Furthermore, without NZoA, there would also have been be a dearth of particular programme forms in New Zealand, these including drama, documentary, Māori and various special interest programmes. Although such programme forms are prone to market failure in such a small national TV market, all of these remain important for their cultural contributions. These programmes provide an immersion in both the indigenous language and New Zealand's distinctive accents, and the depiction of recognisably New Zealand images, people and representations; things that are integral to fostering 'cultural identity'.

Because of the limited capacity of commercial broadcasters to fund and produce a wider range of local programmes, institutional mechanisms and public funding (in this case, NZoA, along with TMP and Māori Television) simply must exist to ensure that the full range of local programmes are available to viewers. 


\section{Chapter Two: The Effectiveness and Strengths of New Zealand on Air and Public Television}

\section{Introduction}

Developing upon the previous chapter, this chapter seeks to provide a more specific and detailed investigation into how effectively NZoA fulfils its public role. First, this chapter will briefly consider the main ways NZoA's funding structure operates to enable the effective delivery of the organisation's objectives in the area of public television. Second, it will examine a range of programming case studies that can demonstrate the various ways that NZoA has succeeded in facilitating the production of TV programming for the benefit of New Zealanders.

This chapter will then consider the ways in which NZoA's facilitation of Māori programming works to complement the efforts and contributions of both the Māori broadcasting agency, Te Māngai Pāho, and the Māori Television channel. This chapter's examination of how Māori programming is facilitated is also important for its capacity to demonstrate the processes for, and significance of, collaboration between different public funding agencies to facilitate the creation of public television programming for more specialised TV audiences in New Zealand.

\section{The Effectiveness of the NZoA Model}

There are a number of reasons why NZoA's funding model, a system that has existed for twenty-four years, is considered to be effective at achieving its central objectives of reflecting and developing New Zealand culture and identity through broadcast programming (Broadcasting Act, 1989: 17). As 
is partially demonstrated by its longevity and prominence in New Zealand's public television landscape, NZoA is an organisation that is considered to be successful. NZoA's clear and focussed mission, responsibilities and values (Broadcasting Act, 1989; NZoA Statement of Intent 2011-14: 4) have meant that it functions at a level that is not only widely acceptable (Public Perceptions Research, 2011: 7), but can also exceed the outcomes that might be expected of it, bearing in mind the constraints imposed by NZoA's limited funding and large public broadcasting remit.

The contestability, transparency and accountability of the NZoA model (which was explained in the first chapter), is one of the main reasons why it has been so successful in its efforts to develop and facilitate TV production in a specified range of categories. NZoA's contestable funding model, and that this funding is separate to the broadcasters who screen the programmes, results in transparency in the application, funding and delivery process. Furthermore this means that NZoA can be held responsible for its actions and decisions by the government who fund it, and the audience, for whose benefit it exists. One of the main reasons for this is that "the very creation of NZoA attested to a neoliberal vision for broadcasting" which would require an appropriate justification for "every dollar of public funding" being invested in it (Dunleavy and Joyce, 2011: 114). The results of this neoliberal approach and the subsequent transparency and accountability of programme funding has been programmes which, more often than not, meet the objectives of the organisation. This is because they are the products of an efficient creative framework and a carefully scrutinised investment of public funding.

NZoA's institutional position, as one which maintains a relative autonomy from the television industry, is also of vital importance in explaining why this agency has been successful. While there are some problems in respect of NZoA's position (which will be addressed later in this chapter), its system entails clear advantages as compared to public funding being allocated by a commercially oriented broadcaster, as was 
the case before NZoA's establishment and was briefly true with the TVNZ Charter.

NZoA is an agency situated between the government, industry producers and a predominantly commercial range of TV networks. A longstanding requirement of $\mathrm{NZoA}$ is that a $\mathrm{TV}$ production must have broadcaster approval in relation to screening it before it is eligible to receive NZoA funding (Dunleavy, 2005: 220). This has the advantage of ensuring everything funded goes to air in an area that is constrained by limited funding. At the same time it can mean that innovation is stifled by the commercial demands of networks (Dunleavy and Joyce, 2011: 115). However, NZoA has managed to "maximise the opportunities for innovation" through a continued and significant "presence in the funding mix and the contributions it can therefore make to negotiations about new productions" (ibid.). In particular this has been in the way that NZoA has attempted to fill gaps in the broadcasting environment (Dunleavy, 2012a: 56) which is evident in the way that it invited proposals for a soap opera in 1991 which resulted in Shortland Street and targeted one-off tele-features with the Platinum Fund.

The establishment of NZoA meant the "separation of 'commercial' and 'public' functions" for broadcasting, a contrast to the earlier blending of these within the original TVNZ (Dunleavy, 2005: 213). This change left TVNZ as a commercially focussed broadcaster, the creation of NZoA meaning that public television's cultural objectives could be funded and pursued separately. Even if the programmes are created for a commercial network and schedule, NZoA's exclusive focus on cultural objectives and outcomes has managed to make a significant contribution in the quality and variety of local programming on New Zealand screens despite its limited funding pool.

Interrelated with this, NZoA has the clear mission to allocate its funding in the interests of "innovation, diversity and value for money" (NZoA Statement of Intent 2011-14: 4) in order to "ensure a sound investment framework" (ibid.). While the imperatives of 'innovation' and 
'value for money' tie in with producing quality programmes, those of 'innovation' and 'diversity' help to ensure NZoA's cultural objectives. The imperative of 'value for money' maximises the potential of all of the above things by making public funding go as far as possible. This mission is intrinsically connected to the four public value measures of reach, impact, quality and value for money, which together work to inform current understandings of public broadcasting (Collins, 2007a: 167). The above objectives drive the TV funding decisions that NZoA makes and therefore are relevant to its success as a hierarchy of perceived programming needs, against which different proposals can be considered, is formed. These objectives also provide a means by which to measure and evaluate NZoA and its activities, establishing some clear criteria against which the resulting programmes can be judged. These characteristics and features of the NZoA model, when considering NZoA-funded programmes in relation to them, have worked to ensure the demonstrated success of NZoA in facilitating public broadcasting.

\section{Case Studies in NZoA-Supported TV Programming}

The following case studies examine a small selection of NZoA's successful projects in order to explore how this agency fulfils its programme objectives and what the repercussions of its funding input have been. Although NZoA has funded many thousands of programmes in the twentyfour years it has existed, these few examples have been chosen to provide an indicative sense of how NZoA's objectives are realised in TV programming.

Much of the focus will be on television drama and the reason for this emphasis is two-fold. First, this production category takes the largest slice of NZoA's annual funding (NZoA Annual Report, 2011: 49), and second, because of its function and popularity, TV drama programmes provide an important way for NZoA to achieve its cultural objectives (Dunleavy, 2012a: 55). 
However, a range of programme categories will be considered, with focus being given to documentary, special interest, children's and Māori programming as other areas in which NZoA has influenced public television in New Zealand. The importance of all of these categories is their capacity to demonstrate the diversity of NZoA's operations and programming responsibilities. Taken together, the programme examples below aim to provide a detailed depiction of how NZoA has succeeded in providing New Zealand TV audiences with quality local programming of cultural significance. In these categories, which tend not to be as 'mainstream' audience-oriented as TV drama, some limitations of NZoA's input and impact will also be discussed to provide the basis by which the necessity for non-commercial provisions in New Zealand public television can be argued.

\section{Shortland Street}

The first programme case study is the daily primetime soap opera Shortland Street because, since it displays and fulfils a number of NZoA's purposes, can be considered among the strongest examples of the potentials and benefits of NZoA's facilitation of TV programmes. Shortland Street first screened on TV2 on 27 May 1992 (Dunleavy, 2005: 236), and was one-third funded by NZoA (Dunleavy, 2003: 20) for its first three years of production (ibid.: 28). After this point, having demonstrated commercial viability, NZoA funding was ceased. Particularly since it was among the first TV production projects to use the 'competitive tender' process that has always distinguished the NZoA system, NZoA's contribution to the creation and success of this soap opera provides a very important example of how this system was intended to work. Though originally met with much scepticism from TVNZ as its host network (Dunleavy, 2003: 20), Shortland Street is regarded an "outstanding success" (Dunleavy and Joyce, 2011: 193). This programme has enjoyed a continuous twenty-one years of broadcast and, although public funding 
was important to creating it, Shortland Street is the only TV drama programme to have attained economic independence from NZoA.

Important to Shortland Street, and developing from the two requirements imposed on it by NZoA in its first three years of production, have been its ability to represent New Zealand's cultural and social diversity in terms of characters and stories, as well as its addressing issues of particular relevance to young people (Dunleavy, 2003: 28). Jason Daniel, who helped to create Shortland Street, highlighted the importance of its concept in being as near as possible to being able to represent a "microcosm of New Zealand" (cited in Dunleavy, 2005: 239). Because the concept of a soap opera informs and is inevitably "transferred to its characters and stories" (Dunleavy, 2005: 239), this notion of a 'microcosm' can be seen, for example, in the multi-cultural composition and range of age-groups that are reflected in the Shortland Street cast (ibid.: 245). Additionally its setting in and around a public hospital, which occurred as a result of the conceptual "revamp" of Shortland Street in the year 2000, has allowed this programme to explore stories originating at "both ends of the socio-economic spectrum" (Daniel cited in Dunleavy, 2005: 239). This particular potential of Shortland Street's post-2000 concept has made it more possible for this soap to approach and explore a range of stories that are relevant to New Zealand culture and identity (ibid.: 237-239).

Reinforcing the above idea of Shortland Street offering a cultural 'microcosm' through its representations, is the programme's centrality to the brand and schedule of its host channel, TV2. The continuing regular appearance of this programme underlines its institutional function and importance as a "flagship" drama for TV2 (Dunleavy, 2005: 8). Its "serialised narrative" (ibid.: 239) and stripped daily presence across the Monday to Friday $7 \mathrm{pm}$ timeslot has given it a high and continuing profile on New Zealand television, and subsequently, a firm place in the consciousness of New Zealanders (Dunleavy and Joyce, 2011: 132).

The ongoing production and presence of Shortland Street has meant that cultural representations of New Zealand have had the opportunity to 55 I $\mathrm{P}$ a g e 
be conveyed to a wide audience on a continuing basis, as it plays five nights a week, most weeks of the year (Dunleavy, 2003: 31-32). This is significant because it constitutes "unprecedented exposure [for] a local TV drama" and has ensured "a necessary immersion in identifiably New Zealand images and accents for an audience that once suffered from 'cultural cringe'” (Dunleavy, 2003: 32). Furthermore, it has demonstrated the "'brand' value" of local drama for networks (Dunleavy and Joyce, 2011: 134) and has also fostered an audience "taste and appetite for domestic drama", especially among the demographic of 14-25 year-old viewers, an important segment of the show's broader target audience (Dunleavy, 2003: 32). These aspects of Shortland Street have meant that it has been of benefit to other drama productions over the years and has had a marked impact on New Zealand public television.

Another positive consequence of Shortland Street is that it has helped to provide an ongoing "employment base for the development of New Zealand artistic and creative talent" (Norris and Pauling, 2012: 20). This is due to its unusually large volume of episode output and to the 'fast-turnaround' mode of production that sustaining such an output requires (Dunleavy and Joyce, 2011: 132). Shortland Street's formal characteristics as a 'stripped' and continuing soap opera necessitates the regular contributions of a large group of personnel - from actors and production crew, to writers and directors. Its maintaining of a very high episode output has allowed the production of Shortland Street to provide the "initial experience and/or regular work" to create and maintain a pool of experienced creative personnel within the television drama production industry (ibid.: 134). Shortland Street's continuity has helped to minimise the loss of such personnel to larger overseas markets (ibid.), while allowing expertise that it has developed to be utilised in other locallyproduced TV drama, most notably in the hour-long series form. Shortland Street is and has been an important "training ground" (Dunleavy and Joyce, 2011: 134) that has facilitated growth and quality in the television 
industry, this achievement working with others already mentioned to illustrate the soap's position as a success of the NZoA model.

\section{Outrageous Fortune}

Outrageous Fortune is an example of renewable hour-long drama series and has been chosen because it is "the most successful series drama" of NZoA's operation history (Dunleavy and Joyce, 2011: 203). Both before and after the inception of NZoA, there has been a succession of locallyproduced examples of the drama series form (see Dunleavy, 2005; Dunleavy and Joyce, 2011) and Outrageous Fortune is highly indicative of the possibilities of this form. It has also been chosen because, as a particularly popular example, it assisted in reinvigorating local series drama programming, helping to legitimise the high level of public investment in it. As Jane Wrightson registers, it "raised the bar immeasurably" and has "made all networks desperately interested in local drama" (cited in Dunleavy and Joyce, 2011: 203). This is important for two reasons: first the high production cost of a local drama series, and second its strategic value to networks in view of the "schedule profile" it can gain (Dunleavy, 2012a: 44). The popularity and prominence of primetime drama, especially if this drama is also locally-produced, gives it the potential to incite "ongoing loyalty" from audiences and contribute valuably to the brand identity of its host channel (ibid.). As a type of drama that is designed to achieve these benefits on a recurring basis, the drama series form seems well-matched with NZoA's aims for the cultural impact of its funded TV projects, as well as being closely aligned with the priorities of New Zealand's TV broadcasters.

Outrageous Fortune is also one of New Zealand's most successful hour-long drama series. It screened for six seasons in primetime on TV3 between 2005 and 2010, making it the longest-running local drama series example (Dunleavy and Joyce, 2011: 198). Importantly, Outrageous Fortune could never have been made without considerable investment 
from NZoA because of its significant cost in relation to the advertising revenue it could earn (Dunleavy, 2012a: 54). It is one of only a few local drama series to have "consistently grown [its] audience from one series to the next" (Murray, 2010: 9) - which is even more impressive when considering its longevity - and is easily the series "returning the highest level of sales income to NZ On Air" (ibid: 3).

In a similar way to Shortland Street, albeit different in its form, episode cost, and schedule function, Outrageous Fortune provides an important demonstration of the role and importance of NZoA funding support and the cultural benefits that this can achieve. As previously stated, television is an important site for cultural reflections because it remains the "current 'super media"' and the recipient of unrivalled audience attention (Deloitte report, 2011: 20). In New Zealand, television remains one of the central outlets for the broadcast and viewing of TV programmes (both foreign and local) and therefore, of cultural representations. Hour-long drama series is one of the mainstays of primetime television because of its continuity, regularity and profile, so it is important that New Zealand continues to be able to produce and air domestic dramas as a counterpart to the many foreign examples of drama that are broadcast in this country (Dunleavy, 2005: 8). The difficulties that local examples of drama face, however, are underlined by Dunleavy and Joyce who assert that:

[F]or a new local series to survive long enough to build its audience and become a popular, enduring programme, it must not only hold its own against the audience allure of a 'new season' import, but also win its timeslot against such a programme (2011: 199).

Outrageous Fortune did manage to meet these challenges though, and just as Shortland Street counters the schedule dominance that soaps such as Neighbours, Home and Away and Coronation Street have enjoyed, Outrageous Fortune has worked as a domestic alternative to the many British and American drama series that air on New Zealand television. 
Dunleavy and Joyce go on to argue that "relatively few local drama series of those produced since 1990 have rated well enough to succeed against these odds" (ibid.) and have not managed, therefore, to endure long enough to rival the popularity, longevity, and influence of Outrageous Fortune. This situation illustrates the dominance of foreign programming in the drama category and the difficulties therefore, that a local drama faces in New Zealand's competitive television environment. This further testifies to the unusual achievement of Outrageous Fortune (Murray, 2010: 9). Particularly in view of its potential for cultural influence, a public funding mechanism for such programming seems both appropriate and necessary.

The enormous success of Outrageous Fortune, and similarly of Shortland Street, can largely be accredited to the finely-tuned blending of intrinsically 'local' characteristics with recognisable 'universal' conventions (Dunleavy, 2005: 8). As something that seems equally true for Shortland Street and Outrageous Fortune, Dunleavy emphasises that the distinctiveness of these shows is derived from the fact that "within [their] conceptual and aesthetic blend, universal conventions and foreign influences are so much inflected by 'localness' (ibid.: 241). Importantly, by blending elements of 'localness' and 'universality', these programmes can fulfil the local cultural expectations that apply to them.

Outrageous Fortune is based around the innovative premise of "a West Auckland crime family trying to go straight" (Wakefield cited in Dunleavy, 2005: 306). The West family of Outrageous Fortune embody the traits of "a disregard for authority and the mockery of establishment; and an irrepressible 'tall poppy syndrome' which sneers at flaunted wealth and other indicators of achievement" (Dunleavy and Joyce, 2011: 199). Dunleavy and Joyce argue that the dispositions of the programme's characters "operate as signifiers of an idiosyncratically 'New Zealand' national character" (ibid.), these assertions highlighting how this programme is considered to meet the representational expectations of NZoA's cultural remit. 
Working in conjunction with its recognisably 'Kiwi' characteristics are the many ways in which Outrageous Fortune has adhered to established universal conventions, both things working together to ensure the show's popularity in New Zealand (Dunleavy and Joyce, 2011: 200). In an effort to emulate the "allure of leading foreign examples of renewable hour-long drama" (ibid.), Outrageous Fortune incorporated the well-tested narrative conventions of series drama, increasing the programme's accessibility to viewers. So although the premise of the programme was innovative, and the characters that inhabited the programme's diegetic world were distinctive, Outrageous Fortune deployed a narrative mode and structure that is typical of relationship-oriented imported drama series. This is an effective approach in an environment where ratings failure for an individual New Zealand TV drama series can have negative ramifications for other locally-produced examples.

The popularity and success of Outrageous Fortune has had some meaningful repercussions for public television in New Zealand. Significantly, Outrageous Fortune has built on the success of Shortland Street and has further developed the skills of New Zealand creative personnel in a tier of drama production that is more demanding than soap opera. Shortland Street can be considered as a production which maintains creative expertise at the "lower layer of TV drama's production industry pyramid" (Dunleavy, 2012a: 52). In contrast, Outrageous Fortune and other locally-produced, hour-long drama series help to build and sustain expertise at the middle and upper layers of this same pyramid. It is generally only experienced TV drama personnel who can progress to being key contributors to the hour-long series form. This, in turn, allows them "to practise their craft and extend their expertise" (Dunleavy, 2012a: 52) in what is traditionally a more prestigious form, as well as one entailing far higher production costs as compared with those of soap opera. The expertise that these two programmes have together helped develop and demonstrate has had a lasting impact, with a string of successful and popular drama series being produced since, most notably Go Girls, The 
Almighty Johnsons and Nothing Trivial. Outrageous Fortune prepared the way for further success in locally-produced series drama by making it particularly clear (to networks and their advertisers, as well as to audiences) that even in an environment of multi-channel 'plenty' in which there is arguably unprecedented 'choice', New Zealanders remain highly receptive to quality, renewable local drama series. As a situation that could not have been achieved without the funding support NZoA provided, this is clearly a case of success breeding further success (Dunleavy, 2012a: $52)$.

Outrageous Fortune exemplified NZoA's central goals and responsibilities, and substantiates the requirement and relevance of having such an organisation in a country such as New Zealand. Because of the high cost of producing a programme like Outrageous Fortune, it was essential that NZoA was positioned to facilitate it by providing the programme with significant public funding. Jane Clifton neatly sums up the significance of Outrageous Fortune as allowing "us to reclaim something simple and fun about the New Zealand character that we've been in danger of losing". She goes on to say that "despite the show's absurdist extremes, we recognised ourselves, good and bad, in this programme" (cited in Dunleavy and Joyce, 2011: 198).

\section{The Platinum Fund}

NZoA's Platinum Fund was created in 2009 with "specific criteria that set it apart from the existing contestable fund" (Norris and Pauling, 2012: 35). Its intentions were for projects to be ambitious, aspirational and innovative in order to inform, educate and entertain a wide cross-section of citizens (Quirk, 2012: 3). The fund also necessitated that projects say something important "about New Zealand or New Zealand's place in the world" (cited in Norris and Pauling, 2012: 35). The Platinum Fund was to be focussed in areas that required high levels of subsidy, suggesting commercial fragility in the sorts of projects it would target. The intention, 
therefore, was that it would help facilitate distinctive programming that currently was not being catered for (Quirk, 2012: 3). Typically, the majority of funding disbursed from the Platinum Fund has been for documentary and drama projects, particularly feature-length one-off dramas, with the most significant successes also occurring in this form.

One-off dramas, of any length, have been a reasonably scarce commodity in local production because of their very high production costs, the lack of an ongoing commercial role that they can play for broadcasters, and because their "reception had been uneven in the 1990s" (Dunleavy and Joyce, 2011: 193). However, this form has some unique dramatic possibilities, with the 'cinematic' qualities that can be achieved combining with sufficient screen duration to allow their narratives to probe deeply into the kinds of complex topics that have been used (Dunleavy, 2012a: 52). A number of drama projects have been supported by the Platinum Fund thus far in the form of one-off tele-features and short-form serials. Popular tele-feature examples include: Billy, Rage, Tangiwai, What Really Happened: The Women's Vote and Siege, while in the serial form there has been Underbelly NZ and Harry. All of the above dramas told unique stories, the majority of these about New Zealand's past, and were highly popular, screening mostly in the TV One Sunday evening primetime slot between 8.30 and $10.30 \mathrm{pm}$ which has a history of being what Dunleavy terms a "prestige drama" timeslot, often reserved for short-form dramas imported from Britain (2012a: 52).

The success of these programmes is no clearer than with Billy which is characteristic of the other examples and garnered enormous acclaim by reaching "record ratings for TV One" of 733, 000 viewers (Quirk, 2012: 8; 12). Based on the life of New Zealand entertainer and comedian, Billy T. James, it was a programme that resonated with New Zealanders. It also achieved many of NZoA's objectives for the Platinum Fund, in that it informed, educated and entertained a diverse range of New Zealanders (Quirk, 2012: 3; 11), as well as examining New Zealand's recent bi-cultural history in an accessible way. As NZoA Chief Executive, Jane Wrightson, 
explains, none of the above projects could have been facilitated "without the resources of the Platinum Fund" (cited in Norris and Pauling, 2012: 35). However, because of NZoA's longstanding tendency to identify local content gaps in schedules and to fill them "by offering contestable funding opportunities" (Dunleavy, 2012a: 52), something new, distinctive, ambitious and of high quality was able to be added to the existing array of local content programming that was available (Norris and Pauling, 2012: $35)$.

\section{Documentary}

Although its effectiveness has been particularly evident in the areas of one-off and short-form drama, the Platinum Fund has also delivered a number of 'high production value' documentary projects to broadcast networks which have, as with drama, fulfilled the broad criteria for which the Platinum Fund exists. These documentaries have varied from one-off documentary projects, to documentary series, and have even included dramatised documentaries (Quirk, 2012: 9). As with their drama counterparts, these documentaries would not have been commissioned in the absence of the Platinum Fund, not least because of their high production costs (ibid.: 11). Unlike the Platinum Fund dramas, which have mostly screened on TV One, a number of the documentary productions have aired on Prime TV. The placement of these documentaries on Prime (which has occurred for a range of reasons) also provides some evidence that the opportunity cost with documentary tends to be considered too high for New Zealand's three leading TV channels, despite the considerable funding that NZoA is willing to provide to meet their costs (Quirk, 2012: 9). Citing comments aired during a 2007 conference for local documentary-makers, Horrocks observed that "there are strong tensions between the culture of documentary making and the culture of broadcasting, particularly in the largest free-to-air channels" (2010: 11). As Horrocks went on to explain, although these same channels "are a major gateway through which new information enters the mainstream", 
the fact is that "sadly that gateway has increasingly narrowed over the years" (ibid.: 11).

NZoA has facilitated a long succession of well-researched, 'high-end' documentary projects over the years (NZoA Documentary Funding Policy Discussion Paper, 2012: 15). However, the current problems for this genre (which the Platinum Fund has attempted to address as far as it can) derive from the significant challenges for broadcasters that increased competition and fragmenting audiences have brought. As a result, broadcasters are considerably less willing than they once were to allocate primetime slots to these programmes. Whilst the network appetite for documentaries has declined, that for light documentaries and 'popular factual' programmes has increased (Quirk, 2012: 9; Horrocks, 2010: 10). This development has led some commentators to speculate that the NZoA model is itself to blame, rather than looking at other possible causes such as the ratings success of 'popular factual' programming and a highly competitive broadcasting environment. The current situation for locallyproduced documentaries, a category that has relatively little in common with 'popular factual' programming, will also be addressed in the third chapter of this thesis.

As Norris and Pauling have put it, "documentary can be seen as crucial to civil society" (2012: 59). In the experience of Horrocks, a scholar of New Zealand documentary since the early 1970s, the in-depth primetime documentary has been "one of the great traditions of New Zealand television" (2010: 10), this assisted by the evident popularity of this form with New Zealand audiences. NZoA has delivered a range of documentary programmes that have been particularly successful. The Work of Art series is described positively by Horrocks as being a "showcase for some of the most innovative documentary-making", screening forty in-depth arts programmes throughout the 1990s (2003: 5). These were indicative of a steady growth in documentary at the time. They also exemplified the kind of in-depth, high production value documentary that is in decline at present and is "starting to look like an 
endangered species" (Horrocks, 2010: 10). Furthermore, there was the popular Inside New Zealand and Documentary New Zealand series which "offered a one-hour, in-depth look at a topic" (ibid.), examples of their subjects including the Wahine and Erebus disasters, and former Prime Minister, Robert Muldoon. Despite these successes, some commentators continue to believe that some vital approaches to documentary are not being addressed.

The two series just mentioned were a form of popular documentary targeted towards a 'mainstream' audience but which still ensured an indepth approach to important topics. While very much in line with NZoA's cultural remit, and important to the television environment and industry for additional reasons, they did not completely placate everyone, particularly those who also want the possibility of something more from their documentaries (Norris and Pauling, 2012: 61-3). Seen as not being funded in the ever increasing commercial environment were "notably documentaries on historical or biographical subjects, those on political or contentious topics or well-researched investigative documentaries" (Norris and Pauling, 2012: 63). Horrocks observed that documentaries of this kind were notably diminishing, particularly in comparison to more popular forms (2010: 10), which is a significant concern to the texture of New Zealand public television.

\section{Children's and Special Interest Programming}

Two other NZoA-supported categories which have some similarities to the position of documentaries are children's and special interest programmes (which include minority programming). These categories are similar to that of documentary because while there have been successes in these areas, there are also significant limitations for them as a result of the commercial and competitive context for which they are commissioned. Although more varied in form, children's programming shares some of the 'public service' purposes and commercial sensitivities of locally-produced 
documentary. To some degree, children's programmes are informed by and produced in the interests of social responsibility, this centring on a shared public concern for children as an audience that is less capable than its 'young adult' or 'adult' counterparts of filtering its own television content (UN's Convention on the Rights of the Child: Section 17). Despite the sense that children's programming is an issue that many New Zealanders feel strongly about (Zanker, 2012a: 68), this is a programme category that frequently flies "under the radar" (ibid.), assisted by its relative invisibility as programming scheduled in morning and midafternoon timeslots.

Due to the lack of a commercial role, and thus the off-peak scheduling of this programming, the position of children's programming is comparable to that of NZoA's special interest category. Mostly screening on Sunday mornings, and late at night, outside of primetime (Norris and Pauling, 2012: 91), special interest programming may find itself in the most commercially logical schedule positions, but that does not mean that these off-peak and marginal timeslots provide the ideal schedule contexts for these programmes to be discovered and watched by viewers.

It is important to underline here that NZoA has no control over the timeslots in which network programmers decide to place NZoA-funded content. Hence NZoA is obliged to simply accept these scheduling decisions. While this is understandable that a stand-alone public agency cannot affect broadcast scheduling, it does still limit the potential 'public value' of these programmes. Because of the off-peak timeslots, in which they are scheduled, inevitably reaching smaller audiences, the reach and impact of special interest programmes is reduced. While 'on-demand' broadcast services, which allow viewers to watch programmes at their own leisure, perhaps mitigate the effects of this by extending viewing opportunities beyond the schedule, such programmes are still less visible as a result of their original scheduling. In both the children's, and special interest categories, NZoA has a responsibility to ensure that a range of programming exists to cater to the diverse interests and needs of the 
different audiences groups that these categories exist to serve (ibid.; Broadcasting Act, 1989: 18). NZoA has made significant contributions to these categories over the years, however, clear limitations exist because of the nature of the commercial environment and the objectives of these programmes.

Within children's programming - which is really a complex 'metagenre' comprising a number of forms and a number of target audiences (Zanker, 2012b: 2-3) - there are a couple of outstanding programme examples funded by NZoA. These can be used to demonstrate the capacity of NZoA to fund relevant and vital children's programming. You and Me, which began airing in 1993 on TV3, was a highly successful studio programme for pre-schoolers and parents alike hosted by the "much loved" Suzy Cato (Zanker, 2012a: 74). It had a very sound production model which "produced a generation of pre-school content that could be repeated every three years for further generations of pre-schoolers" (ibid.). Because of the recyclable nature and universal appeal of the episodes, You and Me was a highly cost-effective children's programme that resonated with its target audiences.

For primary school children, the "heavyweight presence", in terms of local programming, has always been What Now?, which started airing in 1981 and has been funded since the early 1990s by NZoA. It is in magazine format, combining "studio-based personalities" with sketches, phone-ins and competitions in an interactive manner (Zanker, 2012a: 74) and has a considerable fan base (Zanker, 2012b: 3). A more recent example (2009) is The Erin Simpson Show which resonates with both primary and teenage children and is based on a similar model as that of What Now? Both of these programmes continue to be funded by NZoA (Annual Report, 2012: 54 ) and are often a way of blending a sense of local character, which is present in the presenters and competitions, with imported foreign cartoons. Although very different, this blending has some parallels with the way that local dramas have combined a sense of 'localness' with the use of 'universal' conventions in order to facilitate high viewership 
(Dunleavy, 2005: 8). While the production of local content for children, with cartoons being an indicative example, may sometimes be too expensive and carry too much commercial risk for broadcasters, foreign cartoons can be packaged in a way that ensures that local qualities can inflect their packaging and presentation to child audiences.

These particular examples have been highlighted because they are long-running successes in the category of local children's programming. As long-form programmes whose commercial strength owes much to their longevity and sustained exposure, these programmes can be contrasted with short-run forms of NZoA-supported children's programming, of which one sub-category is children's drama, whose "expense and short runs made the genre unpopular with channel programmers" (Zanker, 2012a.: 78). Despite this reaction, John Harris argues the necessity of children's drama (2013: nzherald.co.nz), however he points out that "broadcasters don't actually want children's drama" (ibid.). Although NZoA could make more funding available in this area, it could only be at the expense of other programming categories. Given the limited size of the target audience for local children's drama, there is also the question of how it would be possible to justify the high level of investment in terms of an appropriate timeslot and the potential for audience impact. NZoA is required to consider the audience size to benefit (Broadcasting Act, 1989: 19), and while this is not as relevant in the areas of children's and also special interest programming, children's drama presents a more significant challenge in this regard because of its very high level of production cost. It is easy to see why children's drama can find itself placed in NZoA's 'too hard' basket, particularly when investment in it would also make it more difficult for NZoA to fulfil its objectives across, and within, other programme categories.

Because of its limited funding and the restrictions that the commercial environment creates, NZoA "faces a range of challenges in terms of delivering children's programming" (Zanker, 2012b: 14). Gibson Group chief executive, Victoria Spackman, has noted that, despite a desire 
within the industry to create it, there is a lack of funding as well as a dearth of channels or platforms through which to air children's programming (Hunt, 2013: stuff.co.nz). Lower-budget magazine formats, as acknowledged above, have typically received more NZoA funding because these programmes are relatively low-cost which means that its funding can go further when allocated to them (ibid.).

Special interest programmes have similarly been facilitated by NZoA. A range of communities have been, and continue to be, catered for with highly indicative examples being Tagata Pasifika for Pacific Island peoples being funded since 1990 and Attitude which serves those with disabilities (Norris and Pauling, 2012: 91-2). Of course though, these programmes also perform the function of informing and educating the New Zealand population on these topics.

In creating Attitude, producer Robyn Scott-Vincent addressed criticisms of predecessor Inside Out that it "lacked energy and variety and that the content neither hooked nor held viewers", as well as ensuring that the stories would attract both disabled and general audiences (Norris and Pauling, 2012: 93). In this way, she created an interesting and engaging special interest programme. However problems arose in respect of adequate promotion and recognition from the broadcast network. ScottVincent felt as if "they just have the content because they have to rather than any sense of valuing content that might truly shape the culture of the community" (cited in Norris and Pauling, 2012: 93). In contrast however, Scott-Vincent described the support of NZoA as "fantastic" (ibid.), demonstrating NZoA's capacity to facilitate quality public television through careful and well-informed funding allocations.

The commercial imperatives of broadcasters, however, have meant that there is a significant disjuncture on the one hand, between what they are willing to screen and in what timeslot, and on the other, NZoA's own cultural and social objectives. As Norris and Pauling argue, it is in the category of special interest programming that NZoA "comes closest to fulfilling a public broadcasting remit in the conventional sense" (2012: 
91). These programmes are essentially non-commercial because "the broadcaster can expect little or no advertising revenue from them" (ibid.). It is for this reason that they are less likely to be produced with commercial funding and, when they are produced (most often with a high proportion of NZoA funding support), they are more likely to receive an unfavourable or marginal schedule position (ibid.). Despite NZoA's impressive record of achievement in children's, special interest and documentary programming in the twenty-four years since its inception, the position of these programmes has become more rather than less vulnerable as competition in New Zealand television has intensified.

Public service programmes and local content, while usually meaning different things, are particularly synonymous in regard to NZoA's facilitation of all the programme categories mentioned in this section (Dunleavy, 2008: 799). Because of the inter-related objectives of these categories, the reluctance of broadcasters to invest in them, and because of NZoA's limited funding, there are limitations as to what can be achieved both within these categories and for the audiences of these programmes (Norris and Pauling, 2012: 91). On this basis, there are reasons to argue for the necessity of non-commercial funding and schedule spaces for these types of programmes if they cannot be adequately served by the current model. Although NZoA has helped fund and facilitate programmes in the categories of children's, special interest and documentary programming, more could be achieved if there was a 'mainstream' platform that operated free from the expected constraints of a commercial TV schedule. Considerably more public funding needs to be invested in public television, as well though, if the full range of objectives is to be realised. These issues will be explored in more detail in the next chapter of this thesis. 


\section{Māori Programming}

A further category of public television that NZoA is expected to serve is that of Māori programming, as one which, albeit potentially involving a far larger range of programme forms, shares similar limitations with those that have been described in relation to the above categories. However, in contrast with these other programming categories, Māori programmes are facilitated and supported in two additional ways. One is Māori Television, a non-commercial channel, which is provisioned by public funding so as to ensure a broader and more effective achievement of social objectives when it comes to Māori TV programming, as outlined in its public service remit (Māori Television Service Act, 2003: Section 8). The second is Te Māngai Pāho, a public broadcasting agency (and 'sister' agency to NZoA) "whose role it is to allocate public funding for Māori language and cultural outcomes in broadcast programming" (Dunleavy, 2012b: 1). Meanwhile, in terms of its own contribution to the facilitation of Māori programming, NZoA tends to emphasise programming that is destined for 'mainstream' broadcast channels and timeslots and is designed for a general audience. This is evident in its focus on programmes "of a broad appeal that includes some elements of Māori content, character, or language" (Stephens, 2004: 112). ${ }^{4}$

It is the existence and effective collaboration of all three organisations, NZoA, TMP and Māori Television, that create positive outcomes for Māori programming on New Zealand screens and in turn demonstrates one of the characteristics and strengths of public television in the country. All three of the organisations occupy important positions and fulfil integral roles in the facilitation of Māori programmes. This

\footnotetext{
${ }^{4}$ From the above descriptions, it is obvious that the term 'Māori programme' does not have one single, unified meaning. For each of the organisations, 'Māori programme' has a subtly different meaning and so it must be noted that when this term is used it is referring to the specifications of whichever organisation is being referred to at the time. However this does not mean that these definitions do not overlap in a range of ways. It is important to register that the existence of three publicly-funded providers to maximise the funding and facilitation of Māori TV programming places this category in a unique position as compared to all the others discussed.
} 
means that, even though a full exploration of Māori Television is offered in the following chapter, it is important for the current chapter to consider how the different funders work in relation to one another and what additional potentials this brings to New Zealand's public television.

NZoA's role in the facilitation of Māori television programming can be considered as focussing on "Māori programmes mainly in English, made for the general audience which includes Māori. [They] promote the Māori language by normalising use for audiences not fluent in Te Reo" (nzonair.govt.nz/tv/tvmaoristrategy). From a legislative perspective, this is because of NZoA's imperative to maximise audiences by funding programmes produced for 'mainstream' broadcast outlets. However, there is also value to this approach from a practical perspective. NZoA adds a specific and necessary dimension to the Māori broadcasting ecology by funding programmes that make a "conscious effort to reveal something of the past, present or future Māori world" (ibid.). This tends to mean an emphasis on Māori programmes that are designed for Māori and Pākehā audiences alike, with their presence in schedules allowing for a broad audience exposure to identifiably Māori images and language (Dunleavy and Joyce, 2011: 132). Furthermore, NZoA explains that "Māori broadcasting provides perspectives and stories that help define us as a nation" (NZoA Annual Report, 2010: 16), illustrating the necessity for it if New Zealand broadcasting and cultural representations are going to be accurately reflective of the nation.

Since 2004, and in addition to New Zealand's three commercial TV broadcast networks (TVNZ, Mediaworks, and Prime), Māori Television has provided a dedicated non-commercial and public service outlet for NZoA's Māori programming. However NZoA, since its inception as a proactive, accountable and efficient public funding agency, has made some significant contributions to ensuring that Māori perspectives can be provided on commercial broadcast channels. One such example of NZoA demonstrating its positive input to public television through Māori programming was when, in 2000, amidst public and industry discontent surrounding the lack 
of local content quota regulations for New Zealand TV programming, NZoA took action despite the absence of an evident willingness from the government (Stephens, 2004: 110). The most significant action that NZoA took, as Stephens recalls, "was to ensure that long-running documentary series now included a set number of Māori stories, and furthermore, that the creative teams making these documentaries be [composed of people who are] Māori” (ibid.). This resulted in what Stephens sees as progress, albeit slow, towards developing a "greater sensitivity among funders and broadcasters to ensure that the Māori dimension to national television is catered for and deployed with integrity" (2004: 110).

Despite its helping to maintain the presence of a 'Māori voice' on the main broadcast networks, in lieu of TVNZ's SOE restructuring, NZoA's programming still has limitations because of the commercial nature of New Zealand broadcasters combined with the additional constraints derived from its obligation to maximise audiences. This can be considered as being a result of the ratings pressures that are present within New Zealand's broadcasting context. Although NZoA and commercial broadcasters contribute something meaningful and beneficial to public television in terms of Māori programming, considering the limitations, Māori programmes and perspectives cannot rely on NZoA's provision alone, and nor are they obliged to, since the inception of other institutions that are dedicated to Maori broadcasting outcomes. As NZoA underline "several funding entities are [now] involved" in providing Māori TV programmes (NZoA Annual Report, 2010: 16). Notwithstanding its broader cultural significance, this change acknowledges the limited capacity of NZoA to deliver in this particular area.

The first public institution to be dedicated to Māori broadcasting was Te Māngai Pāho (TMP). Created in 1993, it was initially a part of NZoA, becoming independent in 1995 (Dunleavy, 2005: 220). TMP is charged with the responsibility to "promote Māori language and Māori culture" (tmp.govt.nz/about) by "funding programmes for predominantly Māori and Māori-speaking audiences" (NZoA Annual Report, 2010: 16); this 
creating a distinction between NZoA's and its own policy. TMP's obligations and funding decisions are based on promoting Māori language and Māori culture. This is guided by the notions of: increasing the number and proficiency of people who know the Māori language; growing opportunities and situations in which te reo Māori can be used; and attempting to "foster positive attitudes and accurate beliefs" towards Māori language and bilingualism in New Zealand (tmp.govt.nz/about). In this way, TMP understandably has a much more detailed and focused remit when it comes to Māori programming, along with the objectives of that programming, than NZoA does. TMP has a much more significant obligation to protect Māori language and a more defined cultural role in terms of fostering positive attitudes and accurate beliefs towards the Māori way of life. As a result, TMP focuses on programmes broadcast in te reo Māori whereas NZoA does not. In turn, it aims to facilitate something distinctive within New Zealand public television, for Māori as well as for non-Māori viewers. With Māori Television launching in 2004, TMP has forged a strong relationship with the channel. This is for the reason that the two organisations share very similar objectives (Dunleavy and Joyce, 2011: 177), with Māori Television receiving the majority of TMP funding (Te Māngai Pāho Annual Report, 2010: 43).

All of the organisations that facilitate Māori programming in New Zealand have distinctive roles to play in the environment and as such bring various outcomes to screen. However, it is also through their effective collaboration - which in this context means a sharing of the development and production costs of local TV projects that meet the objectives of the different institutional partners involved - that New Zealand public television has the potential to offer a far wider range of programmes than might otherwise be possible. Although this kind of collaboration has existed since the 1980s when it occurred between public institutions TVNZ and the New Zealand Film Commission (NZFC) (Dunleavy, 2005: 126), it has flourished since 1995, when TMP gained an independent status from NZoA. From this point collaboration between 
NZoA, NZFC and TMP made it possible for some high-end Māori TV programmes to be created, with an indicative example being the anthology drama series Mataku (Dunleavy, 2005: 297). Since the inception of Māori Television in 2004, the potentials for this kind of collaboration between screen funding institutions has further increased, delivering a more diverse range of programmes in categories such as documentary (Parr, 2013).

It is through these organisations working together within the television environment that it is possible for programmes to obtain a degree of institutional support and viability that might not otherwise be possible. The relationship between NZoA, TMP and Māori Television represents an effective model for public television in New Zealand, highlighting the potential and a possible blueprint for any 'mainstream' public service channels that may be created in the future to operate successfully in this environment. Collaboration between these organisations has not only extended the possibilities that NZoA has to fund programmes but has also maximised the diversity of local programmes available to broadcast television audiences in this country as exemplified by Māori Television's Kaitangata Twitch.

\section{Kaitangata Twitch}

Kaitangata Twitch is a Māori Television drama serial that initially aired on the channel in primetime in 2009 and consisted of thirteen episodes. It followed 12 year-old Meredith and her encounters with "mysterious happenings on Kaitangata island" (nzonscreen.com/title/kaitangatatwitch) and is a programme that incorporates Māori language, culture and tradition. It was designed for Māori and general audiences alike, the latter group including export audiences. There are two main ways in which an awareness of this broader audience were incorporated into the resulting programme: first, it adapted a New Zealand novel with a well-established record of popularity with both groups (this authored by leading writer, 
Margaret Mahy); and second, its dialogue, although containing passages spoken in te reo Māori, was predominantly in English.

Furthermore, the popularity of this programme can, in part, be attributed to the fact that it has a strong precedent in New Zealand television history. Following a similar format to the many 'family drama' serials - often addressing bicultural themes - that were commissioned by TVNZ throughout the 1970s and through to the 1990s (Dunleavy, 2005: 77-78), Kaitangata Twitch can be considered as harking back to an earlier period in New Zealand broadcasting before deregulation. Although this would have helped facilitate its success by following a formula that is recognisable to older audiences, it still contained risk as Māori Television's first 'high-end' drama production.

NZoA provided funding of $\$ 3.6$ million for the thirteen episodes (NZoA Annual Report, 2009: 51) and it fulfilled this organisation's objectives in a range of ways. That this programme was a drama and mostly broadcast in English meant that it was accessible and enjoyed by general audiences. It was scheduled in primetime which is important because the larger potential audience allowed the programme to have a wider impact. This timeslot also showed a respect not typically afforded to Māori programmes on commercial broadcast channels (Stephens, 2004: 110). Although the programme was performed mostly in English, it still had significant instances of Māori language and culture. Hence the programme was designed for, and offered within, a context that did not exclude general audiences, making it an ideal outcome in terms of NZoA's Māori programming remit of promoting te reo and presenting stories that reveal aspects of the Māori world.

Kaitangata Twitch is a programme that effectively achieved many of the objectives of TMP and Māori Television as well. Albeit in different ways - TMP as programming funder and Māori Television as the broadcast channel dedicated to Māori programming - both entities are dedicated to the protection, revitalisation and promoting of te reo Māori and the culture of this language (tmp.govt.nz/about; māoritelevision.com/about). 
Additionally, Māori Television details that one of its aims is to build "a connection to Māori culture for all New Zealanders" and to maintain and uphold "core Māori values" (māoritelevision.com/about). At the same time TMP exists partly to facilitate the production of original programmes that reflect "the interests and concerns of the Māori speaking audience" (tmp.govt.nz/about).

Despite the prevalence of English language in Kaitangata Twitch it contained substantial examples of te reo, examples including the Gallagher children learning te reo, as well as te reo being integrated into the script and dialogue. Most significantly, this is through the characters of Mere and Lee Kaa who have the strongest connection to the island and its mythology. Te reo in most cases is subtitled so that non-Māori speakers can understand, but there are also instances when no subtitles are given, offering something tailored specifically to those viewers who are te reo speakers.

The narrative of the programme is driven in two interconnecting ways: first by the housing development project that Sebastian Cardwell plans to build in the area; and second, by the mythology of Kaitangata in which Mere has become involved (Kaitangata Twitch: S1.E1). This second element tells the story of a "girl caught up in a fight over a beautiful wild island, where different values, commercial interests and versions of the past collide" (books.google.com). Both of these narratives pertain to Māori issues surrounding land rights and ownership. These issues are related to a range of debates occurring between the Crown and Māori in New Zealand which are derived from the notion of tino rangatiratanga (the principle of Māori sovereignty) which the Treaty of Waitangi guarantees for Māori over Māori-owned "lands, homes, and all their treasured possessions" (Walker cited in Dahlberg, 1996: 63).

Kaitangata Twitch can be seen to engage with the broader issues underlying this of Māori land ownership, history and mythology. Kaitangata Twitch is important for the provision of a Māori perspective on these significant and closely related issues. By turning to Māori mythology 
to explain the occurrences in Kaitangata, through resistance by the Gallaghers and Kaa to Cardwell's housing development (Kaitangata Twitch: S1.E4), a particular, often under-represented, perspective was able to be offered. The story in many cases is told by Māori, and notions of guardianship over the land are ever present with Lee Kaa being described as the "keeper of the island", along with the idea that perhaps Mere is destined to succeed him (ibid.: S1.E6). To the extent that it includes Māori custom and tradition, Kaitangata Twitch makes available another way of considering contemporary issues that are relevant to Māori.

This programme also progresses Māori Television's own language objectives, specifically the attempt to make te reo Māori more accessible to New Zealand children. The Gallagher family's teaching and learning of te reo in Kaitangata Twitch is an overt example of the programme's effort to promote the teaching and learning of Māori language. In Kaitangata Twitch te reo Māori is integrated into a bilingual context that is relatable for young people, which is similar to how Shortland Street was used by NZoA to reduce instances of 'cultural cringe' for New Zealand youth at hearing their own accent spoken (Dunleavy, 2003: 32; Dunleavy and Joyce, 2011: 132).

Kaitangata Twitch clearly fulfils the social objectives of each of the public organisations that were involved in its creation. However, it is only through the effective collaboration of these three organisations that its production was rendered viable. As Dunleavy explains, the Māori anthology drama series, Mataku, pioneered this collaborative model and forged the path for Māori drama to be funded by means of collaboration (2005: 297). Cooperation between different groups expand their own possibilities and capacity to achieve their respective goals, as well as having demonstrated opportunities to increase the number and range of productions available for Māori programming. Māori Television's noncommercial status and cross-subsidisation of funding for productions are the two main reasons for this. 
As funding agencies, NZoA and TMP can be limited in what they can get to air because they need a broadcaster to agree to air the programmes they decide to fund. Particularly, given the predominance of commercialism in New Zealand's broadcast television, this requirement means that NZoA and TMP can both be constrained in terms of the range of projects to which they can allocate their funding. In such a context, commercial imperatives often constrain or conflict with the social and cultural objectives that these agencies exist to champion. However, with Māori Television operating as a non-commercial public service channel in the New Zealand broadcasting environment (and the only such channel since the demise of TVNZ7), the funding and programme possibilities of NZoA and TMP are greatly increased. Māori Television provides NZoA and TMP with a platform that is unrestricted by commercial limitations, meaning that both agencies can fund programmes with more of a 'public service' orientation than would previously have been possible due to a misalignment of objectives between public funders and commercial networks (Horrocks, 2003: 1). This is demonstrated by Kaitangata Twitch, which, as suggested, has a cultural, social and language focus that would seldom be accepted by a commercial broadcaster in the contemporary environment.

The sharing of TV drama's considerable production costs is a further benefit of collaboration. In this case it made a high production value 'family drama' serial (a genre which has been less evident in New Zealand television since deregulation) viable despite the increased vulnerability of locally-produced 'family drama' in contemporary New Zealand television. This same potential has been realised by a range of high-end local programmes, these including Songs From the Inside, Behind the Brush and the annual coverage of ANZAC Day celebrations (Parr, 2013; NZoA Annual Report, 2011: 50; NZoA Annual Report, 2012: 54; TMP Television Funding Decisions, 2010-11). It has meant that adequate funding is able to be provided to create programmes despite their considered risk. In the case of Kaitangata Twitch, NZoA provided \$3.6 million of funding (NZoA Annual 
Report, 2008: 51), TMP provided $\$ 55,855$ for script development (TMP Funding Decisions, 2007-08), and information on Māori Television's contribution is unavailable because of commercial sensitivity, though it would be reasonable to assume that they would have taken on part of the financial burden. ${ }^{5}$ Drama projects are always risky because of the high costs of producing drama programmes (Barnett, 2011: Forum on the Future of Public Television in New Zealand). However, by obtaining finance from multiple sources, the required funding level is able to be met, while the risk involved for each organisation is reduced due to it being spread across different funding providers.

The success of this collaboration, through the negotiation of public agencies (Dunleavy, 2005: 297) and multiple funding sources, is evidenced in Kaitangata Twitch and the way in which it achieved cultural objectives and a very high production quality. This is demonstrated not only by its domestic success, but also by its garnering of local and international television awards (Dunleavy and Joyce, 2011: 178). It also provided a Māori perspective in television drama, exploring te reo and issues pertaining to Māori; and as Fox explains, telling the "full New Zealand story to an international public" (2002: 268).

In the same way that NZoA, TMP and Māori Television have demonstrated the benefits of collaboration within New Zealand public television, a similar model of cooperation between other public television services could illustrate the viability of a mainstream public service provider in New Zealand. Although by themselves, the impact of such services can be limited due to levels of funding and the like, in conjunction with a range of funding agencies, it would appear that such provision can exist and offer something valuable to the public broadcasting environment. There are clearly lessons to be learned from the partnership that has been formed between NZoA, TMP and Māori Television, lessons

\footnotetext{
${ }^{5}$ In this case, it is not strange that much of the financial burden was carried by NZoA. This is because, of the three organisations, NZoA has the largest budget for the expensive form of drama.
} 
that if explored and expanded could prove fruitful for New Zealand public television.

\section{Conclusion}

The NZoA model and its strategic administration of funding within a complex and fragile environment has meant that NZoA has managed to make a marked contribution to New Zealand public television in spite of a limited funding pool and its corresponding limitations. Because of its clear values, NZoA has ensured that its funding framework has added something distinctive to New Zealand's public television environment in terms of culture and identity.

NZoA has made a particularly significant contribution in the area of local drama, which, although a highly expensive form that is underserved by commercial broadcasters, has demonstrated the capacity to fulfil many of NZoA's cultural and audience objectives through its primetime schedule position and popularity with audiences. Successful examples of NZoA's drama investment have been the primetime soap opera Shortland Street and the hour-long series Outrageous Fortune, both of which revealed the extent to which New Zealanders are willing to watch local drama. NZoA has also made a significant contribution to local drama in the form of oneoff tele-features through its Platinum Fund. Highly susceptible to market failure, these have always been a scarce commodity within local drama overall. However, as a result of the form's unique possibilities, NZoA identified that this could be an effective situation to intervene in the market with a form that could bring distinctive, ambitious New Zealand stories to local television.

The case of drama is indicative of NZoA's successful public television involvement across its programming categories which include documentary and a range of programming for special interest audiences. However, NZoA has also been put under increasing pressure by competition and commercial broadcasters in these areas due to the lack of 
a commercial role that they fulfil. NZoA has done an admirable job in helping deliver quality programmes in the special interest and documentary categories, however, the tensions between the organisation and the commercial limitations of broadcasters have meant that the desired outcomes of these programmes, notably their potential for 'reach' and 'impact', have been greatly diminished.

NZoA however, has not been so limited in the area of Māori television which, despite sharing some similarities with the above generic categories, is uniquely provisioned. This is in the form of TMP and MTS which are two further publicly funded institutions which have specific remits for supporting Māori TV programmes. The positive repercussion of this is their ability to collaborate as a result of their mutual interest and/or responsibilities in the area of Māori programming. Due to the Māori Television channel (which is part of the Māori Television Service), a noncommercial context for Maori programmes to be commissioned for is available. The benefit of this is a space that is free from the stifling conditions of commercialism, and was demonstrated in the successful collaboration that was formed to create Kaitangata Twitch. Providing a distinctive Māori 'voice' and able to deploy te reo Māori in a primetime timeslot, Kaitangata Twitch would not have been a possibility on commercial television in the contemporary environment, thus marking the potential and value of non-commercial channels to public television. 


\section{Chapter Three: New Zealand Public Television - Limitations, Missed Opportunities, and Potentials}

\section{Introduction}

Despite wide-ranging success in the area of public television, there are a number of limitations that NZoA faces which work to limit its pursuit of cultural and social objectives in the local programme categories that it funds. These are most attributable to limited public funding and New Zealand's broadcast television environment, as one that is characterised by a predominance of commercialism and a situation of unregulated competition. Both of these conditions derive from the restructuring of New Zealand's broadcasting system in the years 1988-89, and since these fundamental changes have never been revisited or revoked, they have combined to significantly diminish the resourcing and possibilities for public television.

This chapter will address NZoA's limited public funding in comparison to its extensive remit, the commercial imperatives of New Zealand's leading broadcast TV networks (which air the majority of NZoAsupported programmes), and the lack of a non-commercial broadcast TV channel for 'mainstream' audiences in New Zealand. These are the main features which limit the possibilities of the programmes that NZoA is able to support. These limitations will be demonstrated via an investigation of both the documentary category and of the broader situation for public television programming.

This chapter will examine the case for enhanced provision within New Zealand public television. In particular, the consequences of having no mainstream non-commercial channel will be explored, this situation having been brought to the fore following the failure and subsequent 
removal of the TVNZ Charter along with the decision to cease public funding to TVNZ7, a decision which led directly to the channel's disestablishment. In light of the demise of TVNZ7, the role and potentials of a non-commercial, mainstream-oriented TV channel will be considered. This will be with particular reference to how such an entity could work within New Zealand's existing public television system, and in conjunction with NZoA.

\section{New Zealand on Air Funding}

Dunleavy argues that "[g]iven the broad nature of its remit, the size of NZoA's annual funding purse was geared to be among the most important arbiters of its effectiveness" (2010a: 302). Throughout its history, NZoA's level of funding has often stifled and limited its achievements in terms of public value and public service (ibid.: 302-3). With a total television expenditure of $\$ 86.6$ million in 2012 , for example, NZoA was expected to achieve its large range of outcomes in drama, comedy, children's programming, documentary and special interest programming, as well as to maximise the objectives of the Platinum Fund via its investments in some additional categories (NZoA Annual Report, 2012: 37). While initially intended, and also resourced, to provide "financial support, as opposed to 100 per cent funding" for TV programmes (Dunleavy, 2010a: 303), NZoA, mitigated by the dearth of other investors to share the costs, has acted as the majority funder in most of these same forms. Moreover, in the case of the least commercial of TV forms, NZoA has often needed to contribute almost 100 per cent funding (ibid.: 307).

It is clear, therefore, that the expectations and demands on NZoA's funding are not only wide-ranging but are also significantly underresourced. This problem is underscored by the apparent conflict between the proportion of total funding that NZoA is resourced to provide and the increased dependence of programmes on NZoA funding today as compared with 1989 when this agency began. Although this meant that 
NZoA has strived to make "a little go along way" (Dunleavy, 2010a: 306), it has also meant that significant limits have been placed "on the volume and range" of programming that it can facilitate (ibid.: 299). A particular area of compromise for NZoA has been the statutory requirement to consider "the potential size of the audience to benefit" (Broadcasting Act, 1989: 19). An important consequence is that mainstream, primetime audiences, along with the pursuit of 'value for money', have been at the forefront of programme funding decisions. This is especially true for programme forms that require larger amounts of production funding. While these imperatives are at the centre of public value measures and therefore are important, they can place limitations on NZoA achieving particular programming objectives and approaches.

Furthermore, although it was never a formal requirement, NZoA's interpretation of the need to prioritise programmes "on the likelihood that the proposed programme or content, if produced, would be broadcast" (Broadcasting Act, 1989: 19) has meant that proposals must obtain a broadcaster commitment to air the completed programme before a production project can receive funding. While this requirement has ensured that public funding is spent on programmes that will definitely be aired, it has meant that broadcasters ultimately control what TV programmes are produced with NZoA funding, in the process closing the door to any proposals that broadcasters do not want (Dunleavy, 2010a: 304).

NZoA faces a threat at present, in terms of its funding levels, which can be attributed to the state sector "coming under increasing financial pressure" (NZoA Statement of Intent 2011-14: 7). Over the past few years, there have been slight decreases in television funding from (in millions) NZ\$89.0 (2009), to NZ\$86.0 (2010), and NZ\$82.5 (2011), with a small rise to NZ\$86.6 (2012) (NZoA Annual Report: 2009; 2010; 2011; 2012). This overall reduction between 2009 and 2012 is more substantial when considered in conjunction with inflation which has seen a total percentage increase of 9.2 per cent between the first quarter of 2009 and the first 
quarter of 2013 (rbnz.govt.nz), which creates an alarming pattern of NZoA having to achieve its objectives on a steadily reducing annual allocation of funding. At the very least, it needs to be recognised that in order to maintain the current television hours that NZoA funding supports, the government must provide steady and continued increases to the funding pool, so that the organisation can keep pace with the rising costs of labour and production within the industry. This pattern, though, is one that does not appear likely to change anytime soon. As NZoA itself explains, "additional funding for broadcast content will not be secured for some time", despite the fact that "costs and demands on [their] funding continue to increase" (NZoA Statement of Intent 2011-14: 7).

The risk here is that, despite successive governments supporting it since its inception, NZoA and its level of funding could just be left to denigrate and waste away under inflationary pressure until NZoA can no longer sufficiently fulfil its obligations - due to its even further reduced means - potentially leaving it vulnerable to disestablishment. This is not an extreme conclusion to arrive at considering NZoA's funding position in light of other government policies, which resulted in the abandonment of the Review of Regulation (2006-08), and the 2011-12 closures of TVNZ6 and TVNZ7.

\section{Commercial Pressure for New Zealand on Air}

The commercial pressures and imperatives which NZoA is obliged to work under are often problematic for the organisation. These inevitably become apparent (given a limited funding supply) with NZoA unable to fulfil objectives in some categories of programming. In particular this is in categories that struggle to fit within a commercial schedule, notably children's, special interest and documentary programmes. As suggested, all New Zealand broadcast TV channels (aside from Māori TV) are reliant on commercial revenue earned from the sale of advertising. These also have direct control, by virtue of NZoA's requirement for a broadcaster 
commitment, over what programmes are created with NZoA funding. The one commercial-free exception for these networks is the Sunday morning schedule, as a timezone during which, under the Broadcasting Act (1989), no commercials are permitted to air. Notwithstanding the opportunities offered by this commercial-free window, the broader situation is one characterised by a misalignment between the cultural objectives of NZoA and commercial objectives that are represented by the broadcaster. Horrocks explains it in this way:

As a commercial enterprise the broadcaster has to ask: 'what will make the most money for us?' whereas NZ On Air is required to 'reflect and develop New Zealand culture and identity' (2003: 1).

While these differing objectives can be reconciled to a certain extent in particular programming categories, and achieving this reconciliation has always been a high priority for NZoA, the interests of these organisations are perpetually in conflict. With New Zealand's broadcast TV networks operating purely commercially in an environment of intense competition, and additionally empowered as the effective 'gatekeepers' for new TV productions, it means that certain types of programming are not possible due to their lack of viability for a strictly commercial operation.

It must be noted that while this may seem like a choice for the broadcasters, it is their actual survival which is at stake in view of the significant commercial risks of screening particular local programmes in parts of their schedules. Significantly, the precarious commercial environment that exists for broadcast television providers, due to intense competition and an under-regulated broadcasting environment, perpetuates the potentials for disjuncture between themselves and a public agency like NZoA. In this vein, and with specific reference to the failing of the TVNZ Charter, the then TVNZ CEO Ian Fraser explained that "the texture of our schedule is profoundly incompatible with any recognisable model of public broadcasting" (cited in Dunleavy and Joyce, 2011: 184). Fraser's assertion highlights the difficulties that commercial channels face incorporating programmes that resemble public broadcast. 
As such, it could be considered that it is a lack of a non-commercial channel which further conflates this problem.

There is a seeming imbalance of power between NZoA and programme creators on the one hand, and between NZoA and broadcasters on the other. This is because broadcasters, whose commercial reliance orientates their economic responsibility towards the requirements of their advertisers, ultimately have the final word on what will go to air. If a proposed project is seen as too far outside of what sufficiently fulfils their commercial imperatives, then it will not be afforded a place in a schedule. Accordingly, the programme will not be given NZoA funding and will not enter production.

As Smith (1996: 118) explains in relation to the objectives of commercial broadcasters:

Satisfying the mass sometimes has little to do with what is most relevant, or radical, or challenging, or different. The commercial imperative forces ideas to be skewed towards the bland and inoffensive.

In this way, NZoA's potential to adequately achieve its cultural and social objectives in respect of maximising programme diversity and working to use public funding to counter 'market failure' is greatly undermined due to the limitations of commercial broadcasters. Specifically, this process can limit experimentation and innovation in programme design, as well as reducing the ability of certain programmes to 'push the envelope' in terms of what issues they address and how these are presented. This is because of the necessity for programmes to rate highly for the broadcaster. Whilst this may or may not entail a profit for the broadcaster concerned, the risk of revenue loss is at least minimised (Dunleavy and Joyce, 2011: 121). NZoA can only function as far as the commercial broadcasters will allow it. This is very limiting for certain programme categories, particularly because there is no mainstream non-commercial TV broadcast channel for which NZoA is able to facilitate programming. 
The adverse effects of these competitive and commercial pressures on public television - and specifically on NZoA's position within this sector - become even more apparent when taking a closer look at the category of documentary where the tension between commercial and social objectives is very strongly evident. This tension gains momentum from the traditional relationship between this particular programme form and the values of 'information' and 'education', which have always been important to public service broadcasting. The purpose of satisfying an audience's love or preoccupation for knowledge that documentary often fulfils (Nichols, 1994: 180), means that the form is keyed to achieve its greatest potentials when produced for non-commercial channels rather than commercial ones.

Horrocks underlined the negative repercussions that result from traditional documentary styles being subjected to commercial imperatives, when he asserted that only those with "a single human interest story at the centre" in which "sex and death are the usual topics" (these evoking the viewer's emotional response) are regarded as suitable for primetime (cited in Norris and Pauling, 2012: 62). Horrocks went on to register that to be placed in a primetime slot "every programme must conform to the broadcaster's cautious ideas about what the mass audience wants and how it should be packaged" (ibid.).

This limiting of the opportunities that are extended to documentarymakers, in terms of the approaches they can take and subjects they can handle when producing for a commercial schedule, has adverse repercussions on the delivery of public television. While networks want "fast, colourful storytelling that grabs and holds a sizeable audience in a fiercely competitive environment", some subjects benefit from being "told in a more thoughtful, discursive or analytical way" (NZoA Documentary Funding Policy Discussion Paper, 2012: 2). The latter is becoming increasingly difficult, with one study finding that documentary-makers have noticed "a decline in challenging documentaries" being commissioned for the commercial networks (Geary, 2008: 19). 
These examples illustrate the tension for both public television and NZoA that is created by commercial imperatives. The problem is that this mixed-model approach of trying to get commercial channels to screen programmes that have social objectives and are distinctly in opposition to commercial goals, is almost unprecedented around the world. As Gitlin argues, "safety first is the network rule" (1994: 63) and much of the programming discussed is anything but safe. Therefore, expecting commercial networks to deliver a full range of public programmes is not only unprecedented but understandably difficult as well.

It means that the desired outcomes of public television cannot always be fulfilled, especially in the category of documentary. This is due to it being conceived and produced for commercial networks whose decisions are consistent with their obligations, not only to maximise profits and minimise losses, but also to appease the demands of advertisers. This risk-averse decision-making (ibid.) by TVNZ, TV3 and Prime as commercially-operating networks also comes at the expense of projects with the potential to be creative, innovative, and to deliver social benefits through a diversity of local representations. While NZoA is highly aware of the confinements of the commercial environment and attempts to entice broadcasters into innovation and diversity by offering significant funding so as to get programmes made, there is only so much that NZoA can do to counter the 'opportunity cost' of the types of programmes that it aims to facilitate (Dunleavy and Joyce, 2011: 125).

\section{Fulfilling Cultural Responsibilities: NZoA and the Case of Traditional Documentary}

An important repercussion of the commercial position of leading broadcast channels is that this places some limitations on the ability of NZoA to meet its cultural and social responsibilities. This means that NZoA-funded TV programmes - with the exception of those destined for Sunday morning slots or for Māori TV - are unavoidably shaped by the 
objectives of advertiser-funded TV schedules. These limitations on NZoA's ability to fund a wider range of TV programmes (non-commercial as well as commercial) is clearly demonstrated in the category of documentary where there is a tension between creators and broadcasters as to the reconciliation of cultural and commercial objectives (Horrocks, 2010: 11).

Significantly, NZoA's documentary category is also subject to a loose definition by NZoA, in that it combines examples of 'traditional documentary' with examples of 'popular factual' (including 'reality') programming. The effect of these vastly different factual forms being in the same category as one another is that proposals for information-oriented 'traditional documentaries' are effectively competing for NZoA funding with entertainment-oriented 'reality' programmes. The difficulty for 'traditional documentaries' is that ratings-driven commercial networks are apt to prefer 'reality' proposals instead. By withholding consent to broadcast projects that are regarded as too risky, commercial channels are effectively reducing the number of 'traditional documentaries' to be funded by NZoA which is indicated by their gradual decline in New Zealand's mainstream broadcast TV schedules. As Horrocks explains, 'popular factual' programmes "have now taken over most of the 'documentary' genre, crowding out what one might describe as classic, indepth, one-off examples" (2010: 10). This change has evidently been encouraged by the continued popularity and audience demand for 'popular factual' forms. If NZoA accounts for its decisions without using clear genre definitions it can narrow the range of programmes that are created. Arguably, there is too little specificity in NZoA's official remit as to precisely which categories and sub-categories of programming are eligible for public funding support and to which of these forms and programmes might be considered priorities in public television terms. This is reinforced by the failure of a recent NZoA report to present an unambiguous view of what constitutes a 'television documentary' programme beyond very broad notions of diversity, quality, enjoyment and cultural representation (NZoA Documentary Funding Policy Discussion Paper, 2012: 5-6). 
Utilising populist storytelling modes and subjects, 'popular factual' programming is often created in half-hour series or serial forms (an important contrast with the 'traditional documentary' whose dominant form has been one-off and hour-long) and has "something of a massproduced feel" about it (Horrocks, 2010: 10). Indicative examples include What's Really In Our Food? and Missing Pieces; the former exploring the "real science behind the foods we eat" (tv3.co.nz), while the latter helps to trace long-lost family members. These examples are more accurately labelled 'reality' programmes particularly because their purpose is more overtly to entertain rather than to inform.

As Horrocks observes, looking through "the titles that NZ on Air counts as documentaries leaves no doubt that the character of the genre is not what it used to be" (2010: 10). McCarthy argues that the series mentioned above are not documentaries and therefore should not be funded by NZoA as such. While recognising a place for such series, McCarthy's view is that NZoA's documentary funding should be reserved for documentary programmes that involve "harder subjects needing research and preparation" (cited in Norris and Pauling, 2012: 65). Underlining what has happened to traditional documentary programmes as a result of these problems, Horrocks registers that 'reality' programmes continue to influence the style of documentary, but that "this new genre cannot replace the old" (Horrocks, 2003: 12).

\section{'Reality Docusoap' as Documentary: The Case of The GC}

A recent programme that demonstrates the tensions and problems that arise for NZoA from the commercial environment that shapes NZoAfunded programmes, is the now infamous 'reality' serial, The GC, which screened on TV3 in 2012. As a clear example of 'reality docusoap' (an internationally popular genre as represented by American examples The Hills and Jersey Shore), The GC illustrates particularly clearly the popularising of NZoA's documentary category, and therefore warrants 
careful examination. The capacity of this programme to exemplify the above tensions and problems is underscored by the significant media and public criticism that The GC received and the opposing reactions that it generated with viewers.

The GC demonstrates the problems alluded to above, through its concept design, narrative approaches and content. As Mittell suggests, the "generic boundaries" of television forms are always "permeable, fluid ... and subject to change" (2004: 154). The GC can be firmly located in the category of popular factual television and it closely emulates the rising genre of 'reality docusoap'. Underlining its mixed-genre position, Hill describes the 'docusoap' as “a combination of observational documentary and character-driven drama (2005: 27). However, 'reality docusoap' is a populist genre well-known for the lack of depth of exploration one would attribute to traditional documentary. This is evident in the fact that it is a form defined by its "prioritisation of entertainment over social commentary” (Bruzzi, 2001: 132), "personal, melodramatic stories” (Hill, 2005: 28) and "personal relationships that develop in domestic settings" (Currie, 2010: 26). As Currie observes, this last feature has been strongly influenced by American examples in which the central narrative is removed from the "institutional settings of their British counterparts" (ibid.). Furthermore, this form utilises "fast, colourful storytelling" (NZoA Documentary Funding Policy Discussion Paper, 2012: 2) derived from the "relentless pace" of multiple interwoven storylines (Dovey, 2000: 141). Particularly because these storylines are often fully serialised (as they are in soap opera) networks value reality docusoaps for their similar ability to attract and hold "a sizeable audience" (NZoA Documentary Funding Policy Discussion Paper, 2012: 2).

Accordingly, it is difficult to concur that The GC qualifies as a documentary programme and therein lies the problem with The GC's funding. Instead it could be argued that documentary funding should be earmarked for projects that meet more accepted, traditional definitions of documentary, with a separate category for 'reality' programmes. NZoA 
asserts that a recent focus for it has been the effort to get more documentary into primetime to enhance the accessibility and value for money of documentary and generally to promote this form. But this approach, as NZoA itself explains, "can be controversial if the storytelling style is seen as overly populist" (ibid.: 14). Considering the timing of this NZoA document - which was released in June 2012, the same month that The GC finished its first season - it might even be surmised that this assertion was made in response to the significant backlash and controversy that accompanied The $G C$, which was "centred on [NZoA] contributing $\$ 420,000$ to the show" (Little, 2012: nzherald.co.nz).

It is significant that when first proposed to NZoA, The GC project was described not as the reality docusoap that it evidently became, but more in terms of 'observational documentary'. After a substantial uproar from the public and after a succession of official information requests (Little, 2012: nzherald.co.nz; Keall, 2012: nbr.co.nz), NZoA publicly released the proposal for this series, which was then titled Golden Mozzies. What was described in this proposal was an informative, entertaining and aspirational "observational documentary", whose subject would be the significant proportion of young Māori who are choosing to move and live on Queensland's Gold Coast (Black Inc Media, 2011: 1).

The 'observational documentary' is a form whose distinction from other documentary approaches centres on "the pretence that those portrayed are unaware of the camera's presence", this allowing a programme to become the closest approximation in documentary to "a vicarious experience of the real" (Corner, 2000: 215-16). Accordingly, the form "prefers the crew to be all but invisible", to avoid ever saying "to the people in front of the camera: 'Just do what you usually do'”, in fact, making a point of refusing "to ask them to do anything at all" (Kilborn and Izod, 1997: 67). This dearth of intervention on behalf of the makers has the intention of establishing objectivity in the created text so that the viewer can have a "sense of gaining unmediated access to the world" and can create their own opinions from what has been presented (ibid.). The 
ideological commitment of observational documentary to maximising objectivity (ibid.) exists in clear contrast to the aims of reality docusoap, whose priority is the provision of popular entertainment (Bruzzi, 2001: 132; Hill, 2005: 28). The aesthetic differences, and very different objectives of these two genres, illustrate that NZoA needs more carefully defined and specified categories for TV production, particularly in documentary.

Despite this issue, the blame for the failings of this programme, with public criticism evidently focussing on NZoA's decision to devote any funding to it, was perhaps unfair. This is particularly true in view of the predominantly commercial environment in which both NZoA and the broadcasters operate. NZoA defended its position by underlining that its aim in supporting The $G C$ was to help facilitate representations of "positive, confident Māori in prime time on a commercial channel" (cited in Kirk, 2012: stuff.co.nz). NZoA's reaction perhaps indicates that it was less disappointed in the finished programme than might have been expected considering the initial proposal it was given. However, the clear difference between the observational documentary that was funded and the reality docusoap that was delivered, does highlight the difficulties that arise from NZoA's definition of documentary, which itself is linked to the commercial pressures of New Zealand's broadcast TV system.

The opening sequence of The $G C$ is highly indicative of its dominant theme and cultural messages. The voiceover for this sequence explains that:

Nearly 130,000 Māori now reside in Australia. This show is about a bunch of them living the good life on the Gold Coast. Some live together, some work together. But they're all chasing the dream of...money, sex and fame on the GC (The GC: S1.E1).

It is the idea of "money, sex and fame" that drives the narrative rather than the positive cultural and entrepreneurial representations that NZoA was promised by The GC producers. Although elements of entertainment and 
social lifestyle were not completely excluded from the proposal, the series' focus on these and its corresponding marginalisation of the cultural aspects that had been promised exceeded what could be deemed acceptable by The GC's many critics. Among them was New Zealand TV blogger Chris Philpott who purported that "the show is not a good example of New Zealand culture" (2012: stuff.co.nz) and Paul Little who recognised the "public outrage" about the show which depicted "distorted values and priorities" (2012: nzherald.co.nz). There are many examples of the programme's emphasis on the social, romantic, and glamorous lives of its characters: Tame's house party in episode one; Jessi and Rosie's glamour model shoots; the ongoing relationship melodrama between Tame, Zane, Jade and their female counterparts; along with the consistent depictions of people preparing for their dates in front of the mirror, followed by their night-clubbing and heavy drinking. All of these activities, and the programme's narrative emphasis on them, contributed to the perception that The GC pursued 'entertainment value', which also worked to minimise the possibility for more cultural explorations.

This is not to say that The GC did not function at all in relation to NZoA's cultural remit though. Jade talking about his 'moko' in episode two and DJ Tuini's story-arc of travelling to New Zealand both raise important questions about the programme's promised interest in exploring how these Australian-domiciled young people come to know and pursue what it means to be Māori (particularly in a foreign country), and the understanding of their origins and 'whakapapa' (Black Inc Media, 2011: 1). Similarly Cole's gym venture could be perceived as a positive representation of the "entrepreneurial ambition" and "staunch determination" of young Māori in Australia that was an element of the original proposal (ibid.). There were also touchstones of Māori culture in Cole's 'haka' for his gym (The GC: S1.E8) and Jade Louise's 'hangi' (The GC: S1.E7). Interestingly though, these narratives took a backseat to the relationships, partying and associated melodrama, and were in fact mostly carried by the least central of the characters. As well as this, the cultural 
representations were undermined by their context of an entertainmentoriented populist narrative which celebrated a lifestyle of self-absorbed excess. As with American-produced docusoaps (leading examples of which are The Hills and Jersey Shore), the narrative unfolds in a melodramatic style which works against the 'serious' objectives that underpin the few storylines devoted to the repercussions of being Māori in this particular milieu.

In a number of respects, The GC departs from its original proposal, which suggested a more cultural and socially relevant text (Black Inc Media, 2011: 1). As problems that are overt in documentary because of its traditionally 'serious' aims, the content and form of this programme testify to NZoA being forced toward increasingly populist and sensationalist programme forms because it is what ratings-driven, commercially reliant networks necessitate. As has been suggested, this is occurring at the expense and to the detriment of the cultural goals of NZoA.

\section{The Importance of Non-Commercial Provision in Public Television}

The absolute all-time weakness of NZoA is unless you have some kind of mechanism at the broadcaster end the system just doesn't work. You desperately need a Charter or quotas or a broadcaster that has a genuine public service mandate. Unless you have something at the broadcaster end the funder can have as much money as you like but it won't be able to prevent market failure... That is to say that there are certain kinds of broadcasting outputs that a society needs. A healthy self-respecting, wellfunctioning society needs certain kinds of broadcasting products, and there is market failure.

Horrocks cited in Norris and Pauling, 2012: 148. 
For the reasons addressed in the previous section, it is reasonable to argue that New Zealand requires a non-commercial platform or some sort of regulated provision within its broadcast TV environment if the achievement of a full set of public broadcasting principles and programmes is to occur. In the assertions above, Horrocks succinctly articulates the major limiting factor of NZoA, and in turn, the failure of the government in terms of public television in New Zealand.

While NZoA remains the only source of public television with a remit that addresses all groups in New Zealand society, the objectives of public television will inevitably be compromised by the imperatives and editorial control of the commercially driven broadcasters. Māori Television does exist as a non-commercial broadcast network and has demonstrated success through the range and diversity of programmes that it has brought to air, but its main objective is to preserve and foster te reo Māori (Māori language) which is regarded as the "cornerstone of Māori culture" (māoritelevision.com). It aims to revitalise te reo Māori which is a taonga (treasure), as well as tikanga (Māori culture and custom) which "is the birthright of every Māori and the heritage of every New Zealander" (ibid.). This means that, despite bringing something integral to New Zealand society and culture, Māori Television cannot be expected to deliver the full set of objectives in TV programming that are being alluded to in this thesis. In certain areas, particularly documentary and children's, programming can be more effectively served by a non-commercial channel or provision, of which the TVNZ Charter and channels TVNZ6 and 7 (even if they were successively disestablished) have been the most recent examples. This is because what a non-commercial channel can provide is a context or environment in which public television does not have to contend with the demands and various limiting influences of commercialism. As this chapter has endeavoured to explain, commercialism undermines the pursuit and achievement of public television outcomes in a range of ways.

Given the situation described immediately above, it is important to underline that it is only when a non-commercial broadcast platform exists 
to increase the range of development and commissioning opportunities for $\mathrm{NZoA}$, as well as the fulfilment of further public service objectives, that public television will obtain the capacity to truly flourish. First, a noncommercial channel could provide NZoA with a broadcast platform that is free from commercial limitations, for which to create a range of special interest and commercially sensitive programming. Second, a suitably provisioned non-commercial channel could itself contribute greater diversity in programming by funding programmes that do not fit within NZoA's remit (news bulletins, for example) and which are most efficiently produced on an 'in-house' basis.

It is important to note however, that it is not a matter of replacing NZoA with a non-commercial channel, which in such an exchange would receive NZoA's funding, and to that extent would assume effective control of local content commissioning and production. Improving the existing system through the addition of a non-commercial mainstream channel to the already existing providers, is a method by which the range of programmes on offer to viewers could be extended without the potential risks that would come with disestablishing an organisation such as NZoA, which has demonstrated so much success. In combination, NZoA and the broadcast platform that could be achieved via a new mainstream-oriented non-commercial channel would provide additional, more appropriate opportunities for the creation of public television programmes.

The change that needs to be made in New Zealand public television if it is ever going to fully flourish is therefore less likely to entail adjustments to the NZoA model than it is the creation of a non-commercial channel. If such a change is able to happen (and the pre-requisite for it would be an increased and sustained commitment of public funding, both to NZoA and additionally to the channel itself), public television in New Zealand will finally gain the means to reflect and serve its citizens adequately. 


\section{The TVNZ Charter}

At the end of 1999, a new Labour-led government entered office with the objective of reforming New Zealand broadcasting, with a 'third way' philosophical and policy approach to a sector which was deemed to have inadequately addressed the cultural and democratic functions of broadcasting under a purely commercial system (Thompson, 2004: 61-2). As Thompson explains, "this approach attempts to pursue social democratic policies alongside neoliberal economic policies" (ibid.: 62). In 2003 came the "centrepiece reform" of the period which was the Television New Zealand Act (2003) that "restructured TVNZ as a CrownOwned Company with a public service Charter" (Thompson, 2007: 44). This was implemented in an attempt to return public service objectives to TVNZ, including "addressing the public as citizens, not just consumers" (Thompson, 2006: 61). The Charter was grounded in traditional public service values and it had four main themes, as are outlined by Comrie and Fountaine:

[T] he role of building community and citizenship capacity, the call for quality and integrity, the role of nurturing the creative industries and pushing creative boundaries, and the provision for a wide range of interests with a special emphasis on neglected minority interests (2005: 110).

While TVNZ's new public service responsibilities applied to particular imported programmes as well, Dunleavy notes that it was the Charter's expectations for original local content production that were its most significant and challenging feature (2010b: 3). According to Thompson, the Charter had needed "to ensure the insulation of programming decisions from direct commercial pressure" (2007: 44), and it was on this basis that the government provided direct funding through the Ministry for Culture and Heritage ( $\mathrm{MCH})$ to help achieve the goals of the Charter (ibid.). 
While fuelled by positive intentions to deal with the dearth of public provision in New Zealand broadcasting, the Charter was destined to fail, and did. Firstly, the Charter was "flawed by its very high ambition, yet meagre funding provision" (Dunleavy, 2010b: 4). Despite receiving funding from the government through the MCH, between 2003 and 2006 Thompson calculates that TVNZ received a mere \$64.7 million in funding that was specifically to be used to pay for Charter programming. This represented only five per cent of its income, with the remaining 95 per cent coming from commercial sources (2007: 44). This is low in comparison with broadcasters in other countries; "the ratio for Ireland's RTE which also derives its revenue from combined commercial and public sources is 52\%: 48\% respectively" (ibid.). Thompson and Dunleavy both argue that this level of funding was inadequate in view of the substantial local programming expectations that the Charter brought with it (Thompson, 2007: 44; Dunleavy, 2010b: 5-6). This demonstrates that while the Labour government had the ambition and desire to make a difference to TVNZ's contributions to public television, it had lacked the gumption to adequately equip the Charter initiative with the level of public funding that was required.

Highlighting the key deficiency of the TVNZ Charter, former TVNZ CEO Ian Fraser asserted that it involved "rendering unto God and Caesar at the same time" (cited in Thompson, 2004: 60). In making this comment, Fraser was alluding specifically to the combination of commercial and public service objectives in the Television New Zealand Act which instructed that, “[i]n carrying out its functions, TVNZ's principal objective is to give effect to its Charter ... while maintaining its commercial performance" (2003: 5). TVNZ had been given the dual obligations to maximise cultural and commercial benefits simultaneously. While public service programming and local productions (cross-subsidised by commercial revenue) were integral to the Charter's success and to the "cultural dividend" (Dunleavy, 2010b: 6) expected from them, TVNZ was 
still expected to return a financial dividend to the government. This was an impossible task and as Thompson observes:

In practice, this resulted in the Ministry for Culture and Heritage giving it money with one hand only for the Treasury to take it back with the other. Between 2003 and 2008, TVNZ received \$95 million in Charter funding but returned $\$ 142$ million in dividends (2009: scoop.co.nz).

This left TVNZ in the impossible position of being incapable of fulfilling its dual obligations and, as might have been expected, public service imperatives fell victim to the Charter's conflicting commercial and public objectives (Dunleavy and Joyce, 2011: 180-82).

The commercial pressures ultimately made it impossible for TVNZ's schedule to resemble that of a public service broadcaster's. Referring to the clause about the commercial demands of the Charter, Ian Fraser (TVNZ CEO) in 2005 explained that having to:

'[M]aintain our commercial performance' means that many viewers regard us as being more driven, as a consequence of our dependence on advertising revenue, to sell them things to meet the needs of advertisers rather than to meet their diverse needs as viewers (cited in Thompson, 2007: 45-6).

Local content peaked at 40 per cent under the Charter (Thompson, 2007: 45), far below the 50 per cent mark which had been hoped for (Dunleavy, 2010b: 9). Programmes such as Face to Face and Foreign Correspondent, which were initiatives of the Charter, "were cancelled in the face of increasing commercial pressure" (Thompson, 2007: 45). Eventually, rather than continuing to pursue Charter objectives, TVNZ opted to protect itself from "competitive erosion" (Fraser cited in Dunleavy, 2010b: 10) and either cancelled poorly-rating Charter programmes, or moved them out of commercially-oriented primetime slots (Dunleavy, 2010b: 10).

Accordingly, despite the imposition of the Charter, there was not the dramatic change of TVNZ, and perhaps a shift in the television broadcast landscape more generally, towards a more public-oriented system that 
had been intended. By the end of 2008, with a new National government at the helm, the Charter's demise was imminent when it was stripped of its funding (Dunleavy and Joyce, 2011: 184). In the end, what the Charter's performance and demise demonstrated was a lack of willingness on the behalf of both the Labour and then National governments to properly commit to public service provision by adequately funding and resourcing such a vision.

Contributing to this political failure (which occurred between 2002 and 2012) was the overbearing influence of the neoliberal broadcasting environment (pursued since 1989), into which the Charter was implemented, and which informed its conflicting commercial and public objectives. The seemingly unavoidable expectation from Treasury for a continuing financial dividend from TVNZ was a lingering result of the neoliberal restructuring of New Zealand's public companies, beginning in the late 1980s (Dunleavy and Joyce, 2011: 182; 204). The ongoing requirement this created for TVNZ's dividend to be maximised, meant that giving it a Charter did not insulate programming decisions from commercial pressures (Dunleavy, 2010b: 15). What this reveals is that to be delivered effectively, public television and public service require increased funding than has previously been deemed acceptable, accompanied by a more thorough separation of commercial and noncommercial objectives.

\section{The Rise and Fall of TVNZ6 and TVNZ7}

In direct response to the failing Charter, two non-commercial public service channels were created by TVNZ in an attempt to fulfil some of its obligations, which while not resolving them completely, "their noncommercial schedules did offer a way to reconcile the conflicting imperatives that the Charter imposed on TVNZ's most profitable channels" (Dunleavy, 2010b: 11). These channels were TVNZ6 and TVNZ7 and were 
launched in October 2007 and March 2008, respectively (Dunleavy and Joyce, 2011: 190).

These two channels brought something very distinctive to New Zealand's public television environment because of their non-commercial schedule. Dunleavy and Joyce explain that: "whereas TVNZ6 combined education with entertainment programming, devoting significant parts of its schedule to preschoolers and families, TVNZ7 focussed on the general audience, offering news, factual and arts programming" (ibid.). Important was "their emphasis on New Zealand-produced programmes" (Dunleavy, 2010b: 11). This, combined with their focus on public service forms and content, meant the channels were able to demonstrate that "insulation from the pressure to maximise ratings and revenue facilitates a markedly different schedule from the commercial channels" (Thompson, 2011: 10). The two channels provided a particular diversity of content that the National government wrongly assumed and insisted would still be able to exist if the channels were disestablished. Audiences responded well to this new range of programming, as was illustrated by "rising monthly 'cume' figures and favourable audience appreciation surveys" (Dunleavy and Joyce, 2011: 190). This is consistent with broader evidence that New Zealand audiences enjoy local productions when they are offered, especially when they are anchored by quality standards and diversity which non-commercial, public service providers are well positioned to establish (Thompson, 2011: 10).

However, unsurprisingly, TVNZ6 and 7 were allocated what Dunleavy and Joyce describe as "a relatively lean budget through which to facilitate two non-commercial TV channels" (2011: 190). The government provided funding of $\$ 79$ million for a six-year period (2006-2012), allowing them to operate non-commercially. TVNZ did subsidise the channels though from their commercial revenue over the same period, meaning the two channels had the slender total budget of $\$ 17$ million per year (Dunleavy, 2010b: 12). This small budget, which amounted to not even 25 per cent of NZoA's operating budget, despite its need to fund 
programming for two non-commercial channels, makes the success of the channels that much more impressive. In spite of the severe dearth of funding, Dunleavy observed that TVNZ6 and 7 were "considered to deliver significant public value" (2010b: 12).

The National government, which came into power in 2008 and could have renewed the original funding package for the channels, declined to do so, with the decision being announced in 2011. This forced TVNZ6 to be commercialised and rebranded as ' $\mathrm{U}$ ', a youth channel, with its Kidzone component being moved to a channel behind Sky TV's pay-wall (Thompson, 2011: 7; 13). With the imminent closure of TVNZ7, various models were discussed to maintain the channel. However, Treasury precluded any TVNZ cross-subsidisation, given its insistence on continued dividend expectations, and were firmly opposed to any proposal that included additional public expenditure for TVNZ to keep these channels afloat (ibid.: 7-8). Without a new commitment of public funding, TVNZ7 could no longer function and as a result shut down in June 2012.

The government's unwillingness to help fund and ensure a commitment to TVNZ6 and 7 clearly demonstrates its market-led approach to public television in New Zealand, and the fault of neoliberal politics in creating the difficult position that exists for New Zealand public service television. While, as Thompson suggests, "some cabinet members recognised the public value of TVNZ7, there was no available channel in cabinet for circumventing the macroeconomic commitment to fiscal neutrality" (2011: 8). This, as Brown suggests, is because the government perceives its legitimacy on the basis of ensuring "the health and growth of the economy" (cited in ibid.). Even though public service television such as TVNZ7 is "nice to have" (Minister of Broadcasting cited in ibid.), there was "no discretionary budget" for this in the broadcasting portfolio (Thompson, 2011: 9). It could not be justified under the auspices of health and growth of the economy, which is of the highest importance, so therefore did not fit adequately with the neoliberal broadcasting 
environment and policy stance of the government, and to that extent, would not be facilitated.

Furthermore, Thompson, along with Dunleavy and Joyce, all identify the government's reluctance to reregulate the broadcasting environment in ways that would make such channels and provision more viable (Thompson, 2011: 9; Dunleavy and Joyce, 2011: 204). The deregulated environment in which first the Charter and then TVNZ6 and 7 were introduced, played just as significant of a role in their eventual downfall as the provision and often conflicting obligations that were placed on them (Dunleavy and Joyce, 2011: 204). The Review of Regulation that could have suggested the necessary changes to the broadcasting environment, that would allow public television to enhance its potential, was cancelled by the National government in 2009 (Dunleavy and Joyce, 2011: 185). The arrival of this government in late 2008 brought a reinvigoration of neoliberal politics (Thompson, 2011: 10), which at least the Labour government that created the Charter was making an attempted shift away from.

Alarming for the future of New Zealand public television and public service objectives is that TVNZ7 was perhaps the country's best chance of having and maintaining a successful non-commercial channel that could add something to the broadcasting environment by working in combination with NZoA to provide a more acceptable range and quantity of local programming (Dunleavy, 2010b: 11; Dunleavy and Joyce, 2011: 190-91). The reason for this is that it was beneficial for a non-commercial channel that had limited funding to be connected to TVNZ because of TVNZ's capacity to subsidise such a channel's operating revenue through its commercial revenue (in spite of the Treasury's vehement opposition to this). However, more significantly, this relationship meant that the channel could utilise TVNZ's facilities (Wilson, 2012: scoop.co.nz), particularly its news sector without significant costs to either TVNZ7 itself, or TVNZ (Dunleavy and Joyce, 2011: 190). The news sector of TV One was an enormous resource from which TVNZ7 could create its own news and 
current affairs programmes which are so important to traditional public service objectives. A new public service channel, separate of TVNZ, in contrast, would entail enormous costs in setting up and maintaining a news division and would prove a considerable barrier to its establishment and maintenance. These were resources that TVNZ7, through its parent network TVNZ, already had at its disposal. What this suggests is that it would be difficult for a non-commercial, public channel to ever be established in the future without a very significant financial investment.

An 'open letter' from New Zealand media academics that was sent to the government in April 2011, highlighted the importance of TVNZ7 and public service/or non-commercial channels to New Zealand as well as their concern for the broadcasting environment if TVNZ7 were to be allowed to close. The letter identified a non-commercial public service channel as being an "essential ingredient" to a healthy media environment, because it can provide a range of programming that is "not covered by the commercial sector" (2011: 1). The letter emphasised that commercial channels cannot provide the adequate range of programming that is a necessity to "the interests of democracy" and the fostering of "cultural identity" (ibid.). Although NZoA does exist, and plays an integral role in providing local programming that promotes and advances cultural identity, "it cannot provide a complete answer" (ibid.). This, however, is through no fault of its own, but due to the limitations placed on it by a preponderance of commercial broadcast channels and the absence of any non-commercial channel for 'mainstream' audiences. As the open letter purports, "above all, we are deeply worried about the ways in which the

potential of public television has been undermined in our country and this issue has now reached crisis stage" (2011: 3).

\section{Māori Television}

Māori Television (the flagship channel of the Māori Television Service) has demonstrated the programme possibilities that a non-commercial channel 
can offer in primetime with its approach to te reo Māori and tikanga Māori, as well as the valuable contribution of a channel with a public service remit to the wider public television environment. As discussed in the previous chapter, Māori Television has also illustrated an effective model of collaboration between public agencies that can provide a model that could possibly be followed by a future 'mainstream' public service channel.

Māori Television is a non-commercial channel which despite carrying some advertising - making up a very small six per cent of its total funding (Annual Report, 2012: 20) - can be called a non-commercial provider because it does not have the same commercial imperatives as the other New Zealand broadcasters. It does not function to return profits or dividends to shareholders and instead is responsible to its public service remit which is outlined in legislation under the Māori Television Service Act (2003). It exists to promote Māori language and culture, to perform and achieve public and cultural requirements, and is reliant on public funding.

It is under the Treaty of Waitangi that this provision is necessitated as Māori language is a taonga that must be protected in part by having a suitable presence in broadcasting (Fox, 2002: 260; 266). More specifically, the Act ensures the channel broadcasts "mainly in te reo Māori" during primetime, and a "substantial proportion" at all other times (Māori Television Service Act, 2003: 2). Although the main imperative of the service is this responsibility to te reo Māori, and accordingly to Māori speakers as well as to those wanting to learn and have exposure to the language, there is also a more general public service remit present. While related to the dissemination of Māori subject-matter, the public service remit also necessitates that the programming be of a particular ilk (that being educational, informative and entertaining) and that it add something to New Zealand society or culture as a whole through this process (ibid.: $1)$. 
The position of Māori Television as a non-commercial channel is important in this current broadcasting context which has seen the full impact of competition and commercialism come to fruition. It allows a wider range of programmes to be created and gives the channel the capacity to screen content that would not be as plentiful in the commercial broadcasting environment, or if it was, would most likely be marginalised by its place in the schedule. Writing in the early 2000s, and therefore reflecting on the late 1990s when the effects of competition were being fully realised within New Zealand broadcasting, Stephens remarks, "the usual reasons given by broadcasters for their lack of support for Māori television programmes is that they are not commercially viable" and that the "relegation to Sunday morning transmission" for a number of the Māori programmes that are made for broadcast "is viewed by many as an insult" (2004: 110). Although Stephens recognises the production of Māori programmes for primetime throughout New Zealand's broadcasting history (ibid.: 109-12), since the deregulation of New Zealand broadcasting, Māori content has necessitated increased protection and provision. This is due to the failing to make any formal obligation or allocation in TVNZ's legislation “through which Māori language and cultural needs could continue to be met" (Dunleavy and Joyce, 2011: 177).

In turn, to ensure the maintenance of te reo Māori and in order for Māori to reflect themselves with a distinctly Māori voice, the sort of provision that Stephens describes (as one to which Māori TV programming was limited between 1990 and 2003) was simply not acceptable or adequate. The non-commercial environment however, in which Māori Television operates, means that the objectives of Māori Television's programming can be actively pursued outside of significant pressures from advertisers and producing a financial dividend.

What Māori Television has offered to the public television environment in one instance is a contrast to the ingrained norms of broadcast television genres. This is noticed in Māori Television's 'reality makeover' programme Marae DIY, which illustrates a different approach 
to programme content and encompasses a more Māori-oriented worldview or perspective. The series "unfolds according to the rhythms of a communal life style where links between people expand beyond that of the nuclear family" which is different to a typical makeover programme where the nuclear family and entertainment is usually central to the narrative (Smith, 2006: 32). Reflecting the context within which the programme is made, it is imbued with Māori values and "disrupts the more naturalised relations to homes, commodities and families that mainstream DIY shows promote" (ibid.). Fox raises the idea that "there are significantly different perspectives on what the two peoples [Māori and Pākehā] see as important" (2002: 263), which is reflected in Marae DIY. Within the context of Māori Television, it is more likely that an authentic Māori perspective, in regard to broadcasting, can be raised because there are not the same systematic limitations due to commercialism and personnel as there is within the commercial sector.

Although the basis of Māori Television is preserving te reo Māori, which means broadcasting mostly in the language, the channel has also proved to be a valuable asset for New Zealand public television more generally as a public service network. Smith argues that "Māori Television has undoubtedly made a significant impact upon New Zealand society", which is illustrated by its schedule comprising "at least $80 \%$ locally-made programming" and that it "attracts a monthly audience of around 695,000" (2011: 721). Furthermore, Māori Television CEO Jim Mather explains that more than two thirds of Māori TV's audience is non-Māori "who are looking for local programming" (cited in ibid.). This suggests that "Māori Television has proven that there is an eager market for public service television" and that it has a "pivotal function to play" for both Māori and the "nation as a whole" (Smith and Abel, 2008: 4).

A noteworthy instance in which this is demonstrated has been Māori Television's approach and coverage of Waitangi Day and ANZAC Day commemorations, which has seen significant funding from TMP, and surely Māori Television itself, for "special broadcast" on those days (TMP 
Funding Decisions 2008-09; 2009-10). Committing its entire schedule to Waitangi and ANZAC Day related programmes, the channel garnered significant popularity with audiences due to its dedication to these important annual events. It even influenced the commercial networks as they "generated new approaches to their coverage" because of this success (Dunleavy and Joyce, 2011: 178). In this way, Māori Television shows the importance and the capabilities of a non-commercial channel in the broadcasting environment as a counter-voice to the dominant discourse. Not only can they offer programming that does not fit within a commercial schedule yet has social benefits, they can affect change to the approaches of commercial channels to programming, in a direction that advantages the public.

Due to Māori Television's success, the channel is a vital feature of New Zealand's public television environment for Māori and general audiences alike because of the range of roles that it fulfils. It allows Māori language to be heard on primetime broadcast television and to approach programming from a Māori perspective, as it has proven its ability "to set an agenda and disseminate viewpoints that promote indigenous knowledges" (Smith, 2011: 722). Its provision has also provided New Zealand with its only non-commercial, public service channel which has achieved significant reach and impact across all audiences.

Important to this chapter as well though, is how Māori Television's potential is maximised by its relationship with public programming funders NZoA and TMP, as argued in the previous chapter. These public agencies contribute funding to a number of programmes that air on Māori Television, while at the same time Māori Television allows increased opportunities for these organisations to fund particular programmes due to its non-commercial schedule. The collaboration between Māori TV, NZoA and TMP is an example of the potential success that a mainstream public television channel could have if it followed a similar mode of cooperation. By themselves, the capacity of public television agencies in New Zealand can be limited, however, their impact can be maximised 
when working in cooperation. TVNZ7, though, was not allowed NZoA funding, which was a way that this channel could have been enhanced as well as providing a better working funding model for the channel into the future.

It must be remembered that while having multiple funding agencies has been advantageous to the facilitation of quality Māori and public service programmes, Māori Television has been adequately funded in its own right and given every chance to succeed relative to other public service ventures in New Zealand's broadcast history. With an "appropriate level of funding (some NZ\$176 million over four years)" and "almost two years to establish its operations and build a stockpile of programmes", Māori Television was equipped to succeed in the broadcasting environment (Dunleavy, 2005: 281). It could be argued that, first and foremost, adequate funding is the most important factor in facilitating successful and effective public television services which is evident through the plight of the TVNZ Charter and TVNZ6 and 7, neither of which were provided with sufficient financial provision or protection from commercial objectives. So while suggesting that the relationship between NZoA, TMP and Māori Television offers a suitable solution for the existence of a mainstream public broadcaster, it is only with sufficient funding that such a channel could exist.

\section{Conclusion}

New Zealand public television faces significant challenges and limitations in achieving its cultural and social objectives. The environment and conditions for which NZoA was created in 1989 are drastically different than the environment within which it now functions; yet broadcasting regulation has remained largely untouched in the last twenty years. This has produced significant limitations for NZoA in fulfilling all of its public television objectives. NZoA was always intended to support, rather than completely fund, public TV programmes and was funded accordingly. 
However, due to the aggressive and under-regulated competition that has come to characterise New Zealand television, and the subsequent necessity for NZoA to provide a higher proportion of the total cost of public TV programmes, NZoA has found itself inadequately provisioned to completely fulfil its original objectives. Furthermore, this competitive environment has resulted in precarious financial situations for New Zealand's leading free-to-air broadcasters, reducing their own potentials to take scheduling and commissioning risks. Public television, in turn, has been propelled towards populist and risk-averse programming forms and commissioning decisions; a development that has undermined the achievement of a full range of public television objectives.

Perhaps most notably the effects of these limitations have been realised in NZoA's documentary category. Under increasing pressure from the requirements of advertiser-funded broadcasters, this programme form has been subject to a significant shift away from more traditional forms and values, as represented by the in-depth hour-long documentary, towards more popular factual forms, which focus mostly on entertainment. While there is a place for, and value to, these popular factual programmes - which gain significant audience reach, and therefore are attractive to broadcasters and NZoA alike - the increased prevalence of these programmes in NZoA's funding allocations has occurred at the cost of traditional documentary programmes. Subsequently this has been to the detriment of some of the cultural objectives of public television.

This shift highlights a further dilemma with New Zealand's broadcast TV environment, which is the absence of any mainstream-audience noncommercial channel, or other provision, which could help to counteract this problem. While there have been attempts in the recent past to alleviate this problem, beginning with the TVNZ Charter and followed by the TVNZ6 and 7 channels, these examples (all of which were short-lived) represent missed opportunities for public television.

Māori Television, as the only non-commercial channel in New Zealand, clearly demonstrates the advantages of having a non-commercial 
broadcast platform for New Zealand's public television. Not only has it provided programming approaches and perspectives that are not found elsewhere on broadcast television, but it has also helped to influence commercial networks by providing effective examples of the unfulfilled potentials of public television. Furthermore, its ongoing relationship with public funders TMP and NZoA has been a particular strength of this channel, this enhancing the possibilities for all three organisations. However, these interests tend to intersect in the area of programming that is considered to reflect or develop te reo and/or tikanga Māori. Hence, on their own, such collaborations cannot deliver a full range of programming which addresses the larger potentials of public television. By ignoring the necessity for an additional non-commercial channel that is devoted to mainstream audiences, the government is allowing neoliberal ideology to effectively dismantle, piece by piece, what is left of the public television environment in New Zealand. 


\section{Conclusion}

When the current market reforms were first floated in New Zealand they were hailed as a 'revolution'. The time has come for a counter-revolution that would address the market imbalance between private and public interests that these initiatives have created.

Graham Murdock, 1997: 23.

Graham Murdock did not draw a positive image of New Zealand public television when he described it as a "forlorn" and "dishevelled" figure as a result of the deregulation and restructuring of New Zealand's broadcast environment in the late 1980s (1997: 9). As part of a much larger neoliberal shift in politics and public policy, the significant changes made in New Zealand television meant that it became the most deregulated system of its kind in the world having gone the "furthest in restructuring the entire broadcasting system" (Spicer et al, 1996: 81). As a result, it has been characterised by intense and unbridled competition. This dramatic change has led New Zealand public television to be placed under increasing pressures and limitations over the years. The effect of this has been the ongoing struggle of New Zealand's public broadcasting institutions, the oldest of which, TVNZ, has held neither a direct public income nor any public service objectives for most of the past three decades. In view of TVNZ's position, the focus here has justifiably been on public broadcast funding agency NZoA. Since its 1989 creation, NZoA has struggled to deliver fully on its very large public television remit due to a limited total budget, which is demonstrably insufficient to meet all of the programme outcomes for which it is responsible. This situation has been exacerbated by successive governments which have failed not only to adequately fund public television objectives and initiatives but also to 
adjust or reregulate the broadcasting environment in ways that might assist it.

It is vital for New Zealand's television broadcasting to reflect and represent the country's unique culture and identities through a range of programme forms. As this thesis has shown, it is this work that has been central to the efforts of New Zealand's public television institutions. It is these representations that allow people to understand, comprehend, and recognise themselves (Murdock, 1997: 12-13). Furthermore, it provides a "necessary cultural counterweight to the commercial priorities of networks" (Dunleavy and Joyce, 2011: 194), and the mostly imported programmes that screen on their channels. Significantly though, public television programmes go under-supplied or not supplied at all by the commercial environment, without public funding and intervention. This is market failure, and is important to the rationalisation and legitimisation of public television in New Zealand, while also characterising the country's historic experience of public television.

As a consequence of New Zealand broadcasting's restructuring, which saw TVNZ become an SOE that was to function as a commercial business, NZoA was established in order to intervene in broadcasting. It was created to fulfil a public television remit with an acute focus on funding programmes that would help to develop New Zealand culture and identity. Testifying to the conditions under which it was created, NZoA has followed, since inception, a funding model that reflects neoliberal principles and therefore has required an appropriate justification for "every dollar of public funding" being invested in it (Dunleavy and Joyce, 2011: 114). Although the environment for which NZoA was created has changed greatly since 1989, much of NZoA's success can be attributed to its unique funding approach. As a result of this, it has played an integral role in supporting and facilitating public television in New Zealand. Most significant to the contribution of NZoA has been its ability to consistently fund programmes that represent and foster New Zealand culture and identity. Even though NZoA has no formal obligations to New Zealand's 
television industry, the emphasis on independent production within its model, has nonetheless allowed an independent TV production industry to develop as well (Dunleavy and Joyce, 2011: 123). NZoA has funded programmes across a wide range of generic categories that otherwise are prone to market failure. This has been in order to help create diversity in local content, in fulfilment of NZoA's responsibilities to specified 'at-risk' TV categories and audiences.

NZoA has had particular success in the area of drama, the organisation's significant investment in the category testament to "its potential to reinforce a sense of 'cultural identity"' as well as its "vulnerability in New Zealand" television (Dunleavy, 2005: 1). The most successful drama programme examples, facilitated by NZoA funding, included the daily soap opera Shortland Street and hour-long drama series Outrageous Fortune which are the most significant achievements in a long line of examples over NZoA's twenty-four year history. What these programmes demonstrated and helped underline was that New Zealand TV audiences have an "appetite for domestic drama" (Dunleavy, 2003: 32) and remain very interested in local drama productions (Dunleavy, 2012a: 52). Furthermore, their quality and popularity helped reduce instances of cultural cringe for audiences who were once susceptible to a perceived inferiority towards local accents and representations (Dunleavy, 2003: 32; Dunleavy 2005: 5). Finally, these programmes' popularity, primetime placement, and longevity, meant that they have made unique cultural representations prominent both on New Zealand television screens as well as in the consciousnesses of local viewers. As a result, they made noteworthy contributions to NZoA's cultural remit and the objectives of public television more generally.

Moreover, since 2009 when NZoA's Platinum Fund was established, the agency has delivered a number of high-cost, one-off, local tele-feature dramas. Having always been a scarce commodity in New Zealand television, these dramas illustrate NZoA's pro-active approach to television funding (Dunleavy, 2012a: 56). Having identified a gap in the 
market, NZoA facilitated something distinctive, ambitious, and typically underserved on New Zealand screens (ibid). The particular narrative possibilities of this form allowed important New Zealand stories, often of an historical nature, to be told.

NZoA has also made impacts across TV categories such as documentary, special interest, Māori and children's programming. This has helped to produce cultural representations that are identifiably part of a shared New Zealand culture and identity as well as making available a diverse range of local programmes for all New Zealanders. In these cases, NZoA is particularly aligned with notions of public service television, its funding allocations having facilitated the production of non-commercial programmes across New Zealand's commercial broadcast networks as well as to the non-commercial public service channel Māori Television since 2004 .

However, in spite of its meaningful contributions across a range of TV categories and to public television, NZoA has found itself increasingly limited in its public television endeavours as a result of two overriding factors - both of which are beyond its own control. The first of these is inadequate funding in comparison to the wide remit that it is expected to perform, and the second is the under-regulated, competitive, commercial environment in which it functions. Although these factors reduce the potential diversity of TV drama, they impinge even more strongly on the categories of documentary, special interest, and children's programming, due to their lack of commercial attraction and/or their smaller audiences as compared with popular forms of drama. Alarmingly, the negative situation described, is one that is getting even worse with every year that it remains unresolved. Particularly in regard to what would typically be non-commercial television categories, NZoA has been stifled by the understandable resistance of commercial broadcasters to screen these programmes. Commercial broadcasters have a considerable amount of influence in the NZoA model because of their required consent to screen NZoA-funded content, a position which gives them effective 'gate-keeper' 
control over what kinds of programmes NZoA funding is able to produce. Even when funded in their entirety by NZoA, these non-commercial programmes are often placed in off-peak timeslots or are forced to fit a more 'popular' style so to earn their place in a commercial schedule.

The pressure on some NZoA-funded programmes to embrace more 'popular' programme styles and forms is epitomised in the category of documentary. Traditional documentary forms are being avoided in favour of 'popular factual' ones that are more attractive to ratings-driven, commercially operating broadcasters. This was most notably manifested in a 2012 series, The $G C$, which although being posited as an observational documentary, was in fact an entertainment driven 'reality docusoap'. While programmes such as these are not excluded from NZoA's remit, the fact that they are appearing at the expense of traditional documentary programmes, as a direct result of the commercial objectives of broadcasters, is troubling. This occurs to the detriment of the cultural and social objectives which are so integral to these programmes, and in turn, to the ability of NZoA to unequivocally fulfil its public television objectives.

Compounding, or perhaps even the catalyst for this problem, is that there is no mainstream non-commercial channel in New Zealand which could provide NZoA with a suitable platform for the range of noncommercial programmes included in its remit. While these programmes are marginalised by commercial networks, they have a vital social, cultural and democratic role to play in public television. Therefore they would benefit from a non-commercial broadcast platform for which they could be produced. Such a context would also enhance the opportunity for such programmes to play in primetime slots, rather than the off-peak timeslots into which commercially reliant broadcasters are apt to place them, this reducing their potentials for greater audience reach and impact.

Even though it was not a central aim of the so-called 'broadcasting reforms', the changes in broadcasting that resulted in the implementation of the Broadcasting Act (1989) and the establishment of NZoA, have worked to encourage a useful degree of collaboration between public 
television institutions. Originally, and informed by the Stevenson Report (1988), this was built on the notion that NZoA (as the public funder) would support the production of programmes in conjunction not only with the commercial TV networks but also with additional private commercial investors. The objective then, was that after start-up funding had been provided by NZoA in the first year or so of a new programme, the organisation could end its support as the programme would have proven whether or not it was commercially viable (Dunleavy, 2010a: 306-7). While this approach was effectively employed in the creation of Shortland Street in 1992 (Dunleavy, 2005: 244), it seems to have been based on assumptions rather than any demonstrated experience. In reality, this idealised situation has not been realised since then, due to a lack of available investment not only from the networks (as a result of an ultracompetitive television environment) but also of private investors. Despite the obvious consequences for NZoA, and public television more generally, as a result of this unrealised collaboration, it has never been revisited or redressed in the last twenty-four years. However in spite of this, NZoA has managed to maintain significant contributions to public television since its creation, which testifies to the resilience and effectiveness of the agency in the face of significant and intensifying pressures on its budgets.

As the full effects of competition in New Zealand broadcasting came to fruition through the 1990s and the 2000s (making the financial positions of networks more precarious), and with a dearth of private funding, NZoA found itself funding greater proportions of programmes than had originally been intended for it. This has reduced its possible impact within the broadcasting environment due to funding not being able to be spread as widely as had been imagined when the agency was first conceived and created. This situation, which has gone unaddressed regardless of the necessity for change, has undermined the potential effectiveness of NZoA's contributions to public television by placing significant and ongoing restrictions on the volume and range of programmes that is possible for it to fund each year. 
Three things are needed in order to counteract the ever worsening situation of public television in New Zealand. First and foremost, there needs to be a reprioritising of objectives in regard to New Zealand public television in the form of recognising the importance of it. Second, the level of funding necessary to appropriately support public television must be recognised. Third, collaboration between public institutions must be further pursued in order to realise the potentials of New Zealand public television.

Non-commercial outcomes in television programming simply cannot be provided by a mainly commercial broadcasting sector. However, a range of appropriate outcomes can be delivered when sufficient public funding is made available to adequately support their production, coupled with the provision of a non-commercial schedule on which these programmes can air in primetime timeslots. This has been demonstrated by the achievements of Māori Television, New Zealand's first noncommercial channel. What Māori Television has demonstrated, as a noncommercial public service provider, is the capacity for such a channel to dramatically impact a public broadcasting environment when implemented effectively and supplied with sufficient and sustained public funding.

As a non-commercial channel, Māori Television has provided a context for NZoA to achieve a small range of programming objectives that are becoming impossible to meet via the commercial channels operated by TVNZ and Mediaworks. Again the area of traditional documentary offers a very clear example. The approaches and handling of this form on Māori Television forms a stark contrast to the plight of this category on the commercially reliant TV One, TV2, and TV3. Whereas on these same channels there has been a distinct shift away from traditional documentary towards more popular forms of factual programming, as epitomised by The GC, Māori Television has provided a suitable platform for successive NZoA-funded factual productions such as Songs from the Inside, Behind the Brush and annual coverage of ANZAC Day celebrations 
(Parr, 2013). Being produced for a non-commercial channel has allowed these productions to address their cultural subjects in a much more serious and in-depth manner than would ever have been possible if they had been produced for a commercial channel. In documentary and in many other forms too, Māori Television has provided a non-commercial contrast to the narrower range of programming possibilities that exist for broadcast channels whose schedules are funded by advertisers.

In this way, Māori Television has shown the importance and possibilities of non-commercial channels to improving the outcomes for New Zealand's public television, and the potential for a mainstream audience equivalent to succeed if it were adequately provisioned. While there have been attempts to provide non-commercial programmes for mainstream audiences in the form of the TVNZ Charter and later, TVNZ6 and 7 , both endeavours represent significant missed opportunities not only to equip New Zealand public television with the necessary funding but also to sustain this funding commitment over time, so as to fulfil a larger range of public service objectives. The TVNZ Charter was flawed by an inadequate funding supply and the impossibility of conflicting responsibilities for TVNZ to simultaneously maximise commercial and public service objectives (Dunleavy and Joyce, 2011: 180-84). Similarly, the creation of the non-commercial channels, TVNZ6 and 7 was flawed by too little public funding. The channels did not fail, but rather they were obliged to shut down, following decisions by the current government not to renew their funding (Dunleavy and Joyce, 2011: 190 and 261).

The case for the creation of a new mainstream non-commercial channel (to replace the lost TVNZ6 and 7) is based on the limitations that are inevitably placed on NZoA and New Zealand public television in the context of an entirely commercial, under-regulated, ultra-competitive mainstream broadcast television system. This environment has limited the cultural pursuits of public television in a range of ways that have been discussed in this thesis. However the creation and adequate provisioning of a mainstream non-commercial channel would be a significant step 
forward in ensuring that a fuller range of public television objectives can be achieved. Such a channel would provide NZoA with a further and essential outlet for which to fund a range of non-commercial programmes. In turn, as evidenced by Māori Television, this could have wider repercussions across the New Zealand broadcast television environment. For example, it may stimulate shifts in commercial approaches to programming if the popularity and value of some local programme forms could be given the necessary opportunity that this channel could provide. Additionally, a mainstream non-commercial channel would make supplementary contributions to those categories and genres that are not part of NZoA's remit, again as a distinction from the imperatives and approaches of the commercial networks. There are strong examples in the areas of news and current affairs. Here the experience and interventions of TVNZ7 are highly indicative. Despite its relatively short life, TVNZ7 was able not only to supply news and current affairs programmes created outside of a commercial context but also to successfully demonstrate an audience appreciation and demand for them.

It seems clear that a collaborative relationship between different public institutions - as evidenced in this thesis by the Māori Television example of innovative family drama serial, Kaitangata Twitch - can result in distinctive and important public programmes. Therefore, it seems logical that such institutional collaboration could help to ensure the success of a mainstream public service channel. When multiple agencies are involved in the funding and facilitation of public television programming, the potential investment risk of programmes is reduced with the financial burden on a single organisation also being minimised. The effective negotiation of cultural and public objectives also helps produce programmes that embody a diverse range of social and cultural objectives which can help them to cultivate a broader audience appeal. These things are important in an environment with limited funding and in which the possibility of failure for a public broadcasting or funding organisation, particularly with a large investment, is dangerous. 
Successfully tested in this country's screen production industry in the last two decades through a range of examples, institutional collaboration has demonstrated an ability to reduce the usual sense of risk with costly productions at the same time as enlarging the potentials for audience reach, impact, and value for money in the resulting programmes.

However, such a channel would necessitate a sufficient supply of direct public funding to meet its operational costs and New Zealand's public television experience suggests that obtaining additional funding for public television (and sustaining its availability) is difficult. The kind of increased funding commitment that would be needed for a new noncommercial TV channel was not forthcoming for either of the two previous initiatives of the TVNZ Charter and TVNZ6 and 7. While Māori Television provides a successful operational model and illustrates the benefits of satisfactory funding, and both Thompson (see 2012: scoop.co.nz) and Murdock (see 1997: 27) identify fiscally neutral models for funding a mainstream non-commercial channel in New Zealand, one still does not exist. Although, as Thompson argues, Jonathan Coleman (the Broadcasting Minister at the time of the decision to cease TVNZ7's funding) had been convinced of the need to support "the continuation of 7" (2012: scoop.co.nz), and that feasible funding options were available, TVNZ7's funding was not renewed by the government.

Hence the most significant challenge is perhaps not obtaining the necessary funding for a non-commercial endeavour, but a potentially more worrisome problem of the government's unwillingness to reregulate the television and communications industries in New Zealand. This is a move that would not only be necessary to implement the funding approaches articulated by Thompson and Murdock but also to create a broadcasting environment that protects and is conducive to public television outcomes. This reluctance to reregulate is something that has characterised New Zealand since 1989, but, alarmingly, it has been even more predominant under the current National government. This government abandoned the Review of Regulation that had been implemented by the previous Labour 
government, which, if it had been continued, could have provided the necessary rethink of "regulatory mechanisms so as to provide increased protection for local-content programming" (Dunleavy and Joyce, 2011: 187). The lack of regulation in New Zealand's television industry, a direct consequence of neoliberal politics and policies, has created the kind of intensely competitive commercial environment that is itself detrimental to the pursuit of public television objectives.

Accordingly, it seems that there needs to be a reprioritising of imperatives and objectives within the government and Treasury as to the plight and support of public television, if it is to operate effectively or, in the longer term, to even survive. The diminishing profitability and precarious positions of New Zealand's commercial broadcast networks, TVNZ and Mediaworks, the financial dividend required from TVNZ to the government, and the dominating presence of Sky TV, all underline that the needs of public television are not important to the current government. Furthermore, abandoning the Review of Regulation which could have addressed these issues, testifies to a situation in which the public and social objectives of public television are secondary to neoliberal ideology. While this remains the case, public television will always struggle in a battle that it is already losing, to deliver its objectives.

Interestingly however, Thompson argues the possibility of the reconciliation of regulatory measures that are necessary for public television and neoliberal ideology:

[O]ne can believe in competitive market mechanisms but still recognise that judicious state intervention is required both to ensure that competition produces outcomes in the wider public interest (optimum quality/minimum prices) and does not lapse into market failure and oligopolistic over-pricing (2012: scoop.co.nz).

What this suggests is that there is no intrinsic reason to avoid reassessing and redressing New Zealand's television environment, particularly if the benefits of such action are considered. However, in spite of the 
demonstrable public value of TVNZ7 and Māori Television as noncommercial channels, as well as the capacity that such a channel has to enhance the achievements of NZoA, a mainstream non-commercial channel does not exist in New Zealand.

Whether the necessary changes to New Zealand television are likely to happen in the future is impossible to predict. However, based on consecutive decisions by the current National government, which have harmed public television, it is difficult to assume a remarkable change of policy direction away from their hardnosed neoliberal stance. It is not beyond doubt that a new Labour government would attempt to engender change to the environment as it did, in the early 2000s, with the creation of the TVNZ Charter and the Māori Television Service. Of particular significance, is that the former Labour broadcasting spokesperson, Clare Curran, publicly advocated her support for TVNZ7 and for future public service provision in New Zealand (Pilcher, 2012: stuff.co.nz). This is one positive sign for the future of public television. However, as evidenced by this thesis, there are two potential problems in trying to effect change for New Zealand public television that must be considered.

The first is that for the most significant positive impacts to occur for public television, any changes are predicated upon a reregulation of the television environment in order to provide conditions conducive to it. If this were not to happen then any new public television organisations or endeavours would find it difficult to operate in such a competitive environment, undermining the long-term sustainability of change in this area. The second is that it is not a reshuffling of funding and responsibilities that is necessary or from which any noticeable enhancement of public television objectives stands to be achieved. Rather, additional funding and institutions will need to be added to the existing ones. This is because, as discussed, the existing organisations - of NZoA, TMP and Māori Television - have already demonstrated their effective functioning and distinctive contributions to public television. What these 
organisations need, therefore, is additional support from extra funding and the creation of another non-commercial channel.

A potential danger in adjusting New Zealand television is that if the current providers, which have proven their value and effectiveness, were to be undermined in order to provision new institutions and services, there is no guarantee that the alternatives would be any more successful or effective in the long term. There is also a risk that untested new initiatives could fail. If this were to occur, then the danger is the complete disestablishment of New Zealand public television. Ideally, a mainstream non-commercial channel would be injected into the environment to function in collaboration and cooperation with the existing public agencies that have proven their worth over many years. It is the view of this thesis that without NZoA's interventions in broadcast television over the last twenty-four years, New Zealand-specific cultural representations in a range of programme categories would not have been possible to the extent that they have, nor (it can also be argued) would they have been as accessible and successful as the NZoA model has encouraged them to be. However, what Murdock terms the "counter-revolution" (1997: 23) simply must occur if New Zealand television is going to be adequately provisioned and protected into the future so as to "satisfy [the] cultural and democratic needs" for which public television exists (Dunleavy, 2011: Forum on the Future of Public Television in New Zealand). This means addressing the under-regulated competitive broadcasting environment, increasing the amount of public funding being invested, and creating a new noncommercial mainstream TV channel to complement Māori Television. This is because the objectives of public television, as Dunleavy underlined, simply "cannot be met without public investment on the one hand, and appropriate broadcasting policy and regulation on the other" (ibid.). Accordingly, it is only when both of these vital resources are provided that New Zealand public television will finally have the opportunity to be something more than the "Ghost at the Feast" (Murdock, 1997: 9). 


\section{Reference List}

\section{Books and articles}

Barnett, John (2010) “Outrageous Fortune Goes West”, Onfilm, 13 July, http://www.onfilm.co.nz, accessed 19 September 2013.

-- (2011) "Free to Air TV into the Future", Forum on the Future of Public Television in New Zealand, Victoria University of Wellington, 22 June.

Black Inc Media (2011) "Golden Mozzies Application for New Zealand on Air", http://www.nzonair.govt.nz, accessed 19 September 2013.

Bruzzi, Stella (2001) "Docusoaps", in Creeber, Glen (ed) The Television Genre Book, London: British Film Institute, pp. 132-134.

Collins, Richard (2007a) "The BBC and 'Public Value'”, Medien und Kommunikationswissenschaft, 65.2, pp. 164-184.

-- (2007b) Public Value and the BBC: A Report Prepared for The Work Foundation's Public Value Consortium, London: The Work Foundation.

Comrie, Margie and Fountaine, Susan (2005) "Retrieving Public Service Broadcasting: Treading a Fine Line at TVNZ", Media, Culture and Society, 27.1, January, pp. 101-118.

Corner, John (2000) "Civic Visions: Forms of Documentary", in Newcomb, Horace (ed) Television: The Critical View, Sixth Edition, New York and Oxford: Oxford University Press, pp. 207-236.

Currie, Anna (2010) “MTV's The Hills: A Leading American Docusoap”, MA Thesis, Wellington: Victoria University of Wellington.

Dahlberg, Tina R Makareti (1996) “Māori Representation in Parliament and Tino Tangatiratanga", He Pukenga Kōrero, 2.1, pp. 62-72. 
Dovey, Jon (2000) "McDox 'R' Us - Docu-soap and the Triumph of Trivia”, Chapter Six in Dovey, Freakshow: Pirst Person Media and Factual Television, London: Pluto Press, pp. 133-153.

Dunleavy, Trisha (2012a) "The Threatened Genres - Drama and Comedy", Chapter Eight in Norris, Paul and Pauling, Brian (eds) NZ On Air: An Evaluative Study 1989-2011, Wellington, pp. 43-58.

-- (2012b) "Maximising Public Value in Costly Areas of Production: TV Drama and the 'New Zealand on Air' Model", RIPE, September, http://ripeat.org, accessed 18 September.

-- (2011) “The Challenges”, Forum on the Future of Public Television in New Zealand, Victoria University of Wellington, 22 June.

-- (2010a) “New Zealand On Air, Public Service Television and TV Drama”, Chapter 23 in Iosifidis, Petros (ed) Reinventing Public Service Communication: European Broadcasters and Beyond, Basingstoke: Palgrave Macmillan, pp. 298-310.

-- (2010b) "Television New Zealand and the Charter: the Uneasy Reconciliation of Public Service and Commercialism", RIPE, September, http://ripeat.org, accessed 18 September.

-- (2009) Television Drama: Form, Agency, Innovation, Basingstoke: Palgrave Macmillan.

-- (2008) "New Zealand and the Struggle for Public Service", Media, Culture and Society, 30.6, November, pp. 795-811.

-- (2005) Ourselves in Primetime: A History of New Zealand Television Drama, Auckland: Auckland University Press.

-- (2003) "A Soap of Our Own: New Zealand's Shortland Street", Media International Australia Brisbane: Griffith University, No. 106, February, pp. 18-32. 
Dunleavy, Trisha and Joyce, Hester (2011) New Zealand Film and Television: Institution, Industry and Cultural Change, Bristol and Chicago: Intellect and University of Chicago University Press.

Easton, Brian (2002) "The Broadcasting Reforms", Chapter Nineteen in Farnsworth, John and Hutchison, Ian (eds) New Zealand Television: A Reader, Palmerston North: Dunmore Press, pp. 225-30.

Ellis, John (2000) Seeing Things: Television in the Age of Uncertainty, London: I.B. Tauris.

Fox, Derek Tini (2002) "Honouring the Treaty: Indigenous Television in Aotearoa", Chapter Twenty-Two in Farnsworth, John and Hutchison, Ian (eds) New Zealand Television: A Reader, Palmerston North: Dunmore Press, pp. 260-69.

Gitlin, Todd (1994) Inside Prime Time, California and London: University of California Press.

Gripsrud, Jostein (2004) "Broadcast Television: The Chances of its Survival in a Digital Age", in Spigel, Lynn and Olsson, Jan (eds) Television After TV: Essays on a Medium in Transition, Durham NC: Duke University Press, pp. 210-223.

Harris, John (2013) “John Harris: Children's TV Crying Out for a Local Hero", New Zealand Herald, 5 March, http://www.nzherald.co.nz, accessed 18 September 2013.

Hill, Annette (2005) "The Rise of Reality TV", Chapter Two in Hill Reality TV: Audiences and Popular Factual Television, London and New York: Routledge, pp. 14-40.

Horrocks, Roger (2010) "Docos in Decline: The Rise and Fall of the Television Documentary", Onfilm, Auckland: Profile Publishing, February, pp. $10-11 ; 28$.

-- (2003) The Documentary on Television, Wellington: New Zealand on Air. 
Hunt, Tom (2013) “Kiwi Kids' TV More American Than US”, Stuff, 2 March, http://www.stuff.co.nz, accessed 18 September 2013.

Keall, Chris (2012) “NZ on Air Releases Original Proposal for Documentary that Morphed into Reality Show The GC", The National Business Review, 21 May, http://www.nbr.co.nz, accessed 2 October 2013.

Kelsey, Jane (1998) The New Zealand Experiment: A World Model for Structural Adjustment?, Auckland: Auckland University Press.

Kilborn and Izod (1997) "Shaping the Real: Modes of Documentary", Chapter Three in Kilborn and Izod, An Introduction to Television Documentary: Confronting Reality, Manchester: Manchester University Press, pp. 57-87.

Kirk, Stacey (2012) "NZ On Air Defends The GC", Stuff, 20 May, http://www.stuff.co.nz, accessed 18 September 2013.

Kozloff, Sarah (1995) "Narrative Theory and Television", Chapter Two in Allen, Robert C. (ed) Channels of Discourse, Reassembled, Second Edition, New York and London: Routledge, pp. 67-97.

Little, Paul (2012) "Aussies in Glass Houses are Throwing Stones", New Zealand Herald, 10 June, http://www.nzherald.co.nz, accessed 19 September 2013.

Media Academics (2011) "Open Letter: TVNZ7 and Public Broadcasting”, Scoop, 14 April, http://www.scoop.co.nz, accessed 25 September 2013.

Mittell, Jason (2004) "Making Fun of Genres: The Politics of Parody and Genre Mixing in Soap and The Simpsons", Chapter Six in Mittell, Genre and Television: from Cop Shows to Cartoons in American Culture, New York and London: Routledge, pp. 153-195.

Murdock, Graham (1997) "Public Broadcasting in Privatised Times: Rethinking the New Zealand Experiment", in Norris, Paul and Farnsworth, John (eds) Keeping it Ours: Issues of Television Broadcasting in New Zealand, Christchurch: New Zealand Broadcasting School, pp. 9-33. 
Nelson, Robin (1997) "Flexi-Narrative from Hill Street to Holby City: Upping the Tempo; Raising the Temperature", Chapter Two in Nelson, TV Drama in Transition: Forms, Values and Cultural Change, Basingstoke: Macmillan, pp. 30-49.

Nichols, Bill (1994) Blurred Boundaries: Questions of Meaning in Contemporary Culture. New York: Routledge.

Norris, Paul and Pauling, Brian (2012) NZ on Air: An Evaluative Study 19892011, Wellington.

Parr, Larry (2012) Television Funding Manager, Te Māngai Pāho, Personal Communication, 12 April.

Philpott, Chris (2012) "A Few Thoughts on The GC", Stuff, 3 May, http://www.stuff.co.nz, accessed 19 September 2013.

Pilcher, Pat (2012) “Q\&A: Labour's Clare Curran”, Stuff, 8 May, http://www.stuff.co.nz, accessed 19 September 2013.

Smith, Jo (2011) "Postcolonial Māori Television? The dirty politics of indigenous cultural production", Continuum, 25.5, October, pp. 719-29.

-- (2006) “Parallel Quotidian Flows: Māori Television On Air”, New Zealand Journal of Media Studies, 9.2, pp. 27-35.

Smith, Jo and Abel, Sue (2008) "Ka Whawhai Tonu Mātou: Indigenous Television in Aotearoa/New Zealand", New Zealand Journal of Media Studies, 11.1, June, pp. 1-14.

Smith, Paul (1996) Revolution in the Air!, Auckland: Longman.

Spicer, Barry, Powell, Michael and Emanuel, David (1996) The Remaking of Television New Zealand: 1984-1992, Auckland: Auckland University Press.

Stephens, Tainui (2004) "Māori Television”, Chapter 6 in Horrocks, Roger and Perry, Nick (eds) Television in New Zealand: Programming the Nation, Melbourne: Oxford University Press, pp. 107-15. 
Thompson, Peter (2012) "Public Disservice Broadcasting: The Shameful Demise of TVNZ7", Scoop, 28 June, http://www.scoop.co.nz, accessed 18 September 2013.

-- (2011) "Neoliberalism and the Political Economies of Public Television Policy in New Zealand", Australian Journal of Communication, 38.3, pp.116.

-- (2009) "The Demise of the TVNZ Charter: The Arguments the Government Wants Us to Ignore", Scoop, 30 March, http://www.scoop.co.nz, accessed 18 September 2013.

-- (2007) “From the Digital Sublime to the Ridiculous? TVNZ's New Digital Services and the Future of Public Television in New Zealand", Communication Journal of New Zealand: Special Edition on Broadcasting Histories, Digital Futures, 8.1, pp. 43-62.

-- (2004) "Unto God or unto Caesar? Television after the TVNZ Charter", Communication Journal of New Zealand, 5.2, December, pp. 60-91.

Tracey, Michael (1998) The Decline and Fall of Public Service Broadcasting, Oxford: Oxford University Press.

Wilson, Kristen (2012) "Public Service Broadcasting Matters", Scoop, 27 June, http://www.scoop.co.nz, accessed 18 September 2013.

Zanker, Ruth (2012a) “The Threatened Genres - Children's”, Chapter Ten in Norris, Paul and Pauling, Brian (eds) NZ On Air: An Evaluative Study 1989-2011, Wellington, pp. 68-90.

-- (2012b) "After Public Service Channels Close Down: The Extreme Case of Local Provision for Children in New Zealand", RIPE, September, http://ripeat.org, accessed 18 September.

\section{Official Reports and Acts of Parliament}

Broadcasting Act (1989). 
Broadcasting Act (1976).

Broadcasting Amendment Act (1993).

Broadcasting Corporation of New Zealand Restructuring Act (1988).

Chapman Report (1986) Broadcasting and Related Telecommunications in New Zealand, Report of the Royal Commission of Inquiry, New Zealand Government: Wellington, September.

Deloitte (2011) Technology, Media and Telecommunications Predictions 2011, http://www.deloitte.com, accessed 19 September 2013.

Geary, Shona (2008) Research into New Zealand's Independent Documentary Sector, Creative New Zealand and the New Zealand Film Commission.

Māori Television Service Act (2003).

Ministry for Arts, Culture and Heritage and ministry of Economic Development (2008) Digital Broadcasting: Review of Regulation, Volume One, New Zealand Government: Wellington, January.

Murray, Annie (2010) A Review of Recurrently Funded Television Series 1998/1999 - 2009/2010: Report to NZ on Air, Auckland: Taima Television Ltd, December.

New Zealand on Air (1990, 2008-2012) Annual Reports, Wellington.

New Zealand on Air (2012) Documentary Funding Policy Discussion Paper, http://www.nzonair.govt.nz, accessed 19 September 2013.

New Zealand on Air (2012) Statement of Intent 2012-15, Wellington.

New Zealand on Air (2011) Statement of Intent 2011-14, Wellington.

Premium Research (2011) New Zealand on Air Public Perceptions Research: Quantitative Survey, Wellington: Premium Research, April. 
Quirk, Kathryn (2012) Platinum Fund Review of Outputs: A Report to NZ on Air, Auckland: The Content Company NZ Ltd, February.

Stevenson Report (1988) Report on Implementation of Broadcasting Policy Reform, New Zealand Government: Wellington, August.

Television New Zealand Act (2003).

Te Māngai Pāho (2010) Annual Report, Wellington.

Te Māngai Pāho (2007-2011) Funding Decisions, http://www.tmp.govt.nz, accessed 18 September 2013.

United Nations (1989) Convention on the Rights of the Child, New York.

Varcoe, Jude and Curran, Karin (2008/2009) New Zealand on Air Public Perceptions Research: Executive Summary, Wellington: Premium Research.

\section{Websites}

Google Books, http://books.google.co.nz.

Māori Television, http://www.māoritelevision.com.

New Zealand Herald, http://www.nzherald.co.nz.

New Zealand on Air, http://www.nzonair.govt.nz.

New Zealand On Screen, http://www.nzonscreen.com.

Reserve Bank of New Zealand, http://www.rbnz.govt.nz.

RIPE, http://ripeat.org.

Stuff, http://www.stuff.co.nz.

Scoop, http://www.scoop.co.nz.

Te Māngai Pāho, http://www.tmp.govt.nz.

TV3, http://www.tv3.co.nz. 


\section{Television Programmes}

“S1.E1", The GC, Mediaworks, TV3, 2 May 2012, Television.

“S1.E7”, The GC, Mediaworks, TV3, 13 June 2012, Television.

"S1.E8", The GC, Mediaworks, TV3, 20 June 2012, Television.

"S1.E1", Kaitangata Twitch, Māori Television Service, Māori Television, 2 May 2010, Television.

"S1.E4", Kaitangata Twitch, Māori Television Service, Māori Television, 23 May 2010, Television.

"S1.E6", Kaitangata Twitch, Māori Television Service, Māori Television, 6 June 2010, Television. 